\title{
Creative Expression and Contemporary Arts Making Among Young Cambodians
}

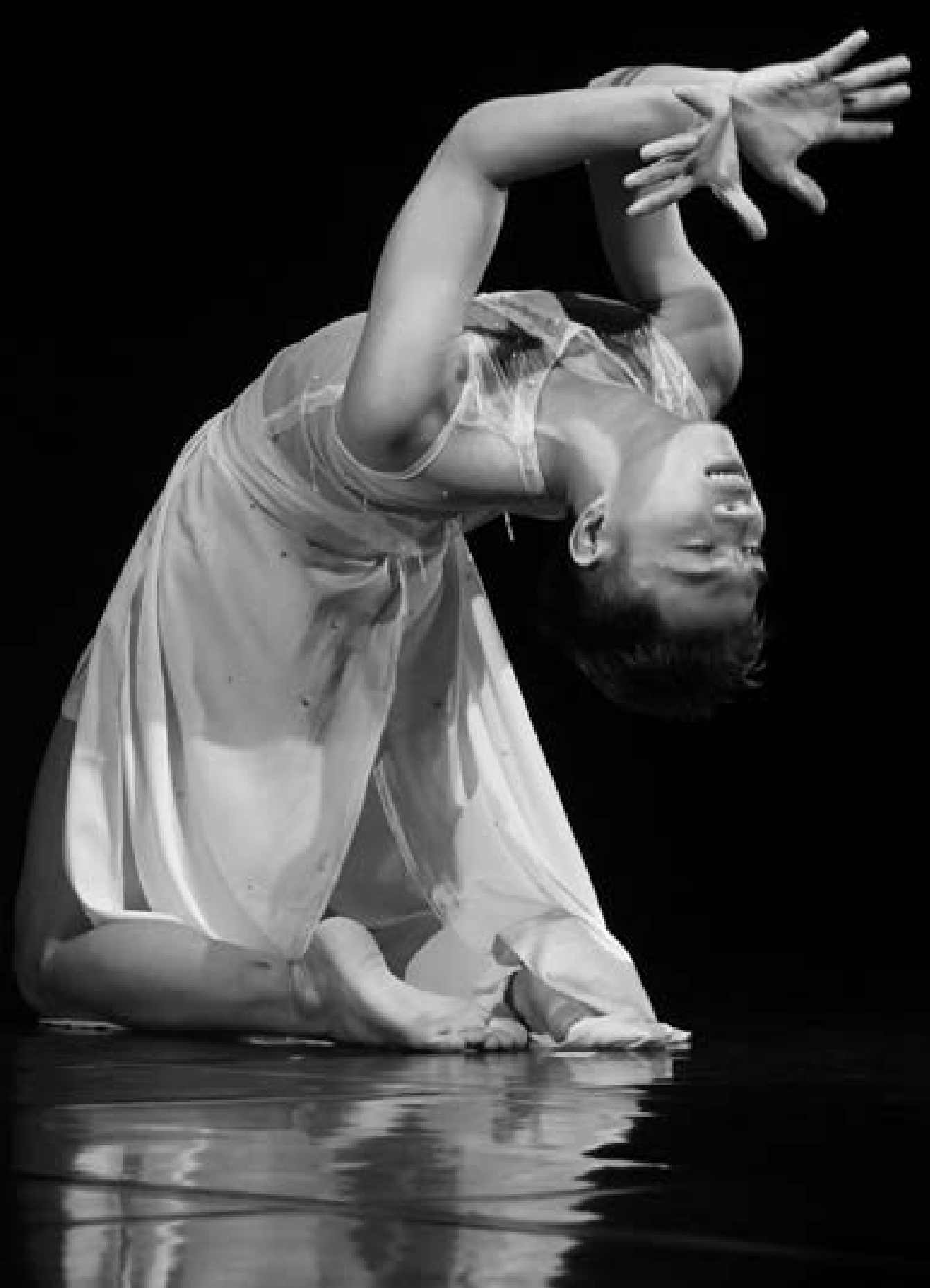




\section{Creative Expression and Contemporary Arts Making Among Young Cambodians}

\section{Research Findings Report}

Amanda Rogers, Reaksmey Yean, Sokim Keat, Vanarath Hem, Sakun Po and Justyna Krolikowska. Swansea University, April 2021.

(c) The Authors 2021. All text is subject to a Creative Commons Attribution-NonCommercial International 4.0 (CC-BY-NC 4.0) License hitps:// creativecommons.org/licenses/by-nc/4.0/

Citation Information

Rogers, A., Yean, R., Keat, S., Hem, V., Po, S., and Krolikowska, J. (2021)

Creative Expression and Contemporary Arts Making Among Young

Cambodians. Swansea University. DOI: 10.23889/SUReport.56822

Report Design

Joelle Evans

Cover Image

Lim Sonalis

Photographs

Choeun Socheata

Hem Vanarath

Lim Sonalis

So Phina

All images are subject to separate copyright. All image rights reserved.
Project Report

Amanda ROGERS, Reaksmey YEAN, Sokim KEAT,

Vanarath HEM, Sakun PO and Justyna KROLIKOWSKA

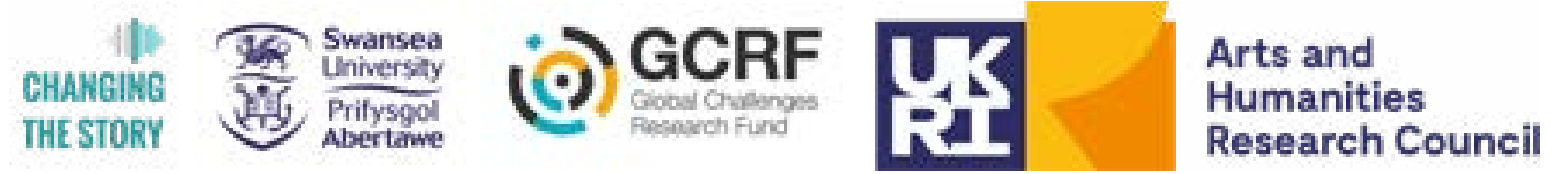


Executive Summary P6-9

$\bigcirc$ Background

O Project Aims

$\bigcirc$ Key Findings

\section{Research Context}

P10-15

Methods

P16-19

Artists' Perspectives

\section{P20-59}

Legacies of the Khmer Rouge

The Tradition-Contemporary Continuum.

O Art as a Mirror to Society?

$\bigcirc$ Identity

\section{Audiences}

P60-89

Who is the Audience?

$\bigcirc$ Audience Responses

$\bigcirc$ What else do young audiences want?

Organisational Considerations P90-97

\section{Future Dynamics}

P98-103

Key Findings

P104-107

Acknowledgements

P108-109

References

P1 10-113 


\section{Executive Summary}

- 00

\section{Background}

This project analysed the creative practices and concerns of young adult artists (18-35 years old) in contemporary Cambodia. It examined the extent to which the arts are being used to open up new ways of enacting Cambodian identity that encompass, but also move beyond, a preoccupation with the Khmer Rouge (1975-1979). Existing research has focused on how the recuperation and revival of traditional performance is linked to the post-genocidal reconstruction of the nation. ${ }^{1}$ In contrast, this research examines if, and how, young artists are moving beyond the revival process to create works that speak to a young Cambodian population. The research used NGO Cambodian Living Arts' 2020 Cultural Season of performances, workshops, and talks as a case study through which to examine key concerns of young Cambodian artists, trace how these affected their creative process, and analyse how the resulting works were received among audiences. It was funded through the AHRC GCRF Network Plus Grant 'Changing the Story' which uses arts and humanities approaches to 'build inclusive societies with, and for, young people in post-conflict settings. ${ }^{2}$

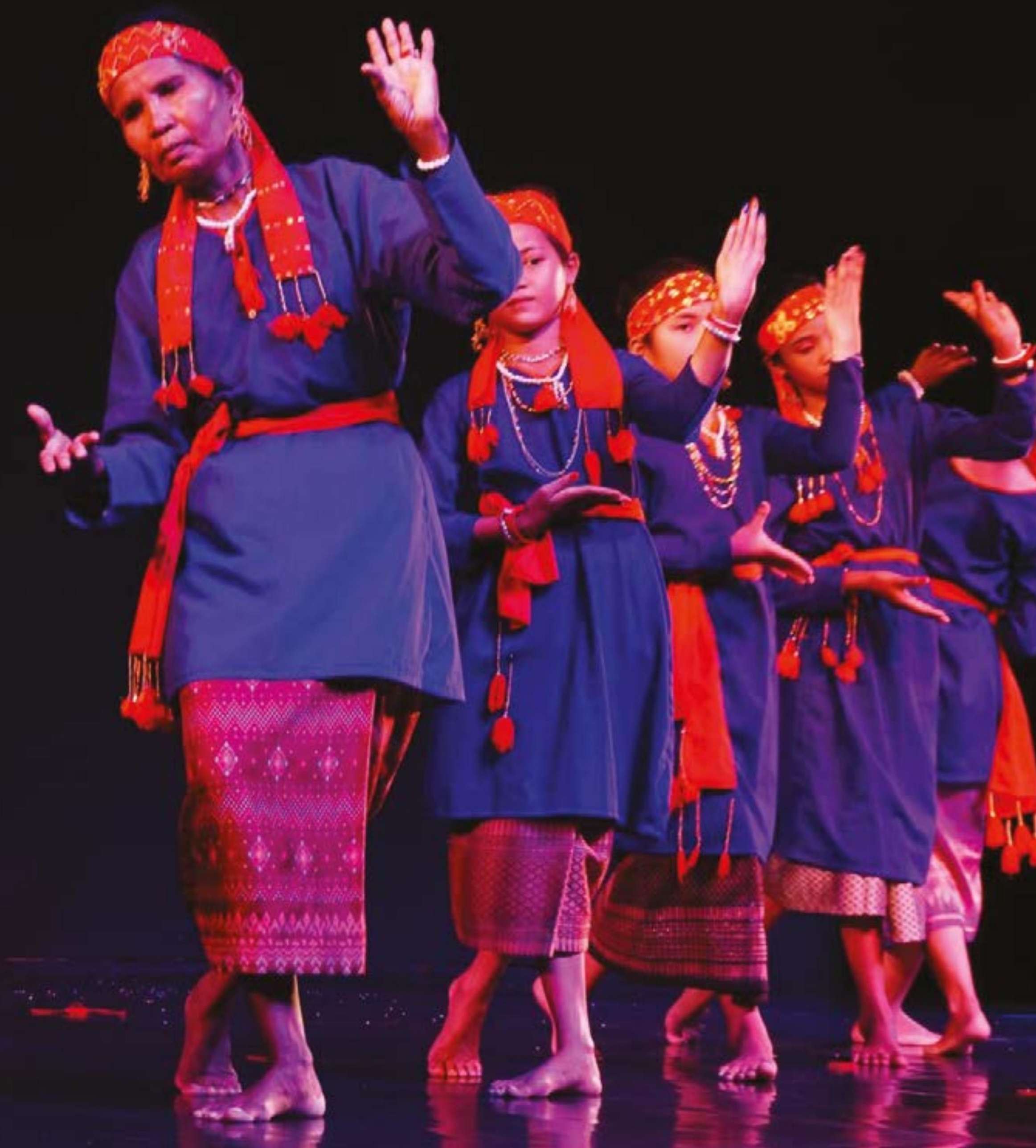


000

\section{Project Aims}

The project aims were:

- To find out what the interests of young Cambodian artists are today.

- To consider the extent to which they are concerned with the Khmer Rouge.

- To examine in what ways young artists are concerned with Cambodian identity and society.

- To analyse what their sources of inspiration are.

- To investigate CLA's role in relation to artists developing new work and to consider the different ways this operates.

- To examine how audiences interact with, and respond to, these works.

- To reflect on the implications for the sustainability of the Cambodian arts sector.

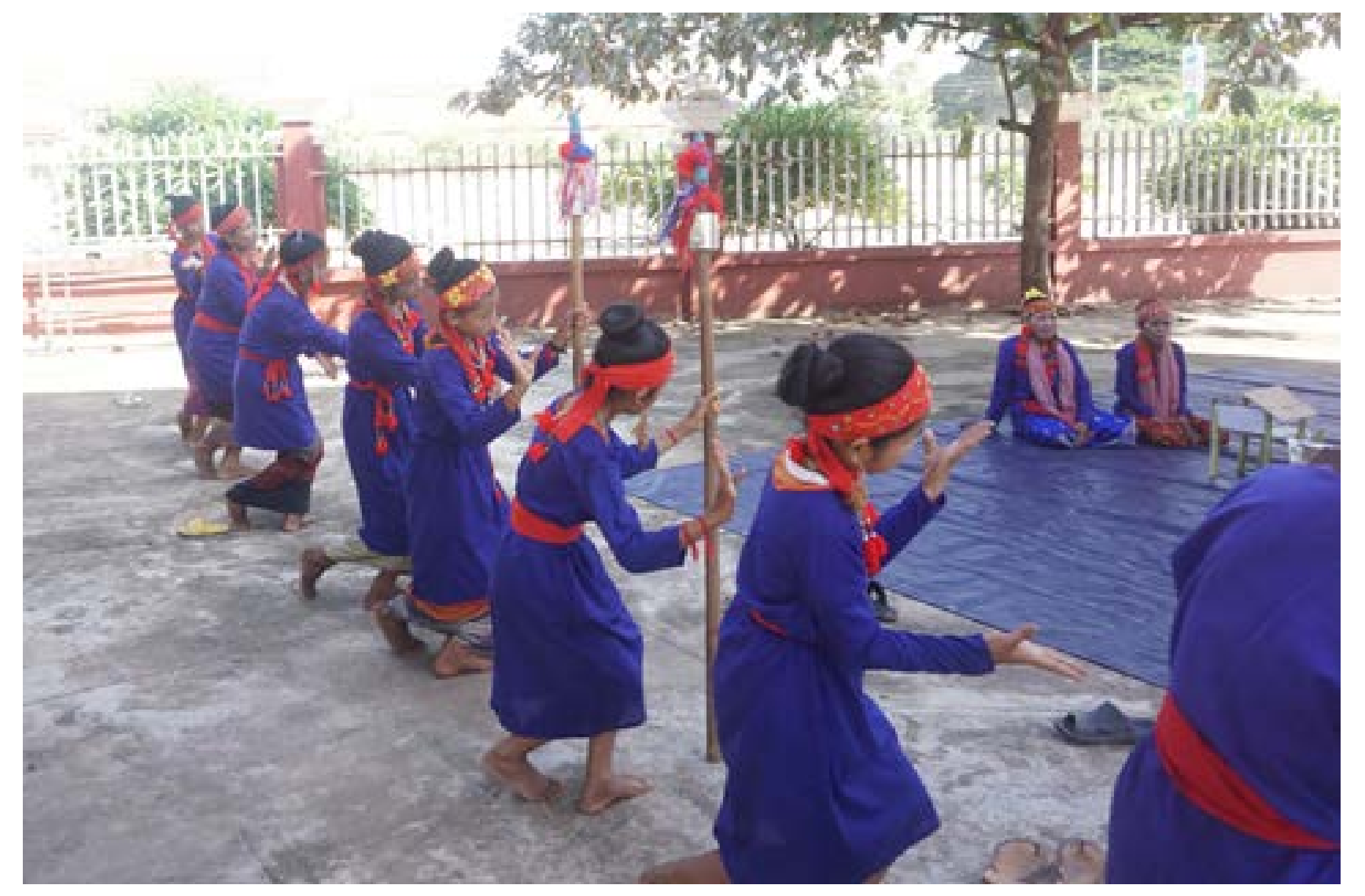

000

\section{Summary Key Findings}

By virtue of its curatorial framework, the Cultural Season presented all works and all artists as Cambodian, on the basis that all works were equally valid. This allowed critiques of the programme to move beyond existing debates of what is Cambodian in contemporary arts-making. Young artists are moving on from using the Khmer Rouge as a starting point for creative expression and are interested in a variety of social issues.

9. A healthy arts scene needs to be diverse and lively. Both artists and audiences want to see more venues, more regular performances, and a greater range of
artistic offerings.

9) Artists show immense respect for their role as the guardians of Cambodia's 3 cultural heritage and traditions. Contemporary performance is approached

4

Young audiences primarily want to see new, contemporary works. The research shows that the contemporary can also be a route to learning more about, and preserving, traditional art forms for both artists and audiences. The contemporarytraditional dynamic discussed in the art world is not a zero-sum game.

5 Young audiences do not always understand what they are watching. Audiences wanted to see more information about what they were watching, experience more interaction with artists, and gain greater insight into the creative process. Both artists and audiences highlighted that there needs to be much more arts education in schools at all levels. The majority of non-artist audiences do not encounter the arts in a significant way until they are at university.

(2) The research raises a bigger question around who the arts are for. There are ideological choices attached to this, and to how policy is implemented in the future. At present, the arts can feel a 'small world', especially for audiences. If the arts - as part of Cambodia's cultural heritage - is for everyone, then the sector needs to find new ways to access wider audiences and to engage with them. Evidence points to positive signs that this is happening. 


\section{'Art can show about the past, the present and the future'}

Ko Seyhak

\section{Research Context}

This project analysed the creative practices and concerns of young adult artists (18-35 years old) in contemporary Cambodia. Existing research has focused on how the recuperation and revival of traditional performance is linked to the post-genocidal reconstruction of the nation. ${ }^{3}$ In contrast, this research examines if, and how, young artists are moving beyond the revival process to create works that speak to a young Cambodian population. The project examined the extent to which practitioners are expressing themselves in ways that might depart from existing repertoires of practice and open up new conversations about the relationship between art and identity. The research examined key concerns of young Cambodian artists, traced how these affected their creative process, and analysed how the resulting works were received among audiences. In so doing, the project examined the extent to which the arts are being used to open up new ways of enacting Cambodian identity that encompass, but also move beyond, a preoccupation with the Khmer Rouge (1975-1979) and the associated legacies of memory, trauma and violence. It was funded through the AHRC GCRF Network Plus Grant 'Changing the Story' which uses arts and humanities approaches to 'build inclusive societies with, and for, young people in post-conflict settings. ${ }^{4}$ This wider project also aims to evaluate and inform the practice of civil society organisations working with young people in such contexts. 
During the Khmer Rouge, an estimated 90\% of Cambodia's artists were executed or died from torture, starvation and exhaustion. This legacy has meant that much artistic practice and research has focused on recuperation, documentation and preservation in order to safeguard Cambodia's intangible cultural heritage before surviving master artists die. ${ }^{5}$ However, Cambodia, like many post-conflict societies, is now primarily comprised of young people, with two-thirds of the population aged 30 and under. ${ }^{6}$ This demographic did not live through the Khmer Rouge and can have different impulses and aspirations to previous generations. Indeed, the academic Ashley Thompson has argued that the Khmer Rouge has 'risked becoming a mortal trap that reduced Cambodians to their history rather than liberating them from it. ${ }^{17}$

Existing research on Cambodian arts has been slow to reflect the current moment, and to fully attend to the needs and desires of this younger generation. ${ }^{8}$ Emerging research is beginning to examine the extent to which they engage with the memories and experiences of war, and how new forms of creative praxis are emerging that reflect young people's concerns and identities. ${ }^{9}$ There is also an absence of work on how young people respond to new artworks as audiences, and the choices that surround their support for Cambodian arts. Yet understanding these dynamics is key to the arts' continued survival, the form that they may take, and their role in Cambodian society.

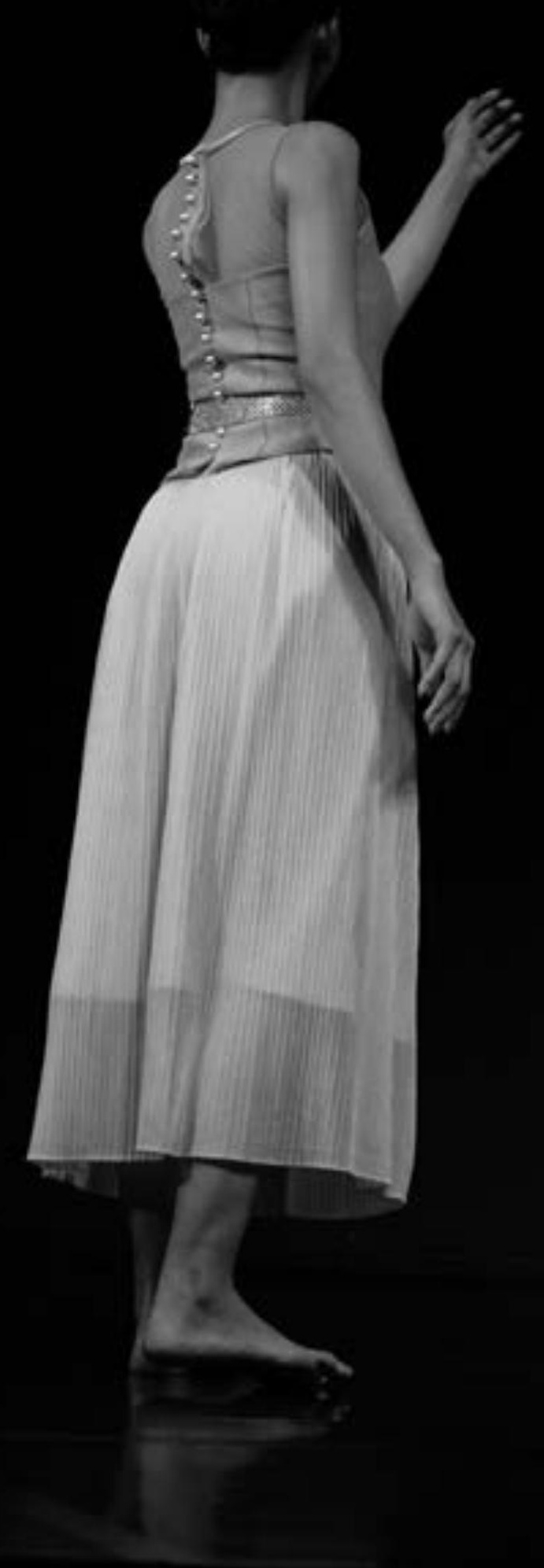

The research project examined these issues through a focus on the work of Cambodian Living Arts (hereafter CLA) during their 2020 Cultural Season which was themed 'Expressing Identities: Them and/or Us'. The annual Cultura Season (launched in 2018) supports young artists from across Cambodia in developing and showcasing new work, including various forms of dance, music and modern theatre. It also encourages young audiences to attend artistic events (see p.15). As such, it provided a practical focus for the research. The arts NGO sector in Cambodia has been criticised for locking artists into a dependency relationship that fails to cultivate innovation, for not always maintaining the high standards required of traditional arts, for serving foreign (rather than domestic) audiences, and for fulfilling the role of the state. ${ }^{10}$ However, their role is also being reappraised as they respond to the concerns of young artists. ${ }^{1}$ The research project worked with CLA, who, having spent a decade focusing on the transmission of artistic knowledge and ensuring its sustainability, has moved towards a focus on creativity and expression in artistic practice. Their aim is to be a 'catalyst in a vibrant arts sector inspiring new generations ${ }^{12}$ something that also includes widening participation and engagement with the arts. ${ }^{13}$ The research offered an opportunity for the organisation to evaluate how they work with and develop young artists, and how they engage with young Cambodian audiences.

The research therefore addressed the following questions:

- What are the interests of young Cambodian artists today?

- To what extent are they concerned with the Khmer Rouge?

- In what ways are they concerned with Cambodian identity and society?

- What are their sources of inspiration?

- What is CLA's role in relation to artists developing new work and what are the different ways this can operate?

- How do audiences interact with and respond to these works?

- What are the implications for the sustainability of the arts sphere? 


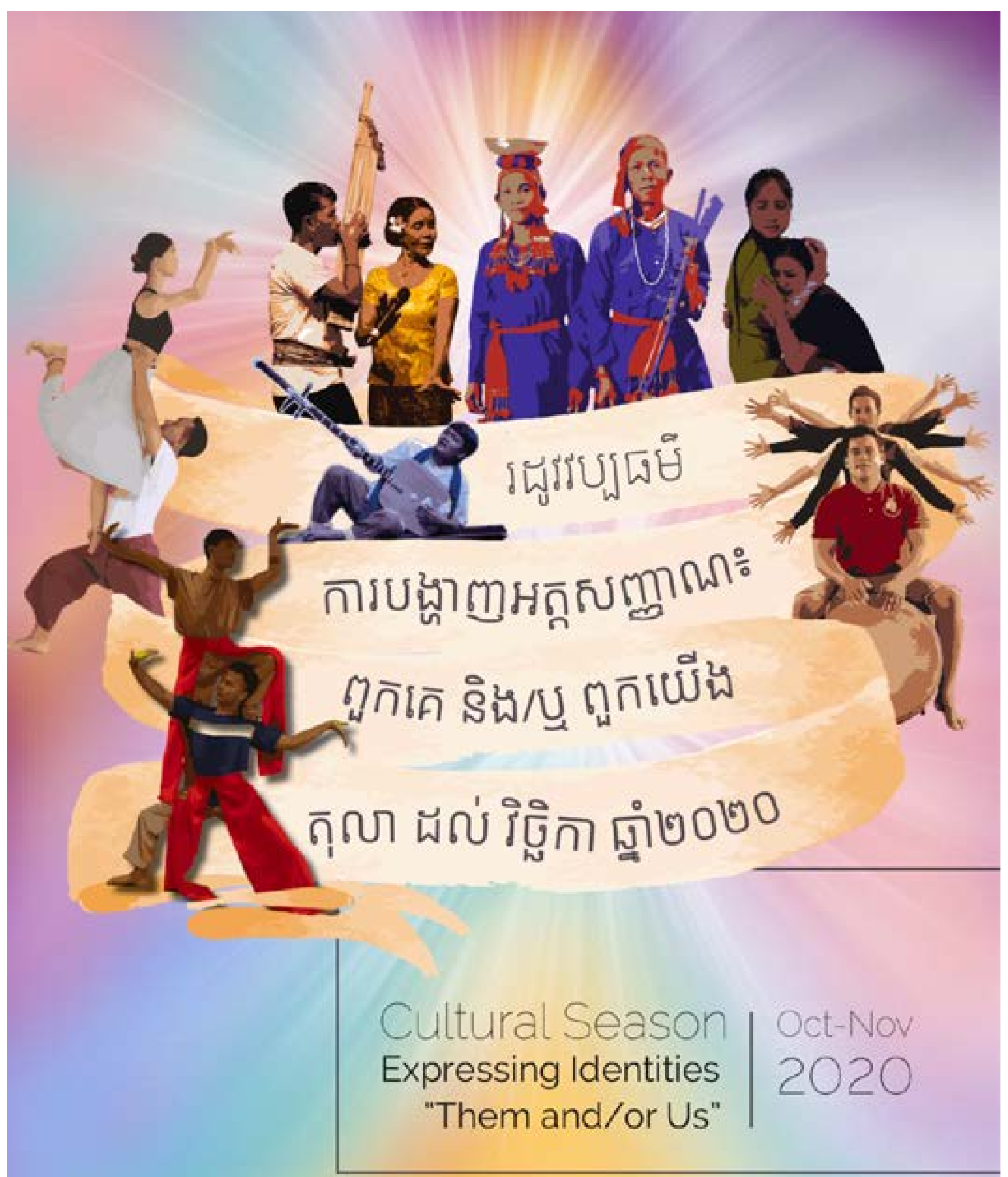

\section{Cambodian Living Arts Cultural Season}

The Cultural Season is an annual event started in 2018. It is a 2-3 month programme of events curated around a theme that aims to start a conversation between artists and audiences, and to encourage reflection on Cambodia. In 2018 this theme was 'Exploring Identities'. In 2020 it was 'Expressing Identities: Them and/or Us'. The theme in 2020 was grounded in a recognition that Cambodia is undergoing many shifts, particularly with globalisation and rapid urban development. Some Cambodians see this as a threat to traditional identities and values. However, the Cultural Season also sought to challenge assumptions of who 'we' are, particularly by drawing attention to the role of ethnic minorities and to consider the extent to which they are included in the dominant national imagination. As such, it aimed to stimulate reflection on questions of difference, and who constitutes 'them' and 'us'.

As an event, the Cultural Season stages a series of arts events, including photo exhibitions, staged readings of new scripts, film screenings, and of course staged performances ranging from spoken and modern theatre to varied forms of dance. The majority of these events are new commissions by CLA. The Cultural Season also has an interactive programme that accompanies the arts programme. This includes workshops, talks, demonstrations, and panel discussions. These aim to engage audiences by encouraging additional forms of participation (e.g. trying out different art forms) and stimulating dialogue and debate on ideas related to the theme. The 2020 Cultural Season involved 98 artists and practitioners, 7 performances (of which 6 were new pieces) spanning music, modern theatre, solo theatre performance, and dance, alongside staged readings, 3 interactive talks, demonstrations and workshops, and a panel discussion.

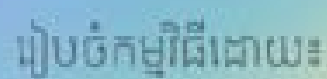

Organized by:

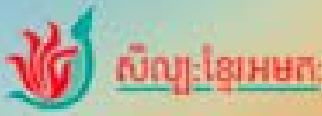

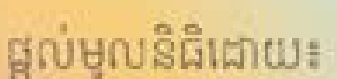

Funded by

\section{CHANGING Shansee
THE STORY}




\section{Methods}

A commissioning process of 5 new performances or works-in-progress organised and led by CLA independently of the research team. These were: Art and Environment Band led by LY Vanthan; Dark by CHOUNG Veasna; My Village Traditions led by KHA Sros; Root by NGET Rady; and The Pillar by SOK Nalys. This involved over 40 artists in total. visits, performance analysis, and in-depth interviews with the artists involved - both in the commissioned works and across the Cultural Season as a whole (21 interviews in total: 10 dancers; 6 musicians; 3 writers; 2 organisers).

Although the project's core focus was on young artists, some wanted to explore intergenerational dynamics, or work with traditional instruments. Four in-depth interviews were therefore with older artists. Some arts leaders (particularly Kha Sros) leading projects with young artists were older, and so also appear in interviews.

Performances were selected for development through both a competitive open call, and through direct commissions drawing upon networks and expertise.

This was based on the recognition that not all groups will be equally reached through an open call, particularly those that are marginalised, and that many artists may lack confidence or experience to apply through an open call.
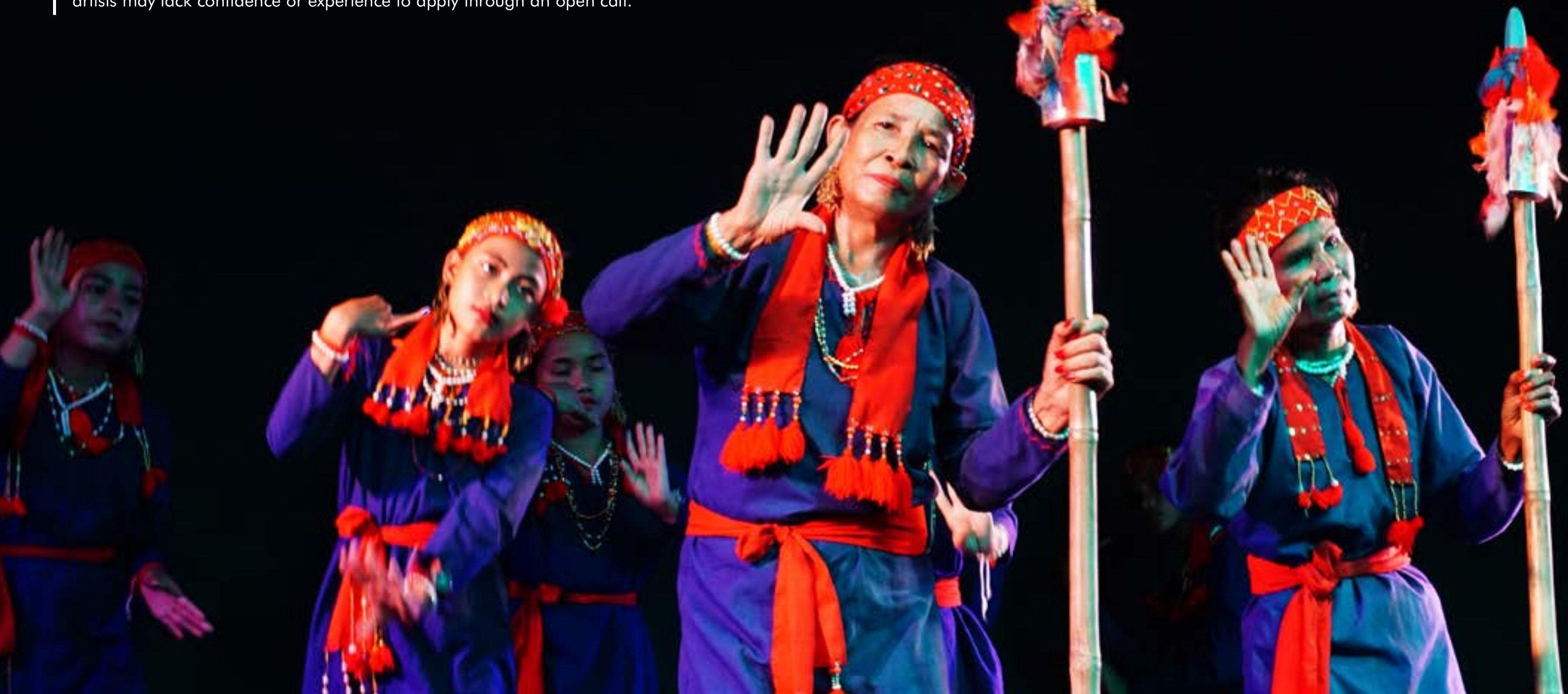
3 nterviews with 3 key members of CLA staff (Phloeun PRIM, Executive Director; SO Phina, Knowledge, Networks, and Policy Program Manager; and YON Sokhorn, Head of Arts Development).

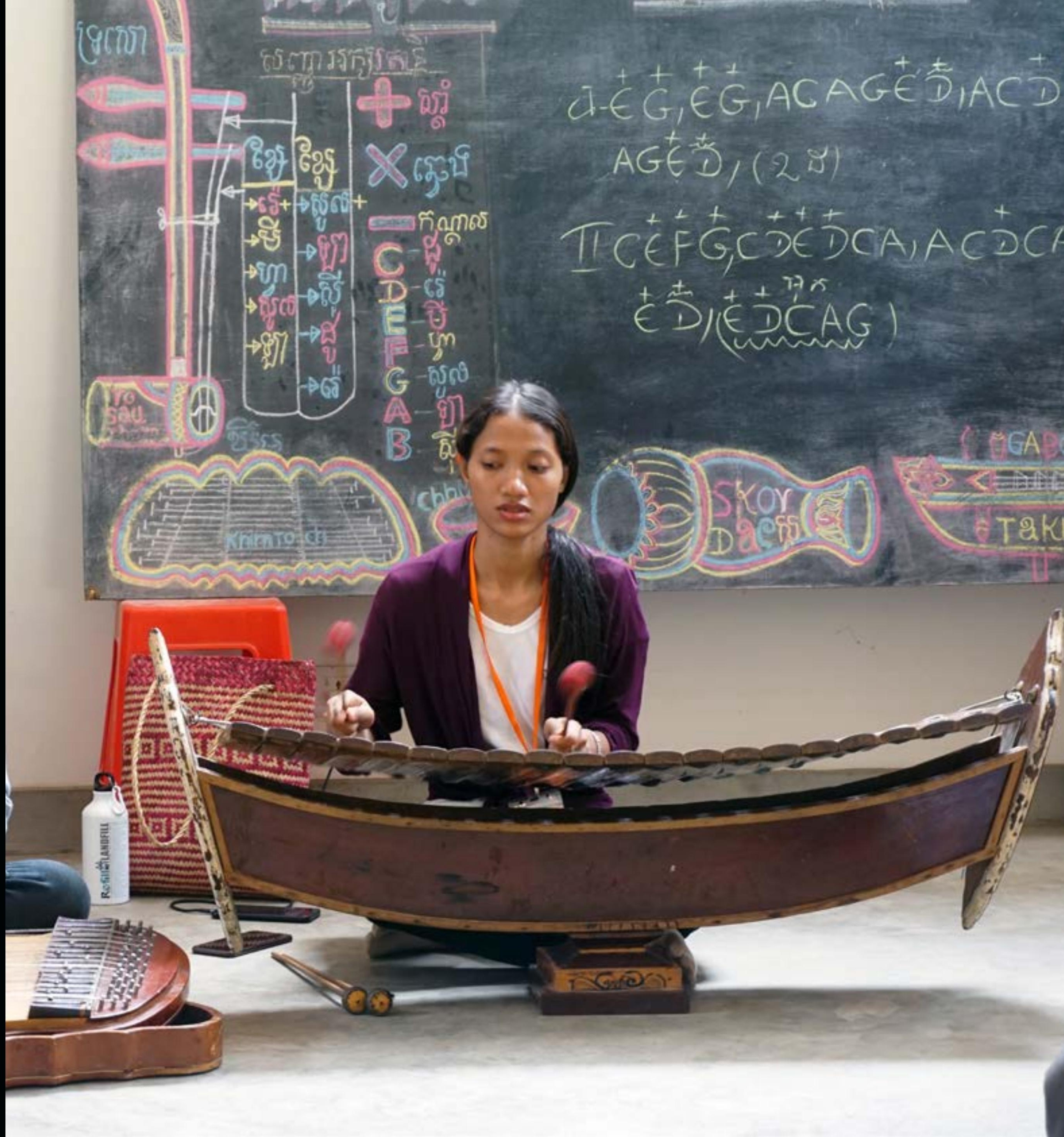



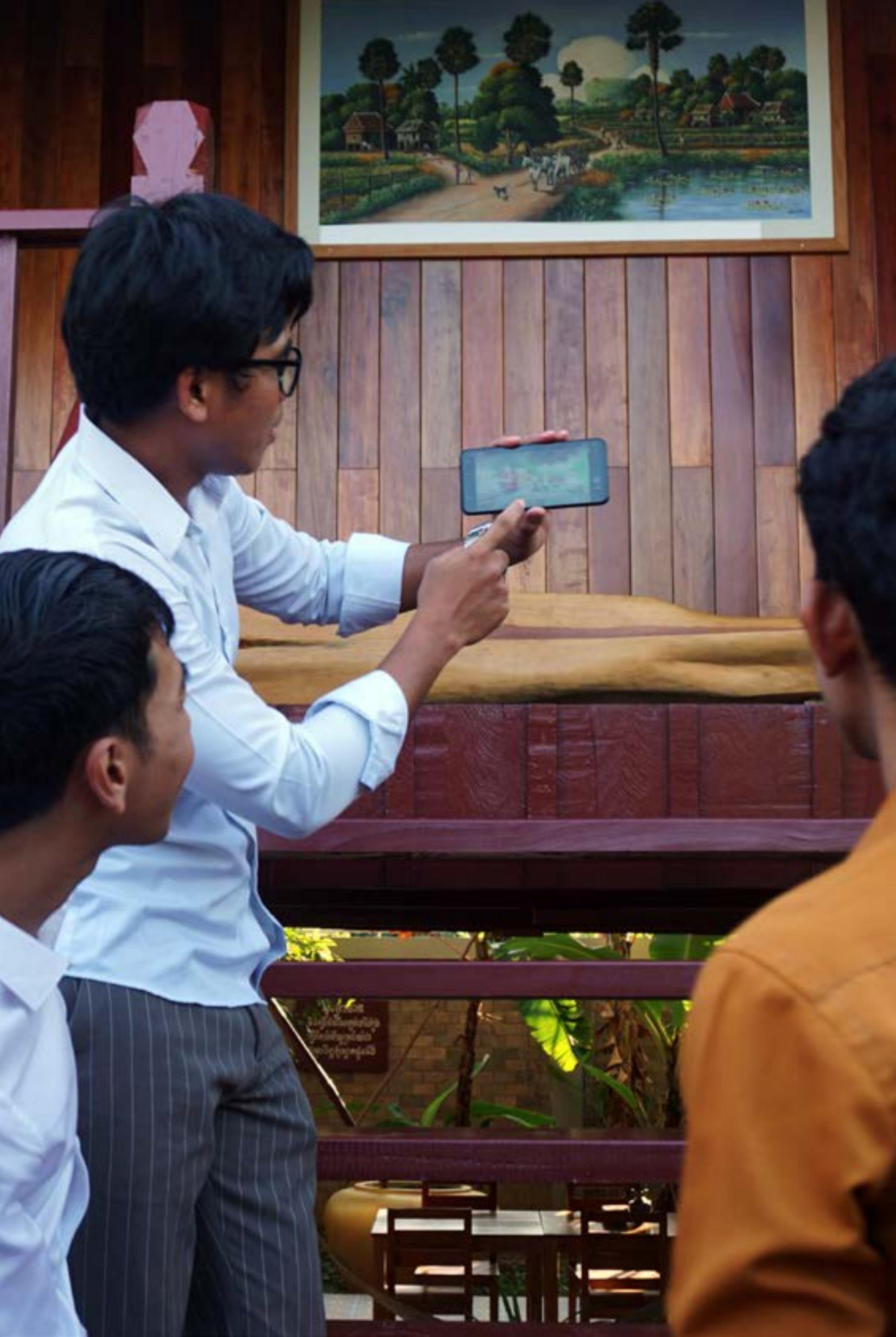

7
$\frac{2}{6}$
0
0
0
0
0
0
0

This section focuses on the concerns of artists and discusses four key themes:

the legacies of the Khmer Rouge; the tradition-contemporary continuum; the idea of 'art as a mirror to society'; and identity. 


\section{0}

\section{Legacies of the Khmer Rouge}

In the foreign imagination of Cambodia, the Khmer Rouge is very prominent and matched only in importance by the 'tourism and temple' complex. ${ }^{15}$ The arts are encapsulated within this imaginative frame, not least because of the association ofthe Apsara dance with Angkor Wat. ${ }^{16}$ However, what was immediately apparent in the research was that the Khmer Rouge was not directly a topic of any of the works presented. Irrespective of the fact that CLA shaped the theme of the Cultural Season and the selection of work to be performed, looking at the proposals received in the open call, the Khmer Rouge was scarcely present as a topic that young artists wanted to make work about. This is unsurprising as young Cambodians are the 'post-memory'17 generation who did not live through the regime and who only know this experience second-hand (if at all) through their parents, friends, education and information online. However, this does not mean that its legacies do not exist, nor that artists did not view the era as important.
In interviews and discussions, young artists displayed a varied set of responses to the idea of the Khmer Rouge as a starting point for creativity. Many recognised that the Khmer Rouge was a topic that interested foreign artists and tourists, and that it was therefore strategically used by some as a way to gain attention and income:

It is important that we do not repeat the same history. I am disappointed with some people who are still trying to show something about this nightmare through their art. I always make a joke that they are doing this for money. I am not happy with the fact that Cambodia is known for the Killing Fields. Foreigners do not know much about Apsara, classical dance, Chapei that have been listed as world heritage because they are not promoted as much as the story of Khmer Rouge. It does not mean we have to forget about Khmer Rouge regime, but it is time to move on and we are in the 21 st century

(Suon Sotheara).

This quotation neatly encapsulates a wider feeling that, whilst important, and indeed a source of income, there is more to Cambodia and the Cambodian arts scene than the Khmer Rouge. Much of Cambodia's other history and heritage simply goes unrecognised because it lives in the shadow of this particular historical period. The quote also conveys how many young artists were caugh between the past and the future, between the recognition that this era cannot and should not be forgotten, but also the desire to move on from this. Some artists had previously worked on performances about the Khmer Rouge and felt that they had addressed it and wanted to make something new. Others had written stories about the era that were unfinished. The more physical legacies of the Khmer Rouge were also recalled among the older artists, including violent or aggressive behaviour from their teachers - something that they suggested may have been the result of post-traumatic stress disorder. ${ }^{18}$ 
Yet despite this, the Khmer Rouge era was not really the starting point for creative expression for many young artists, with some simply stating that they never even thought about it:

I have never worked with any piece about Khmer Rouge conflict. I focus more on current issues rather than the issue of Khmer Rouge because I do not want to bring back those memories and we should not live with these memories forever. Instead, we should think of creating something new and move on. [...] That is not what I experienced. I have learned about Khmer Rouge from my parents, but I still have no clear picture of how it was, so I cannot go into detail on that issue' (Synath Rotana).

The idea of creating from one's own experience or from society today was therefore more important for these young artists (see p.36-45). It was also easier to learn about current issues in enough detail to inspire creative ideas. However, to suggest that Cambodian society has moved on, and that the arts can present a new image of Cambodia, entails recognising that this may dovetail with a national narrative of progress, peace and stability that has been critiqued. ${ }^{19}$ Nevertheless, whilst recognising that the Khmer Rouge will always be part of Cambodian history and society, there are many new ideas and modes of expression that can be created.

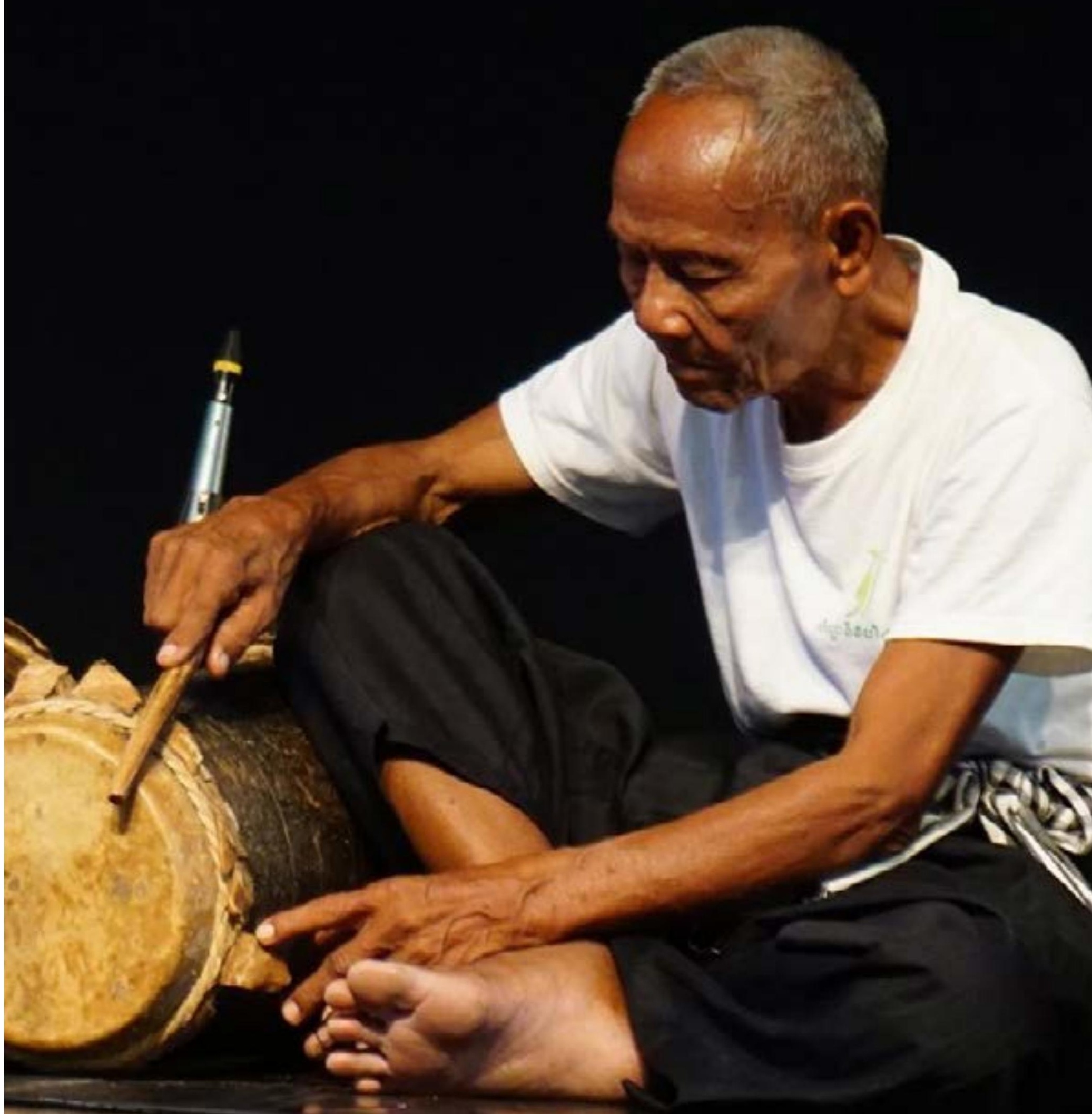


Season, it is worth highlighting that one of the wider legacies of the Khmer Rouge on the arts is the desire to preserve traditional forms for future generations. There is deep respect for older generations, and pieces driven by young artists sometimes explicitly involved older artists. However, there can be a reticence towards new forms of expression among the older generation who reconstructed Cambodia's art forms because they are acutely aware of cultural loss:

\section{I want to keep these songs alive, passing on from generation to generation' (Chorng Cheav).}

'If we lose our music and tradition, we lose
our identity'
(Oum Eng).

For some communities, particularly indigenous peoples, the arts also help to preserve their local culture. Kha Sros, for instance, described how teaching traditional Kouy dance to young people also enabled her to teach them Kouy language and the rights they have to protect their way of life as a minority - something her students also highlighted as an important way of maintaining their indigenous identity.

\section{The Tradition-Contemporary Continuum}




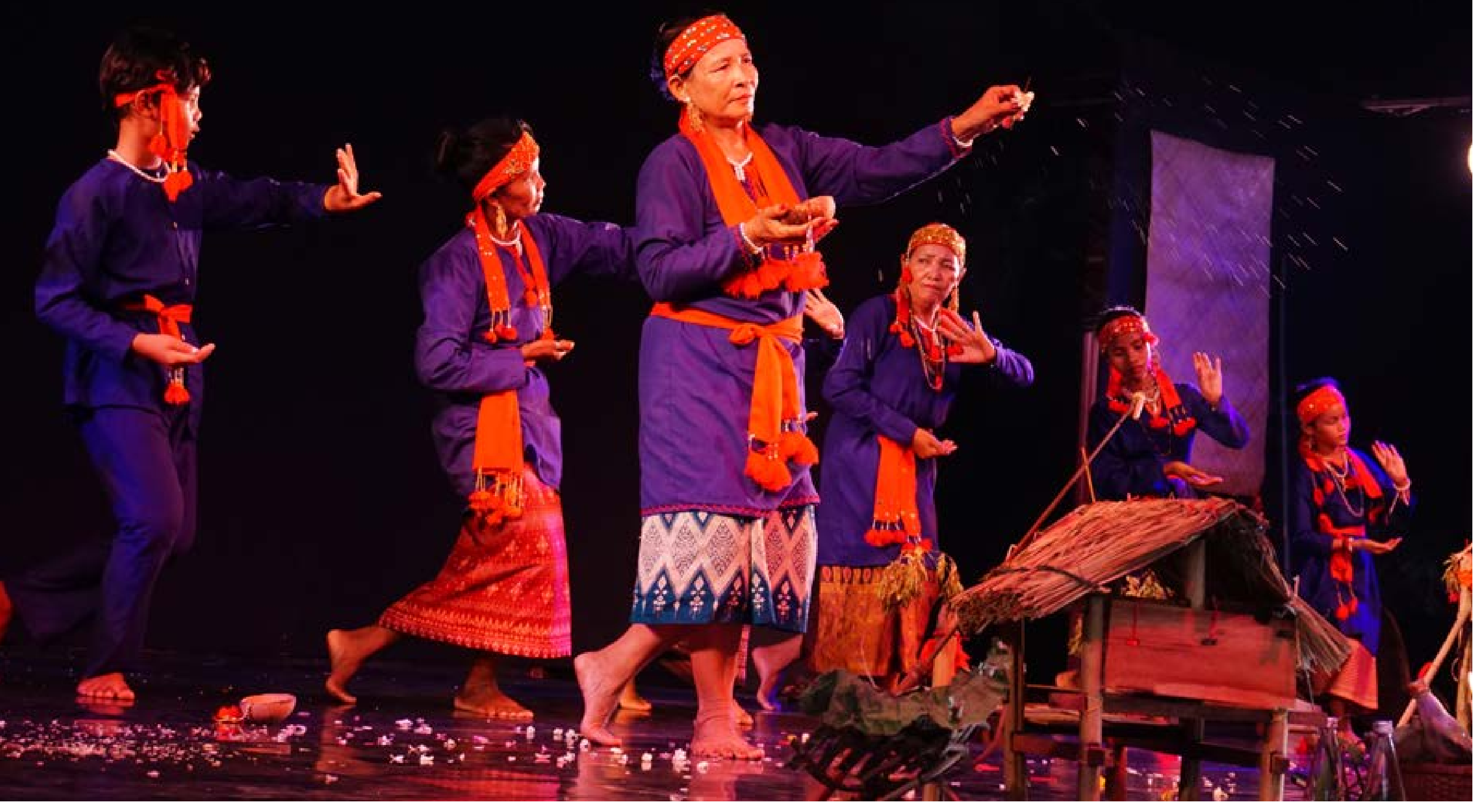

Young artists are therefore tasked with the responsibility of continuing the work of preservation and cultural transmission through the arts. This was particularlyfeltwhen theirpeers stopped practising traditional performance forms. Traditional instruments can also be more difficult to transport and therefore do not always 'fit in' as part of young people's socialisation activities (particularly when compared with for example, guitars). The majority of young artists we spoke to were proud of their cultural heritage and wanted to pass their knowledge on to the next generation as part of a vocational 'contribution to society' (Sok Nalys). 

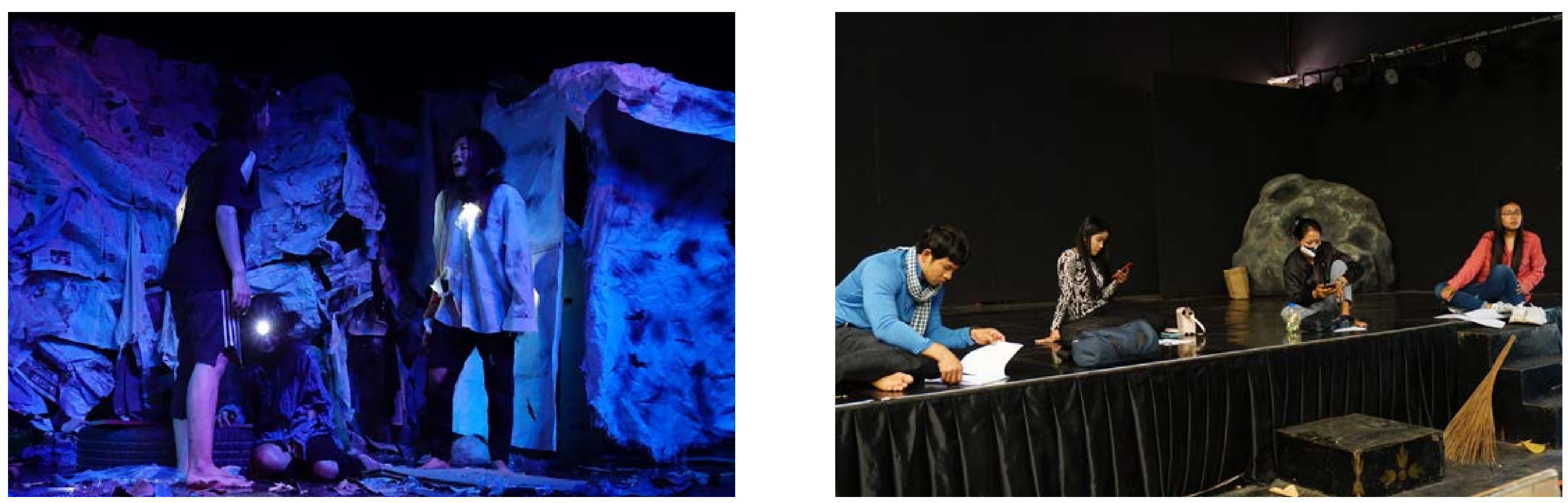

However, it is often the contemporary realm through which young artists feel most able to express themselves (see p.46-59). Yet their sense of responsibility meant that they undertook more labour (not less) in preservation activities:

'You need to practise harder when returning to classical dance. I usually rehearse five times prior to a classical performance. However, the rehearsal time doubles when performing a classical dance after you become a contemporary dancer in order bring back the movements and gestures'

(Sok Nalys).

It would be wrong to characterise cultural preservation as a 'burden' for young people who expressed a love of traditional arts and culture. Clearly, these artists were cognisant that even as they worked in a contemporary vein, they did not forget their traditional backgrounds. Many highlighted the lack of performing opportunities and loss of cultural awareness around traditional performing art forms in wider society and were concerned that knowledge of these would be lost.

Nevertheless, many saw contemporary arts as part of the development of traditional forms and did not view the 'traditional' and the 'contemporary' as incompatible spheres:

'I chose only 6 art forms to work on. I believe these 6 art forms belong to one family like the six tree branches from the same root. We move forward like the branches that grow bigger and longer yet we never forget where we are from' (Nget Rady).

'We have to be patient and tolerant in order to preserve this art form [Chapei]. At the same time, we adapt this art form to create something more attractive. Any ar form has been changed or adapted in order to survive'

Suon Sotheara). 
The language of preservation and development is promoted by the Ministry of Culture and Fine Arts for obvious reasons, and this has been internalised by young artists. Indeed, the reproduction of this language signalled that they worked for and with the government. What is described as 'traditional' has also evolved over time - something well-known in the Cambodian context and in broader Asian performing arts circles. ${ }^{20}$ There is experimentation not only with forms (such as the modern theatre solo performance of Grandpa's Chapei) but also techniques (such as breathing) - taking these from another international context but adapting them to the artist's own use rather than 'copying'. Young artists therefore engaged in experiments with contemporary arts reflexively:

'I think people (in general) do not really understand what contemporary dance is. I read some books and I still cannot find the exact and common definition of contemporary art. Life is about learning and I am learning more about contemporary dance. Creating a piece requires critical thinking and ideas but it is important that we know who we are and what we

This engaged and critical process of incorporating different styles, presentational frames, musical instruments and movements, some of which may not stem from the Cambodian context, was very much part of the younger generation's creative 'toolkit'. Young artists also explored this to different degrees, with some using traditional forms more than others. For instance, Nget's piece Root explicitly used traditional performing arts forms as the basis for creative inspiration and development. In contrast, Choung's piece Dark involved a greater mixing of traditional Cambodian and Euro-American dance movements - something that offered a different, but equally valid, expression of Cambodian identity. In our workshop on the future of Cambodian arts, some young artists were keen to see this develop much further. They wanted to see more 'new creations' (workshop participant) through collaborations between traditional and contemporary artists. Discussions here described not only preservation and development, but also a third dynamic of innovation that they wanted to see more widely supported and practised. 
However, among both artists and audiences there was a clear sense that contemporary expressions could be a route towards preserving traditional arts. ${ }^{21}$ Experimenting with how to adapt traditional performance forms into a contemporary frame gave young artists the opportunity to explore traditional forms further. It was also seen as a way to promote the arts among young audiences who otherwise may not be interested in traditional culture:

'[We have] mixed traditional and modern music and instruments during our performance with the purpose of promoting and preserving our culture. [...] The rhythm and melody are also mixed with contemporary music so we can promote Khmer traditional music through contemporary music' (Kann Sophat).

'This piece shows the importance of our art forms to young people and how they can help preserve these art forms'

It is here that traditional and contemporary forms were seen as compatible. Even among practitioners working explicitly in contemporary dance, the mode of teaching and transmission appeared to be occurring within the traditional structures of the master-student relationship. There was a clear sense of groups helmed by an established artist who worked as a mentor, collaborator, teacher, and 'critical friend', with particular contemporary dance movements and stylistic expressions characterising each collective. It would also be incorrect to simply characterise the contemporary as the domain of the young. Older generations sometimes shared an ethos of adaptation and experimentation, embracing contemporary developments led by young artists. However, in this project, this seemed to occur within the domain of the more obviously 'traditional':
'I write songs and improvise some songs, mixing O Tok, Bonchol Lok-ta with our songs and sing in our own language'

(Kha Sros).

'We want to promote young people's interest in art, so they want to learn more about it and create their new pieces or adapt our traditional music

We should create new pieces with Khmer traditional music like Arak and Khen music to create great pieces'

(Oum Eng).

In rehearsals we also witnessed how learning new styles of music and playing occurred in both directions. Such dynamics signal a willingness among some masters to open up to contemporary forms of expression and to collaborate with young artists. There was a clear recognition that this would ultimately ensure the continuity of the arts for future generations.

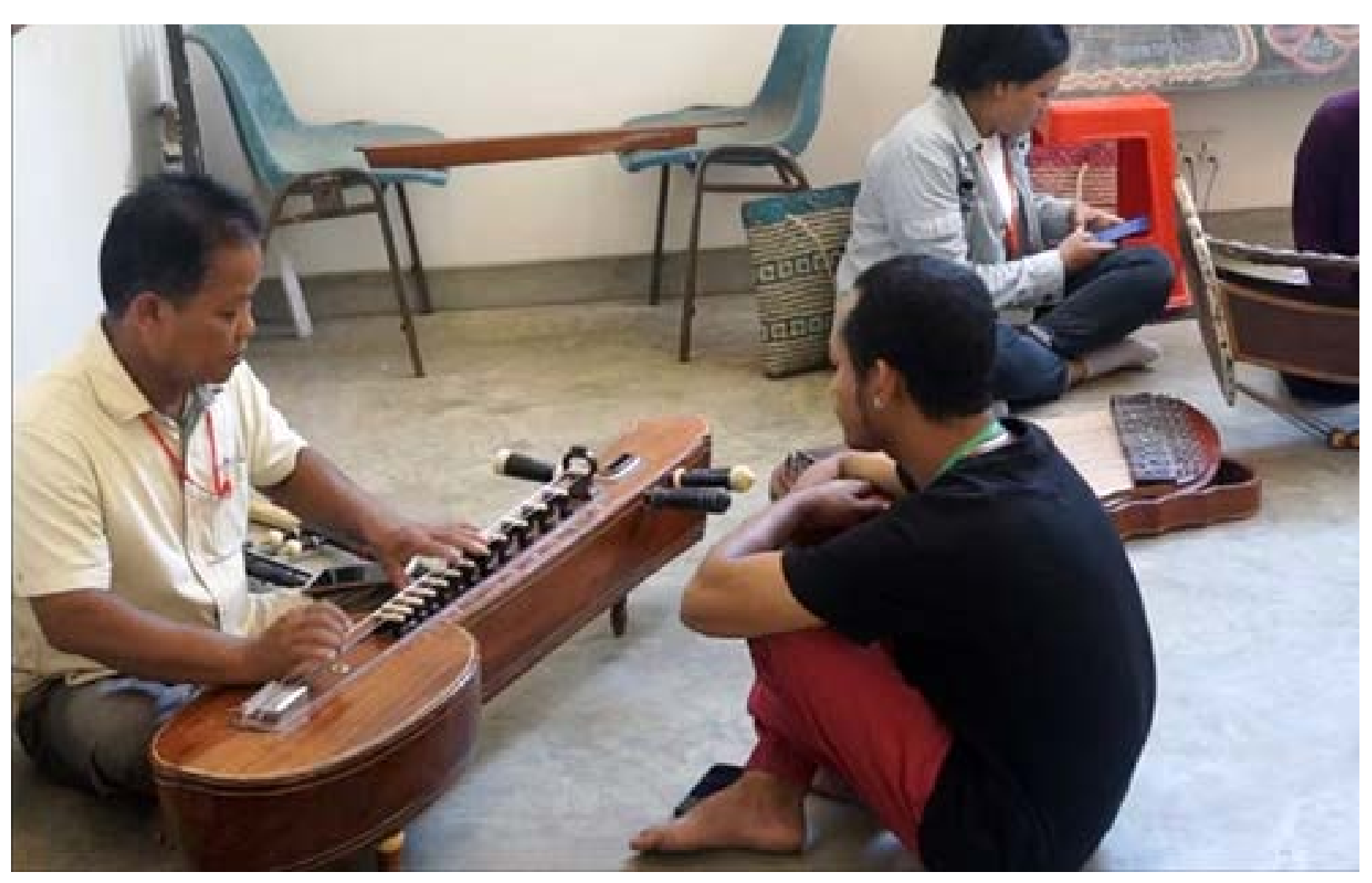




\section{0}

\section{Art as a Mirror to Society?}

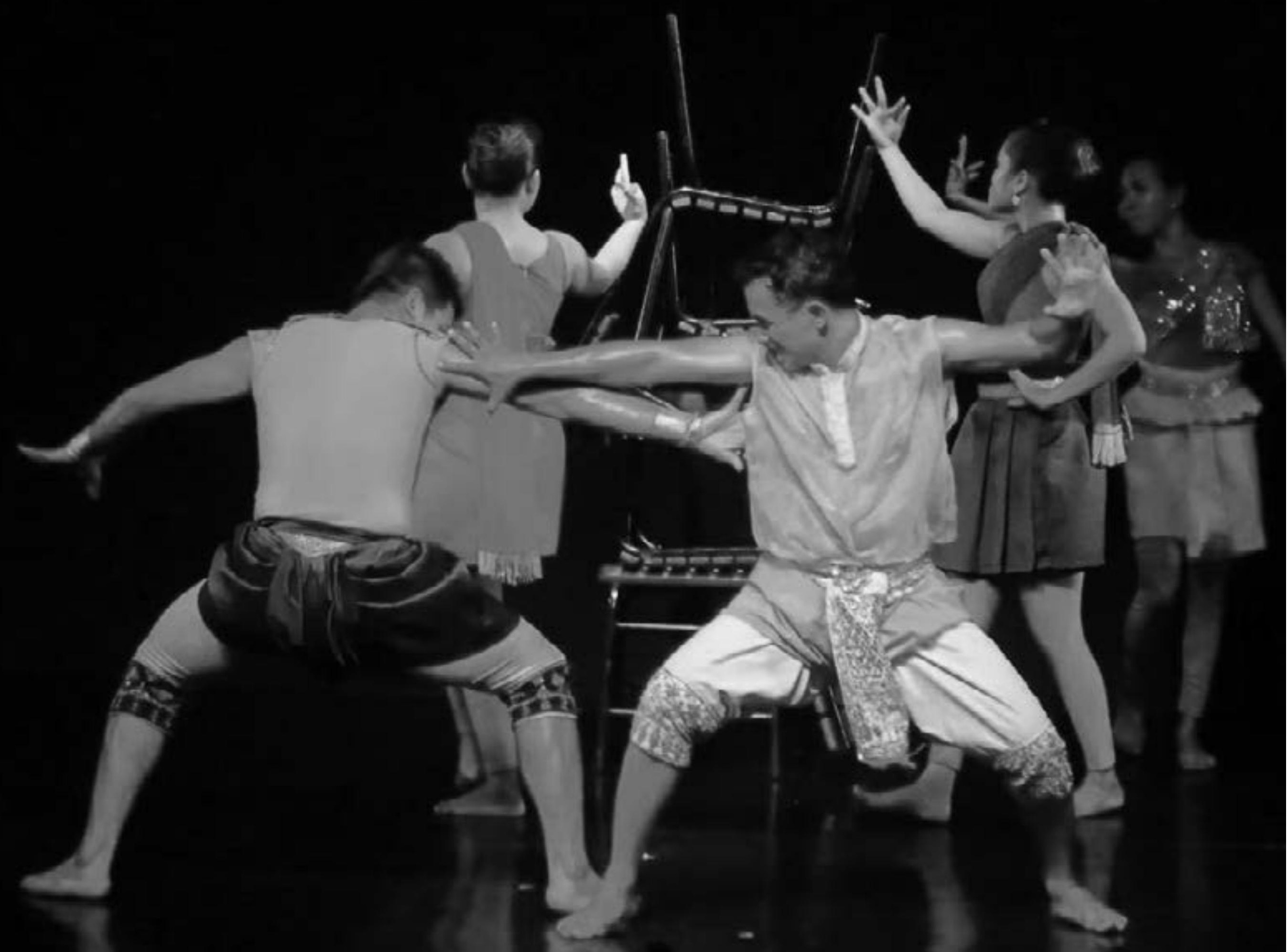

In discussing contemporary dynamics within the arts scene, the most common phrase used among participants was that 'art is a mirror to society'. The arts were seen as a means for promoting social cohesion and a sense of community. This could create social transformation by promoting mutual understanding:

'We are finding a way to live together peacefully. So art is the way to bring people together, learning from one another and understanding each other' (Sous Sinath).

Among many of the pieces there was a collaborative ethos that was driven by the artists themselves. The language of learning, teamwork, sharing knowledge and developing ideas together, was very strong throughout all the interviews. Teamwork was also repeatedly described as a new experience, something that was learned, and something that required individuals to adapt to one another's ideas, skills and experience. The arts therefore demonstrate the potential to create new forms of social support and collectivity 'because we are rehearsing together' (Chhoeng Sreypov).

Artistic practice was also repeatedly described as 'flexible', working as a hook to address a range of social issues, including learning cultural mores like gratitude towards parents, promoting peace-making and educational development, or raising concerns around inequality, poverty and rapid urban development. Several musicians and writers were concerned with cultures of drug taking and alcoholism, and the way that traditional performance forms could work as therapy to give addicts a second chance. Unsurprisingly, these artists were associated with Phare Ponleu Selpak in Battambang, who have a long-standing reputation for using the arts for social transformation in this way. 
One focus among artists in this particular Cultural Season was the environment, and how it underpinned Cambodian ways of living, rights and identity. Given the adverse and pressing effects of climate change on the Kingdom this is unsurprising. ${ }^{22}$ Both younger and older artists used performance as a way to focus young people's attention on environmental issues. This was particularly true of the Art and Environment Band and the Kouy piece My Village Traditions. Here, arts practice reflected socially located currents. For instance, illegal logging ${ }^{23}$ was a key concern of the Kouy from Tonsong Village in Stung Treng, who described a long-standing practice of using dance, singing and music to raise awareness about the need to prevent deforestation:

'I first worked as an activist to protect Prey Lang. I used to be at the front line against diggers. I worked with other activists to create dances and songs to raise awareness on Prey Lang among people in Cambodia [...] Then I created dance to raise awareness among our young people on the importance of our natural resources. [In Tonsong Village] the forest provides us with shelter. We live in the forest, so we should care about it and protect where we live. Nature is our life. [...] Young people do not know even how instrument like Tro are made out of wood'

Although such efforts had mixed effects, indigenous group leaders like Kha Sros were determined to use performance as a way to articulate their rights to land, to home, and thus to the environment, and to try to protect these for the next generation. Although My Village Traditions was not 'about' these environmental issues per se, the piece cannot be fully understood outside of this context in its promotion and explanation of Kouy ways of living.

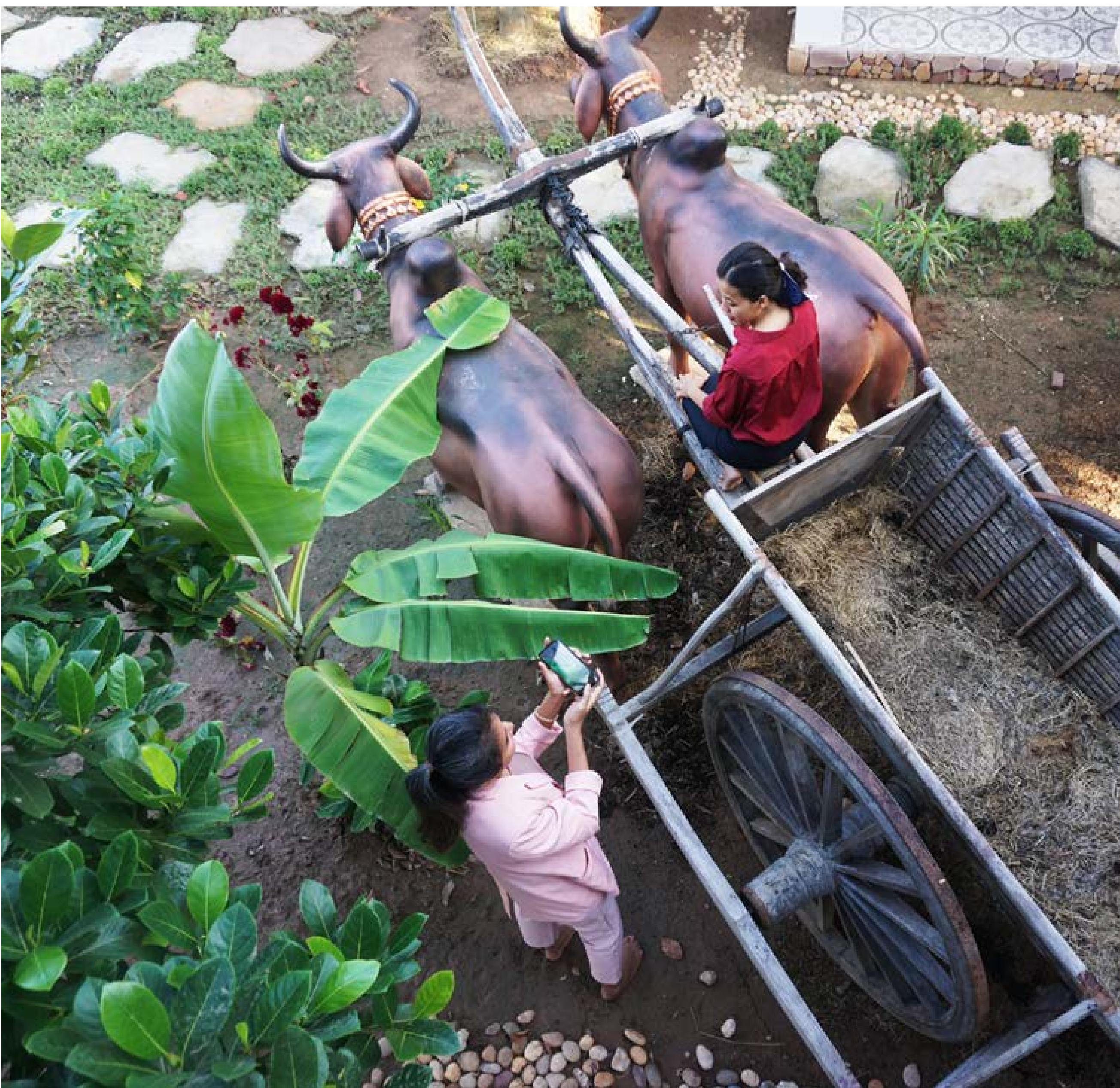


Similarly, the Art and Environment Performance was seen as a route to engage Band involved a wide range of musicians people in discussions that otherwise they and was driven by artists who run the Art might turn away from, and to teach them and Environment Festival. Here, music was about environmental destruction. Again, used as a fun and interactive way to raise performances may not necessarily address awareness about environmental protection issues of environmental preservation

'We use art to get people's attention to listen to us. We need to gather them so we can spread the message on environment issue at the same showing the identity of our group'

(An Raksmey).

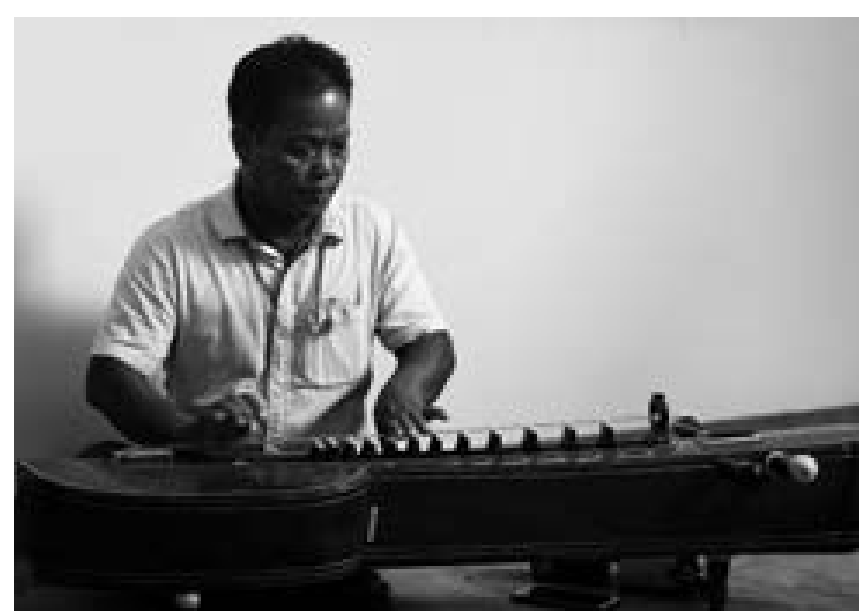

and rhythms. As highlighted above, it also encouraged intergenerational dialogue between artists:

'I am glad that I can see other art forms, for instance, Arak, Jvia and Khen music. I planned to adapt these musical instruments with mine to create new pieces and $m y$ plan was fulfilled [...] We mixed traditional music with modern music equally to create something new'

(Ly Vanthan) of activities and workshops orientated towards these concerns. Indeed, the Art and Environment Band was also interested in mixing and adapting traditional and
However, this became the dominant focus of the performance as staged in Phnom Penh. Although arts can be used as a 'hook' to discuss environmental issues, these were not directly addressed in the performance as such, and there were no accompanying workshops or discussions about the environment through which such messages could be promoted. There was therefore a mismatch between the band's naming/billing and the performance itself. Audiences nevertheless appreciated it as an opportunity to see rare 'traditional' Khmer music, and to enioy a piece that mixed this with bass rhythms, creating something 'distinctive (new) that those traditional and modern music were mixed together' (audience member). In this respect, the meaning and agenda of the group and its work shifted when they performed in Phnom Penh, but the musical originality of the piece was recognised.
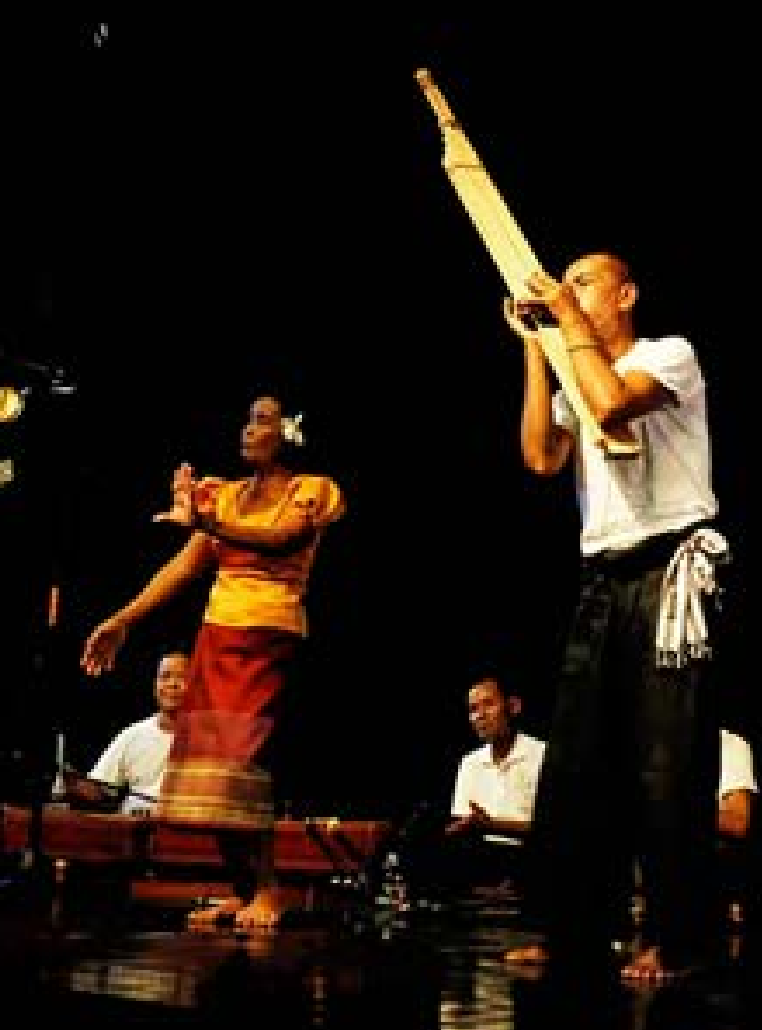
In considering this further, it is possible to question the extent to which art actually explores social concerns, and to perhaps suggest that this occurs in an oblique way. When asking about artistic sources of inspiration, comments about the role of daily life and the 'people around me', including family members, featured prominently. Yet a key source of inspiration was also the arts themselves. Participants described how watching international dance performances gave them new ideas, meeting or watching other artists (both domestically and internationally) spurred them on to be better, mentors from international exchange programmes introduced them to new artistic forms, and they discussed how learning more about their own art form developed their creativity. This was particularly the case with Nget's performance, Root, but it was also a wider phenomenon:
It [Root] is about the challenges that artists like us have been through and fought to survive. Although we have different art skills, we are uniting to work on something together. We strive to succeed, and those challenges push us to work even harder to achieve our dream. Not only that, this piece tells the stories of the six artists and their art skills. They have different skills, but they have one goal to achieve. [...] I want them to create something new out of their art forms. I want them to do some more research on their art form to understand their identities'

(Nget Rady).

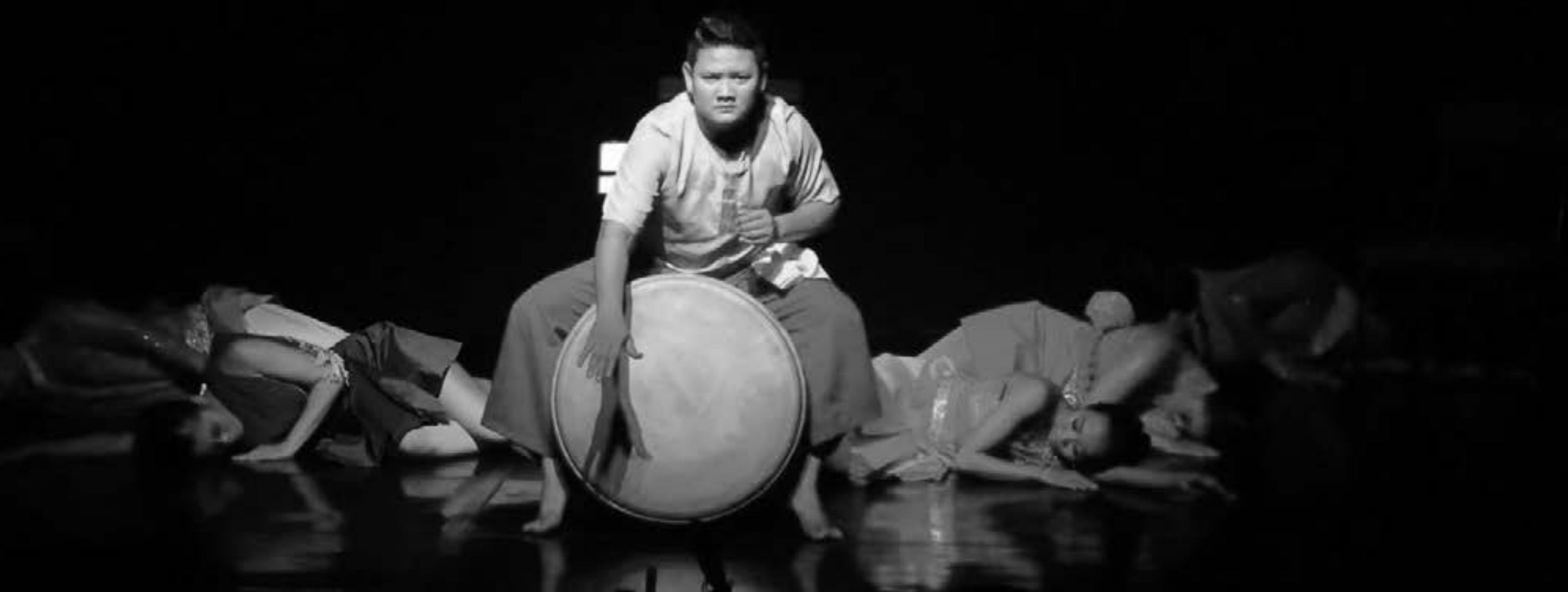


Although artists often talked about being a bridge, or of wanting to initiate a dialogue with audiences/society, it may be more accurate to suggest that some of these conversations are actually with the Cambodian and international ar worlds. They are part of a wider dialogue around what constitutes Cambodian arts practice in and of itself, what its own 'identity' is, and what direction the arts field is moving in. Indeed, whilst discussions around traditional and contemporary arts practice are inevitably shaped by the legacies of the Khmer Rouge, it is also debatable around the extent to which those are of interest to society more broadly. For example, one of the starkest audience responses around the connection between arts and society suggested a direct immediacy and relevance that they felt was lacking in the performances:

'It must be distinctive, attractive, emerging, hot (current and relevant), ho issues in society, burning issues for discussion. For example, now it is disaster (flash floods). There should be a show, film, performance relevant to the floods or Covid-19' (audience response, focus group)

This is not to suggest that the performances created were not well-received, but it is possible to consider more precisely how, and in what directions, the arts relate to society, and to open up a discussion of their relevance.
It is also clear that in considering the relationship to society, artistic practice only travels along particular avenues. Professional performers, for instance, cannot simply discuss any topic that they wish, and with many working as employees of the Ministry of Culture and Fine Arts, know the limits of what can be addressed. There was concern that if artists created something that did not align with traditional culture heritage or social norms, they would be judged as incorrect, or, in the film world, not granted a license. Yet in considering expectations around social and cultural values, artists were not interested in what they described as 'trendy' and pithy light entertainment (particularly love stories). They did not want to make superficial works that might be seen as debasing their art forms. Rather they wanted to use the arts to promote educational values or inspiring messages whilst also being entertaining - even if these might challenge cultural expectations. When seen in the light of the strong emphasis on traditional arts and cultura values among young artists, alongside the fact that none of them envisaged an artistic future without state support, there was a strongly expressed desire to learn how to navigate and work with government to address more challenging topics productively.

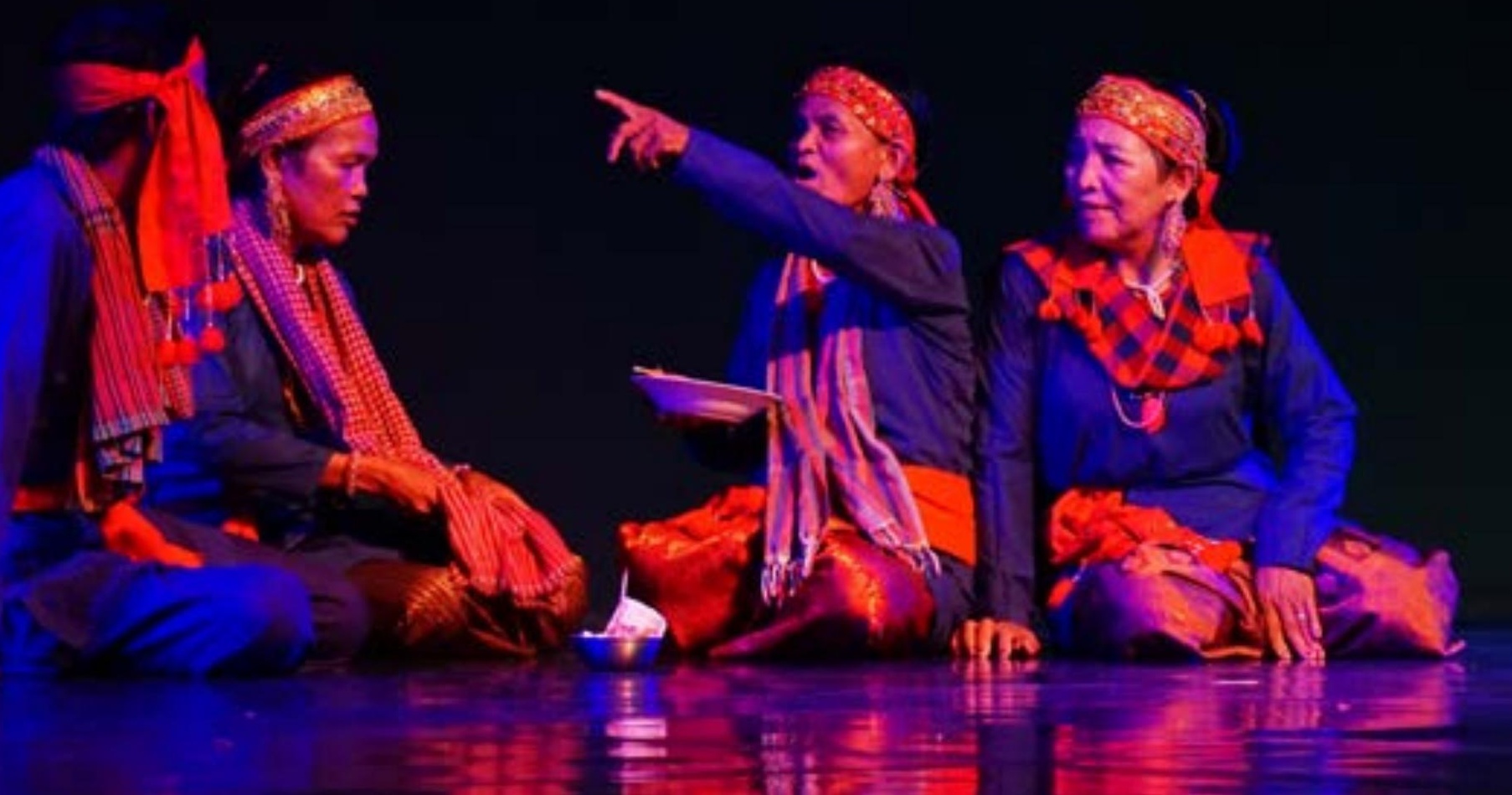




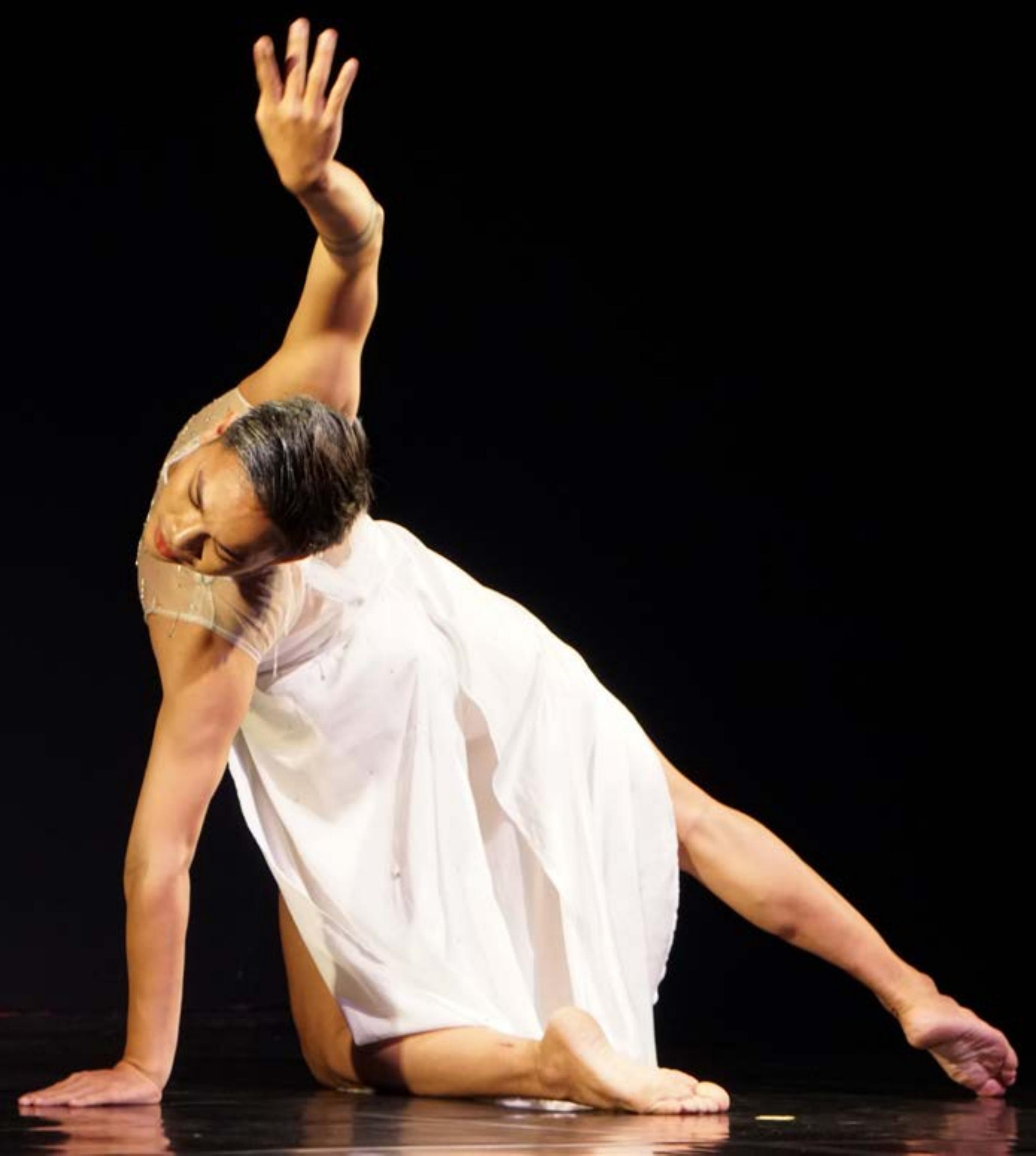

\section{Identity}

Identity is a relatively safe ground through which social currents and relationships can be explored. The Cultural Season theme of 'Expressing Identities: Them and/or Us' allowed for a varied consideration of how the boundaries are drawn between different communities. However, there is also an impossible task of representing everyone's interests in a single event. Communities can exist beyond established labels of identity (e.g. gender, ethnicity, disability). In the commissioning process, emphasis was placed on criteria such as something that was new, a clear idea that spoke to the festival theme, and in ensuring representation of artists from across Cambodia. Consideration was also given to make sure that women were represented. Artists were spoken to during the commissioning process and encouraged to submit their ideas in accessible formats (e.g. a video or oral application). In presenting this research, we have been repeatedly asked whether or not performances have explicitly addressed issues of, for example, gender or disability - in other words, how 'inclusive' the Cultural Season was. During the commissioning process there was no expectation that artists from a particular background should create a work addressing that experience, and as indicated above, the two approaches to commissioning were based in the recognition that more effort needs to be made to reach marginal groups. The 2020 Cultural Season also has to be seen in a broader context, where, for instance, the 2018 Season explicitly included an inclusive dance piece from Epic Arts called Buffalo Boy which was performed by two dancers, one with cerebral palsy and one who is deaf. Nevertheless, there is a balancing act in operation, and there is difficulty in ensuring equal representation for everyone. In this respect efforts are, and can be further focused on, equity of opportunity as much as equality of representation. 
Working with identity as a theme allows for a broad range of experiences to be articulated within a relatively loose curatorial framework. The emphasis on giving artists a platform to express themselves has been a core part of CLA's organisational mission in recent years:

'We're not trying to influence a creative direction for Cambodia, it has to come from the artist themselves

(Prim Phloeum).

By focusing on individual creative expression within a theme, the Cultural Season re-framed and moved on from existing debates that dominate the Cambodian performing art world. Although themes of traditional and contemporary performance emerged, the Cultural Season did not overtly reproduce questions such as, 'What is contemporary?', 'What is traditional?' and, 'Is this Cambodian enough?' - questions that have been asked of contemporary performance for years. ${ }^{24}$ Although they simmered beneath the surface, they were never directly articulated by anyone during the course of the research. Instead, the Cultural Season implicitly established that everything presented was Cambodian, even as it asked audiences to reflect on the differences and divisions within that collective identity.
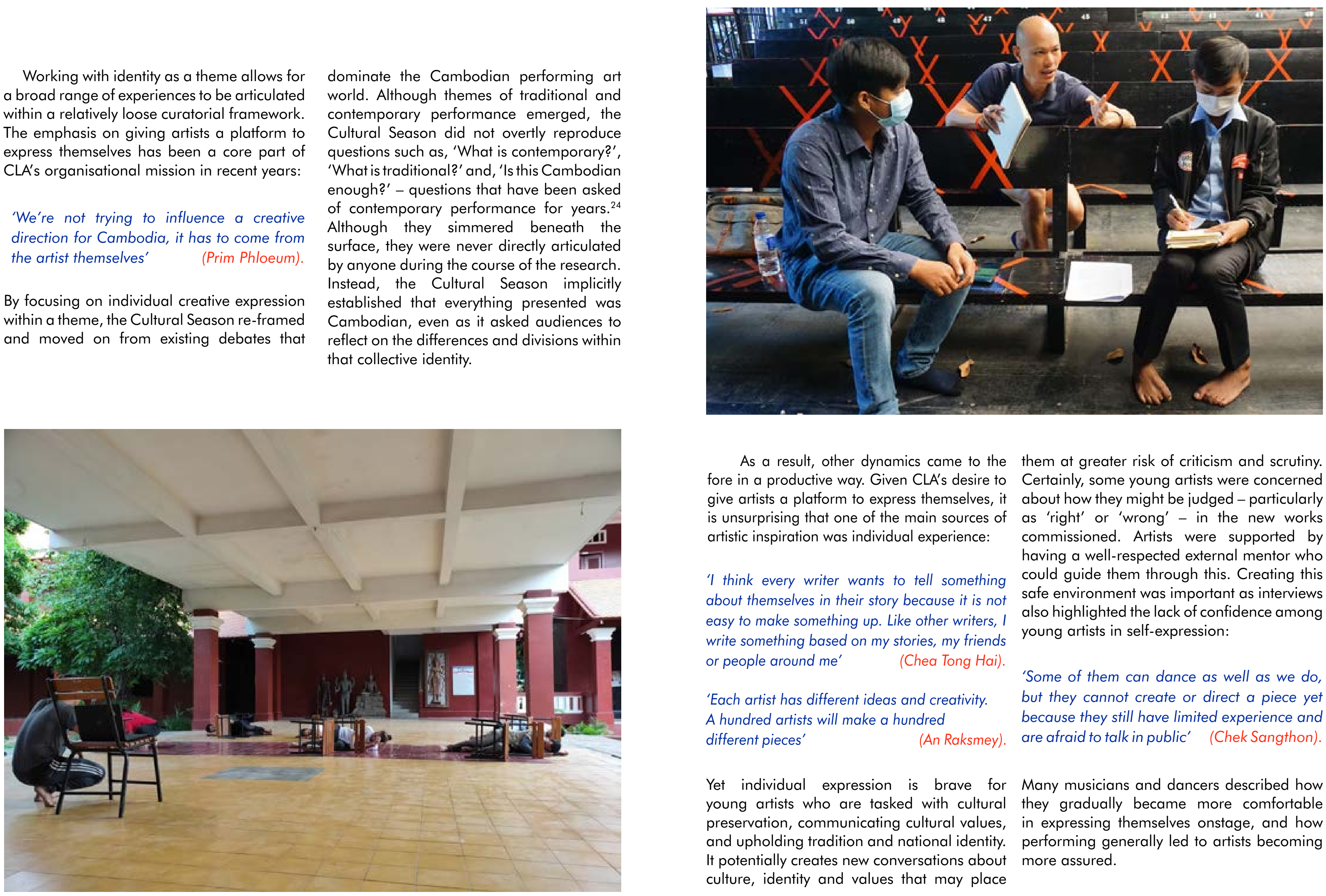

As a result, other dynamics came to the them at greater risk of criticism and scrutiny fore in a productive way. Given CLA's desire to Certainly, some young artists were concerned give artists a platform to express themselves, it about how they might be judged-particularly is unsurprising that one of the main sources of as 'right' or 'wrong' - in the new works artistic inspiration was individual experience: commissioned. Artists were supported by having a well-respected external mentor who

'I think every writer wants to tell something about themselves in their story because it is not easy to make something up. Like other writers, I write something based on my stories, my friends or people around me' (Chea Tong Hai)

'Each artist has different ideas and creativity. A hundred artists will make a hundred different pieces

(An Raksmey). could guide them through this. Creating this safe environment was important as interviews also highlighted the lack of confidence among young artists in self-expression:

'Some of them can dance as well as we do, but they cannot create or direct a piece yet because they still have limited experience and are afraid to talk in public' (Chek Sangthon).

Yet individual expression is brave for Many musicians and dancers described how young artists who are tasked with cultural they gradually became more comfortable preservation, communicating cultural values, in expressing themselves onstage, and how and upholding tradition and national identity. performing generally led to artists becoming It potentially creates new conversations about more assured. culture, identity and values that may place 
In telling their own story, young artists tended to turn towards the contemporary as their mode of expression. This involved mixing or presenting traditional forms in new ways or mixing traditional Cambodian forms with those from elsewhere (which should not be simplistically described as 'western'). The move towards the contemporary was nearly always seen as allowing freedom of expression, particularly in terms of being free from the rules and roles of traditional performance forms. This was nicely expressed by Sok Nalys when discussing The Pillar, a piece about the important people in her life, particularly HRH Princess Norodom Buppha Devi, and the experience of overcoming loss and grief when she died:

'My art piece [The Pillar] tells my story including my childhood memory and the important people in my life who help me become who I am now. It tells who I am, and what and who made me become who I am. [In classical dance] I think people might know me only through the costume I wear and the character or the role I am playing, yet they might not know who I am exactly. Though this piece they will know who I am and my story. My piece is about challenges and how I coped [...] Classical dancers are usually shy. They do not want to talk about their challenges. During our rehearsal we are told not to show our tears but the beauty and the flexibility, no matter how much pain we have' (Sok Nalys)

Several dancers commented on the performance of individual feeling, and freedom in terms of movement vocabularies and storytelling. In turn, this enabled them to develop new creative expressions and made them feel as though they were also improving artistically.

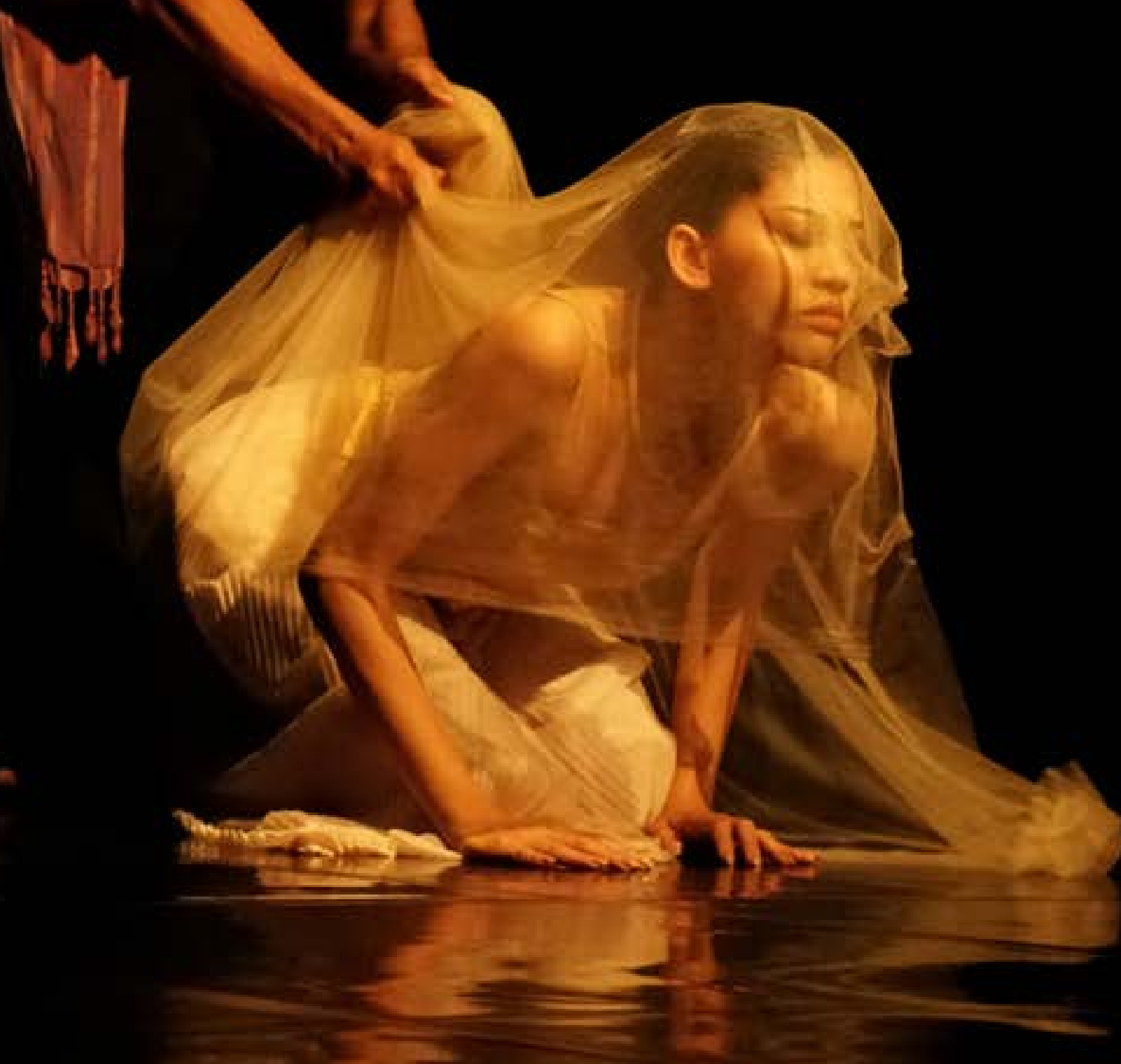

\section{"My art piece...made me become whe I am today"}




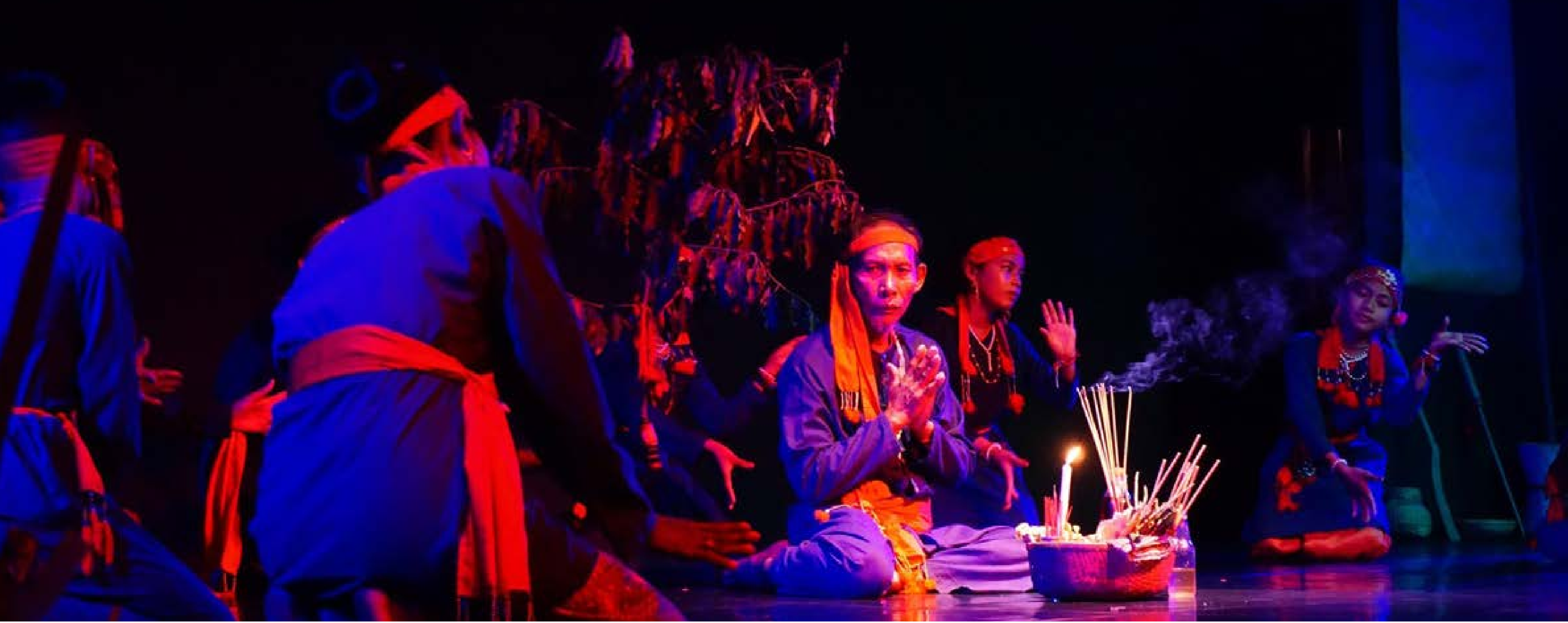

In terms of the Season theme, the idea of us/them was articulated along different axes. These were perhaps most obviously articulated and recognised in the indigenous Kouy performance My Village Traditions. The piece relied upon the articulation and expression of unique cultural difference not least because it was performed in Kouy language with Khmer explanations:

[Before taking part in the Cultural Season] we just danced but we did not show how important our tradition and culture are and we did not express our identity and language through our dances. This time I hope we will do better!' (Kha Sros).

Indigenous communities expose the power imbalances that exist within any form of collectivity, particularly at the national level. This is because in Cambodia indigenous people need to explicitly maintain and express their identity in order to try and establish rights claims, particularly to land, but also to health, education, and other social services. ${ }^{25}$ Indeed, the use of the arts to promote language learning outlined earlier is vital because this is often identified as a key marker of being part of an indigenous minority. Lost language ability is often the result of wider discrimination and a lack of legal recognition, but it is also required as a way to establish rights claims and belonging to the wider ethnic group. ${ }^{26}$ Young Kouy performers described telling only their close friends that they were part of an indigenous minority. Although they were not embarrassed about being Kouy, they did not feel able to publicly claim their identity either because they did not speak the language or felt that they did not speak it well enough. However, they still wanted to be involved in the performance 'to help preserve Kouy tradition' (Sophanny). As will be discussed below, audiences explicitly supported and appreciated this performance of ethnic difference. It was seen as a way to understand and promote Cambodia's varied cultures and traditions, to include 'them' as part of a collective ' $w e^{\prime}$ '. 
The inequalities between majorities and minorities and the desire to challenge assumptions about communities was widely held among young artists. For instance, Chea Tong Hai's staged reading, Invisible, drew upon his experiences of moving to Phnom Penh to send a message that we should not judge others - particularly based on appearance. Similarly, the staged reading of Give Me Back My Heart by Bros Sok and Choung Veasna's dance piece Dark, both addressed LGBTQ discrimination. Bros was very concerned with the social isolation and stigma of lesbian couples. He clearly viewed his piece as articulating a demand for social justice:

'I want to show other people that there is nothing wrong with same sex marriage. want our government to adopt a law to protect lesbian people against discrimination. Also, they were born lesbian but they can do anything that straight people can. We should not discriminate'

(Bros Sok).

Similarly, Choung's piece explicitly addressed his experience of discrimination for being gay and expressed his fight to overcome this. This was reflected in the use of two dancers: himself; and Chamroeun Dara as the shadow representing hate, insults, criticism and discrimination. The interplay between them, as an expression of power and control, sent a strong message to 'be who you are' and to fight back against inequality:

II want to show everyone who had the same experience as me to stand up and fight back. They can do it as I already did. People criticise and devalue who I am doing by saying that a classical dancer like me is useless. They criticise us because we are gay. Those criticisms can change who we are and what we are doing. We should ignore those criticisms and go forward. This criticism is like a dark cloud that we should clear away, or we will be covered by that darkness. [...] I want to encourage our young people who are experiencing any form of discrimination to be hopeful because people in Cambodia nowadays are more open to LGBT. Our country is moving forward'

(Choung Veasna).

The ability to stand up from a minority position and demand equality is a powerful message, one that rests on the recognition and acceptance of difference. Yet elsewhere in the research project, it was clear that being able to express such a message of tolerance was unevenly experienced. For instance, a film maker did not have her film about LGBTQ issues licensed because it challenged normative cultural values. Inequalities still persist, and the arts only reach so far in being able to articulate new social voices and visions.
"I wount to showe eweryone whe had the soume experience as me to stand up and fight back" 
Sitting as a backdrop to all these discussions is the inevitable observation that the Cultural Season enabled a reflection on Cambodian identity more broadly. The close historical association between the arts and the imagination of the Cambodian nation ${ }^{27}$ - both popularly and as promoted by government - almost demands it. The performing arts can be seen as both expressing and re-creating the image of Cambodia, particularly when it comes to the promotion of marginal groups, celebrating locally distinctive cultures, or highlighting dynamics of inequality. ${ }^{28}$ These differences can be brought together as a celebration of who constitutes the national 'body':

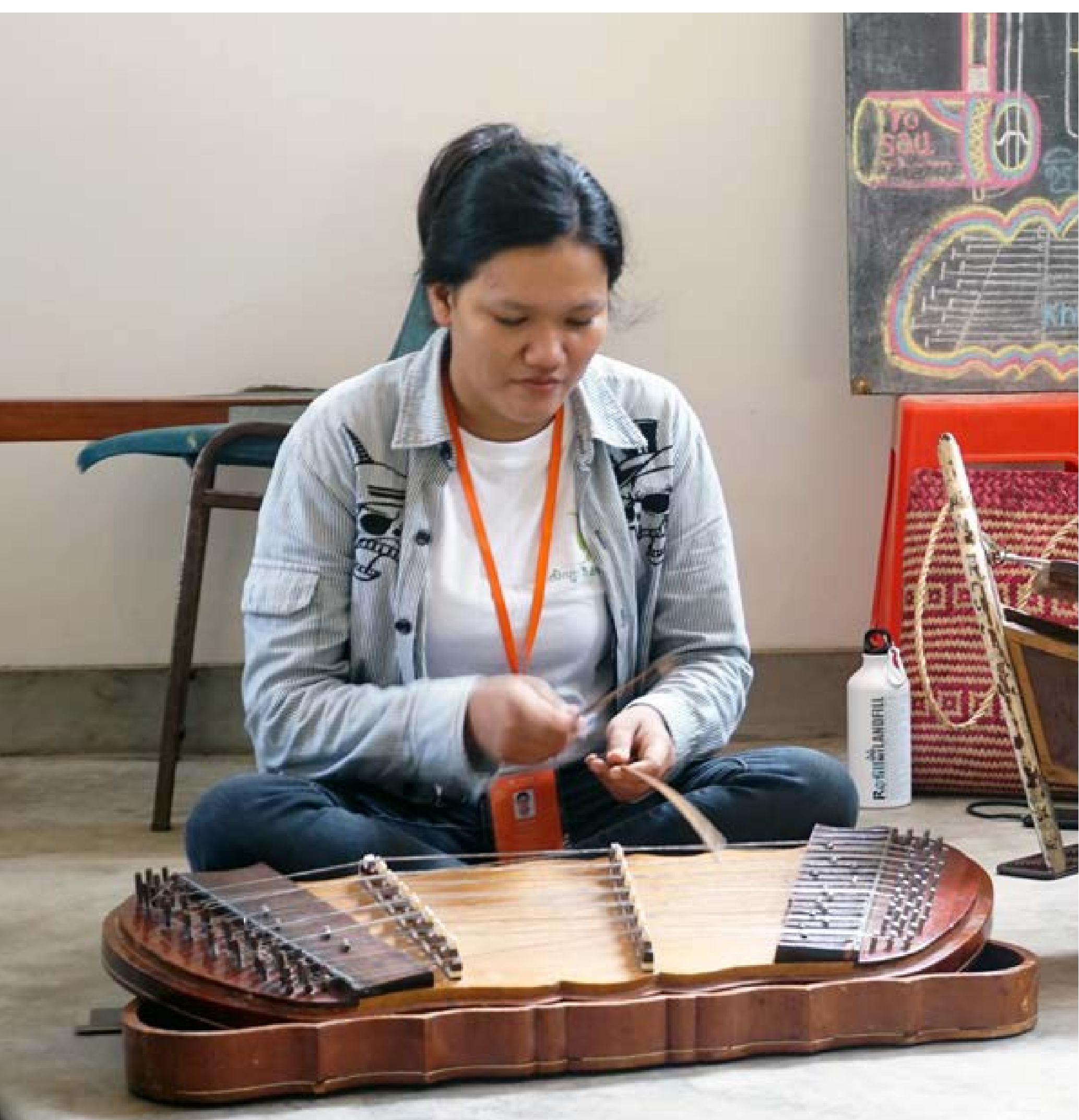

'They have different identities, but we are one nation. However, every group has its own identity in term of language and way of living. This is something special about each group, which can be combined together. Each group can bring and show their art work related to their certain areas'

(Sous Sinath).

This vision of a multicultural nation was imaginatively embodied in the Art and Environment Band and My Village Traditions. In the latter, reviewers and audiences reflected on the similarities and differences between Khmer and Kouy culture, particularly regarding dances and ceremonies. ${ }^{29}$ The performance also encouraged this reflection on intercultural exchange and the political dominance of Khmers, whilst also staking a claim for inclusion in the national imagination. Reviewers commented on cultural exchange as part of national identity, ${ }^{30}$ but issues of power, and particularly inequality, were more muted. When we asked those from minority groups about the relationship between art and identity along the theme of nationality (both here and with musicians performing with the Art and Environment Band) they queried the use of the term 'Khmer'. This reinforced that the elision between Khmer as the dominant ethnic group, and as the common translation for citizens of Cambodia, is inherently exclusive. This critically highlighted questions around who was being collectively represented, but it also led to much wider discussions about discrimination within the nation as a political formation. However, whether this emerged among audience responses is more debatable, despite a widespread support for, and interest in, seeing Cambodia's multiple artistic and ethnic communities. 
In pitching the national into an international area, many young artists talked about representing Cambodia internationally, of having performed in different countries, and of wanting to perform abroad (not least because they could earn a substantial amount of money). However, two observations can be made around this. The first was that for the majority of respondents, international exposure occurred through traditional, rather than contemporary, forms of dance and music:

'Cambodia is known by its precious art which is recognised internationally'

\section{(Suon Sotheara).}

'I know Khmer people in France who recognise our tradition'

(Chhoeng Sreypov).

Many wanted greater opportunities to perform abroad, were very proud of their arts, and saw this as a key form of cultural diplomacy. However, they also wanted to gain experience, exposure, and knowledge of new ideas and techniques. They felt that for Cambodian arts and artists to be truly international, there needed to be greater emphasis on contemporary development and innovation, so that a wider culture of experimentation could be fostered. It was also suggested multiple times that the government could provide more funding to support international exposure - particularly regionally. Interviewees highlighted asymmetries of opportunity for international exchanges for students in different disciplines at the Royal University of Fine Arts (RUFA). Artists wanted to see international arts placements and exchanges at schools and universities across all arts subjects:

'I want to see [...] participation from schools abroad in order to help [students] win opportunities to study abroad' (Suang Thina, workshop participant).

'In the next 10 years, I want to see [Cambodian] culture and arts developed into an international stage, get acknowledgement internationally, and have creativity with all kinds of arts forms [traditional and contemporary] internationally famous. I want to see new creations full of educational meaning [...] and quality oriented' (anonymous workshop participant).

South Korea was an aspirational touchstone for these artists in terms of being international with a highly diverse and self-sustaining scene. ${ }^{31}$ There was a desire in maintaining and showing cultural uniqueness, but also in pushing existing developments much further.
Simultaneously, however, the second observation is that there was also a comparative lack of wider awareness of contemporary performance scenes both regionally and internationally among emerging artists. This perhaps signals that a more senior (but still young) generation of contemporary artists, such as Ly Vanthan and Nget Rady, have had international exposure and exchange, but that the next generation of emerging artists may not necessarily have the same opportunities. This was signalled by an audience question after the screening of Dark and The Pillar as part of the UK's Being Human Festival. Sok and Choung were asked to comment on how their contemporary dance works related to a wider South East Asian, or Asian contemporary dance scene. The absence of this international imaginary, and knowledge around what those wider scenes are, was surprising - but should not be interpreted as a negative critique of these artists and their work. The relevant point is that for artists across the world the internationa is a key route through which contemporary forms are developed and presented, but at the current moment, for some in Cambodia, these experiments appear to be more internally focused and drawing on relevant in-country expertise. In order for the arts scene to remain lively and diverse, greater opportunities for younger dancers to be exposed to contemporary forms internationally, and their presentation abroad, should be considered as part of a longer-term policy around artistic exchange and development across the arts sector.

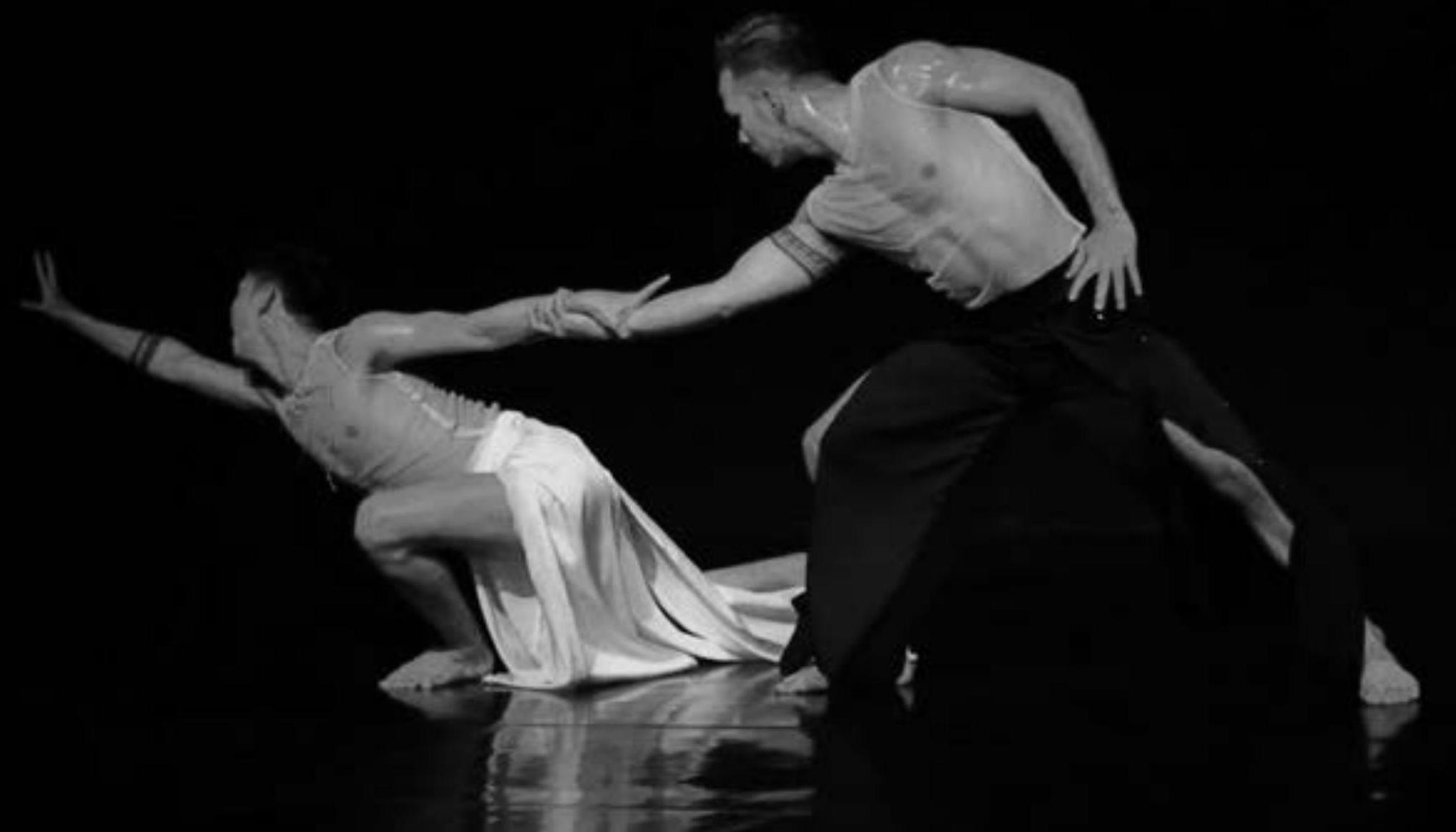




\section{Audiences} The audience research from this project comprises the largest data gathering exercise on arts audiences in Phnom Penh to date. Audience research is vital to find out who existing arts audiences actually are, to see what young audiences want to watch, and to know what makes them come to the arts (or not). This information will hopefully assist in efforts to engage young people in the arts and therefore ensure the sustainability of the sector. It is often assumed that tourist and expatriate audiences comprise the majority of arts-going audiences in Cambodia. ${ }^{32}$ Although this may be true for particular enterprises (e.g. Phare, The Cambodian Circus in Siem Reap), it is debatable whether this is the case for contemporary arts in Phnom Penh. The decline in tourism that has occurred in Cambodia since $2015^{33}$, alongside Covid-19, offered an opportunity to reassess existing assumptions. It was clear that the majority of performances sold out to domestic audiences (and sometimes domestic tourists). There were only two instances of expatriates taking part in short interviews and none took part in focus groups. Given that survey data was anonymous, it is harder to ascertain how many foreign tourists and expatriates attended the Cultural Season. Nevertheless, the evidence we have (including direct observation of audiences) suggests they constituted a very small proportion of audiences as a whole and sometimes were completely absent.

In terms of audience engagement, the Cultural Season not only hosted performances but also a curated an interactive programme, comprising workshops and discussions that explored the theme of Expressing Identities: Them and/or Us in more depth. 5 performances from the Cultural Season, along with three interactive programme events, were screened online by CLA via their Facebook page. These were directly viewed by over 11,400 people (organic reach) 34 but it is difficult to gather meaningful responses other than 'likes' and brief comments that are largely supportive. In future work we would like to explore digital viewing further given the potential importance of technology to the arts (e.g. through watch-alongs and 'in time' live analysis). The research therefore focused on the responses among live in-person audiences for the 5 commissioned performances (the second performance of the Art and Environment Band was cancelled due to Covid-19). A tour of many of the pieces was also cancelled due to Covid-19, although initial data was collected when My Village Traditions toured Stung Treng and Mondulkiri provinces. 


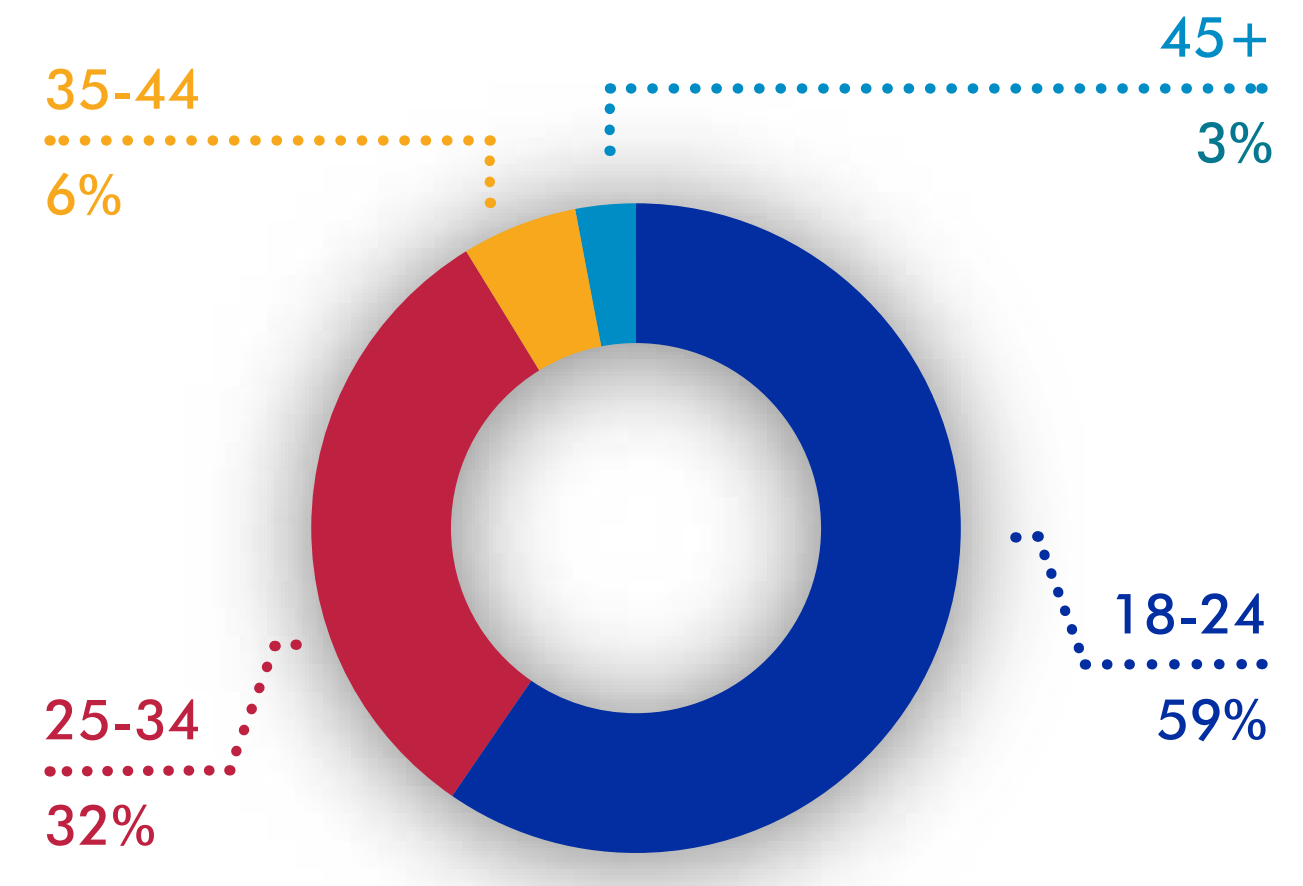

000

\section{Who is the Audience?}

From a sample of 126 survey responses in Phnom Penh, 91\% were under the age of 35 , with the majority (nearly two-thirds) in the 18-24 age bracket (see Figure 1). There was a roughly equal proportion of men and women, and a small percentage $(2 \%)$ who identified as transsexual or other. By far, the largest proportion of audiences aged 18-35 were students $(66 \%)$ with a substantial portion $(19 \%)$ of young professionals in white collar occupations (see Figure 2). Audiences who explicitly identified a creative occupation (e.g. dancer, video editor, graphic designer, architect) comprised only $7 \%$, and $4 \%$ identified as civil servants. These proportions remain relatively constant across the sample as a whole $(60 \%, 20 \%, 6 \%$ and $6 \%$ respectively).
Figure 1

Ages of Phnom Penh Respondents

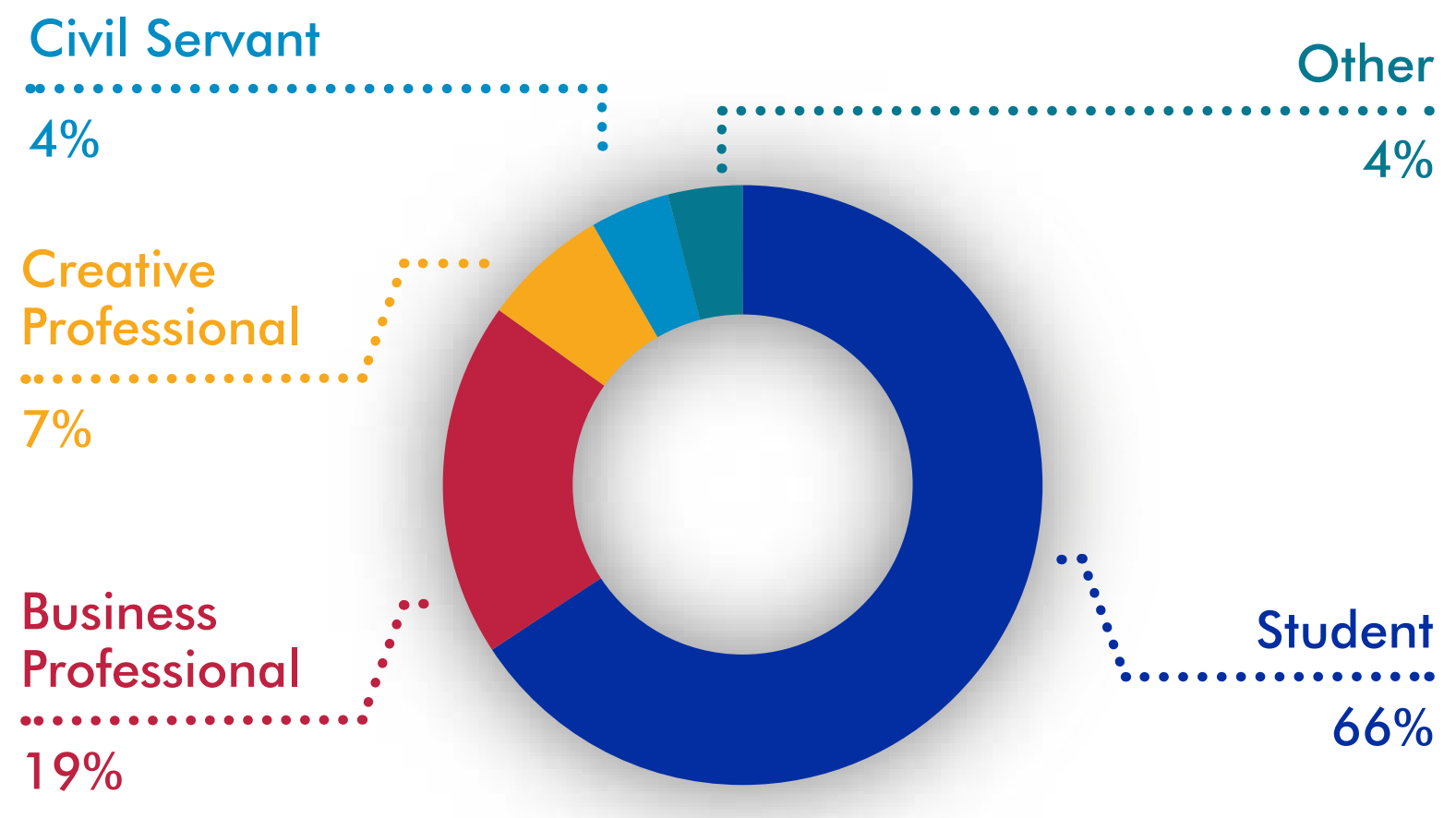

Figure 2

Professions of 18-35 year old respondents 
In considering this data, it is possible that those identifying as civil servants could be artists given that many professional artists are employees of the Ministry of Culture and Fine Arts. It is unclear if the majority of students are studying arts as they simply stated 'student' in their response. However, from our short interviews, it was clear that although there was a slightly higher number of arts students, there were also students from a range of disciplines, including engineering, law and international relations. A key reason behind this could be the recruitment of youth volunteers by CLA to help promote the Season, the hosting of interactive programme events at RUFA, and the wider marketing to this age group through Facebook and YouTube (particularly, for example, the Wow Arts Facebook page). However, a recurring theme in focus groups was also that many audience members did not really become interested in the arts until they went to university. They may have been to see performances or exhibitions, but they did not view the arts as a 'free time' activity until they met friends who were interested in the arts or made friends with arts students who they then wanted to support. As such, university is a key site for developing an interest in the arts generally. What is also clear is that there is an emerging middle-class of young Cambodians who are not arts professionals but who are interested in the arts as an activity (and who will support it financially). However, whether that interest started at university cannot be determined by this data. 
The majority of the audience is a regular arts- of the Cultural Season's audience was new going audience who go to an arts event (e.g. or comprised of individuals who went to film, exhibition, performance) once a month something artistic less than once a year - a or more (see Figure 3). It is likely that answers fairly substantial proportion. In looking closer to this question were based on pre-pandemic at this group, the top three reasons that they experience. Nearly 20\% stated that they gave for coming were (in order): to learn had never or rarely watched a performance something new (the largest reason at $32 \%$ ) before, and there was also a substantial non- to support or promote the arts $(22 \%)$; and response to this question - which could include because they had seen something on social people who had not been before. However, in media about the Season or knew a friend who answer to the question 'Is this the first time was an artist involved in the Season $(17 \%)$ you have attended a performance?' $40 \%$ of (see Figure 4). This contrasts slightly with the respondents stated that this was their first wider sample as a whole, where an interest time. There is, therefore, some inconsistency in Cambodian culture was the joint highest in how people responded, but a closer look reason alongside the desire to support or at the data also reveals that some individuals promote the arts ( $24 \%$ each) (see Figure 5). who stated that this was their first attendance This was then followed by learning something at a performance described having previously new (15\%). It is also worth noting that there is been to arts events (which could include a also an explicit group of people in both results film or exhibition), although this was still not who were interested in contemporary dance a regular occurrence for them. Nevertheless, both as a core arts-going audience and as a it would be fair to assume that at least $20 \%$ new activity.

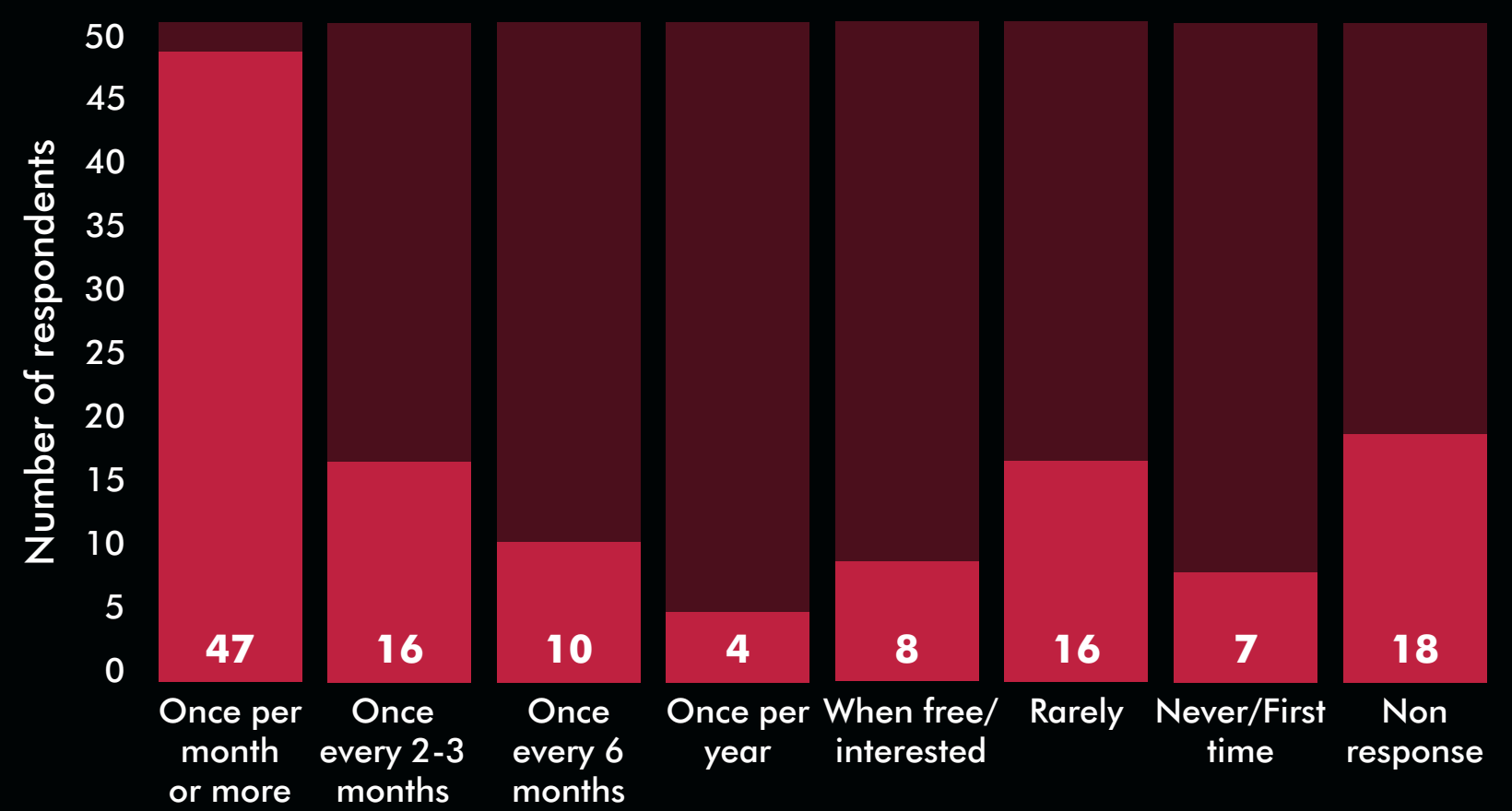

Figure 3

How often do you attend arts events?

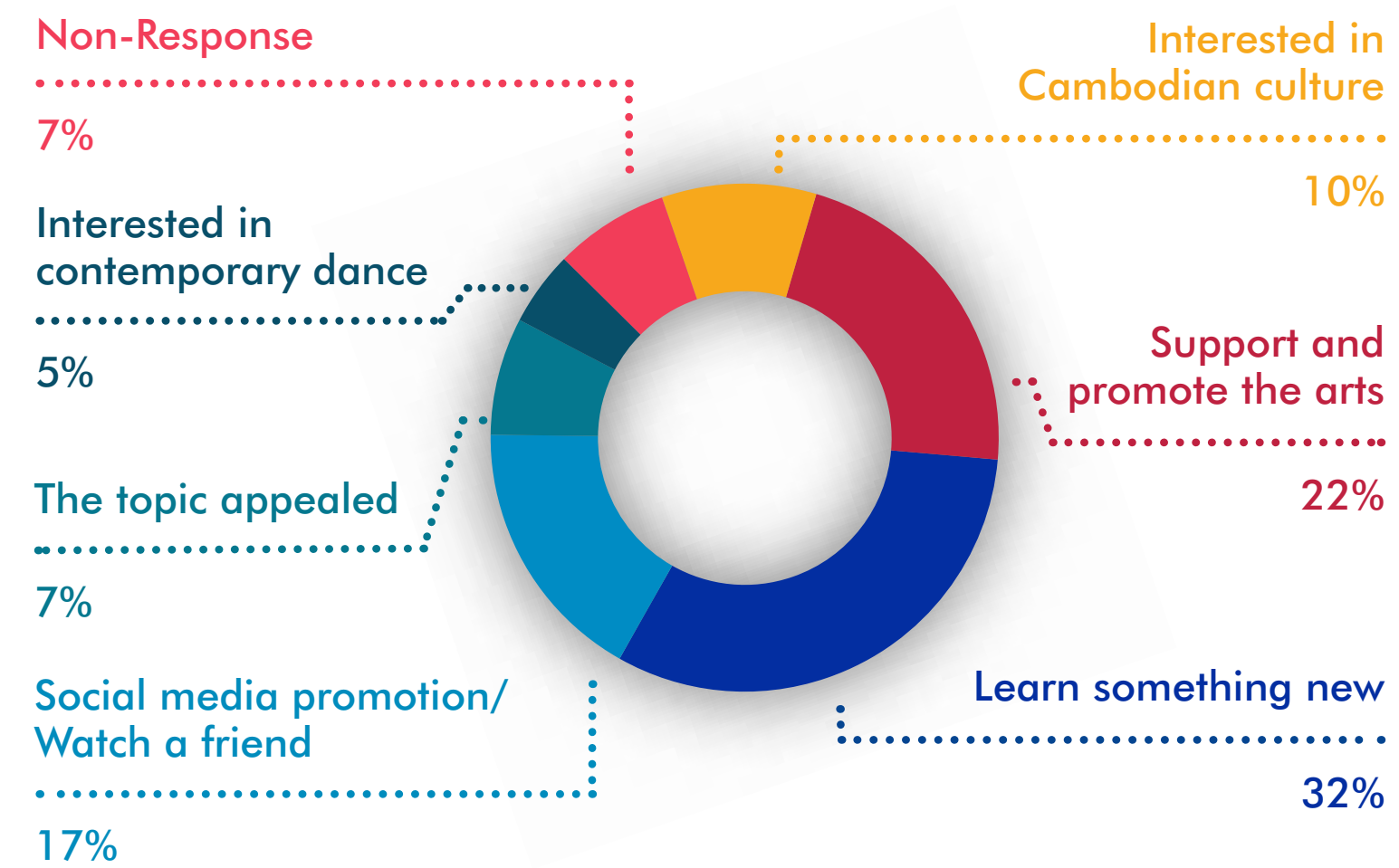

$17 \%$

Figure 4 Reasons for Attendance Among New/Low Attending Audiences

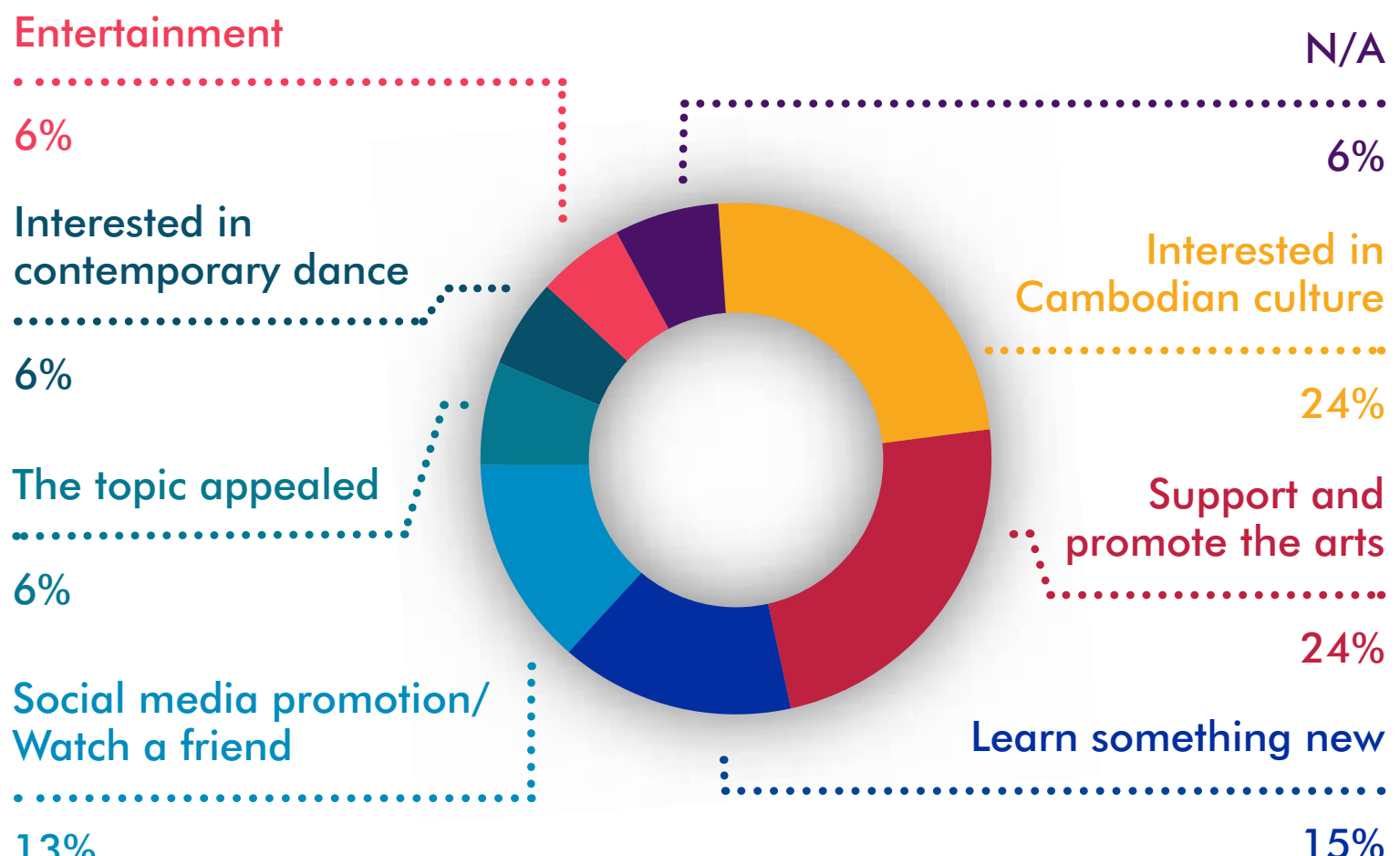

Figure 5

Reasons for Attendance as a Whole 
000

\section{Audience Responses}

The data from 43 short interviews and 5 focus groups with audiences supports these findings. There was overwhelming support for the arts among audiences - though it is also more likely that those who freely gave us their time for short interviews and focus groups were invested in the arts. Respondents often described that they 'want to help promote our national arts' (focus group participant), even if they did not always understand them. They clearly also saw performance as a way of helping to preserve culture and share knowledge:
'The performance helps us to know culture and helps us to conserve both indigenous peoples' culture, minority culture and Khmer culture. It helps us to conserve both cultures [...] We know about their culture and so we help to conserve, promote and spread the information about culture' (short interview respondent).

'I love new creation and found that arts are almost extinct, so I help to support' (survey respondent). 
There was also a very strong emphasis on wanting to gain knowledge about the arts in and of themselves. Some audiences explicitly prepared before attending a performance, and would look up the artist, the art form, or any instruments that they were about to see on Google, Facebook or YouTube. Having watched performances, audiences often remembered details that they had learned (for example, the survey respondent who stated that they were 'amazed to see the drum made from mud!') and found themselves wanting to find out more:

After watching this performance [Root], I feel more love towards Khmer arts. I want to know more about Khmer ancient arts because our current youth do not understand about Khmer arts or help to promote Khmer arts. The more we participate to watch our Khmer arts performance, it means we help to conserve and promote our Khmer arts to stay forever'

(short interview respondent).

'It was good to watch and it made me wonder too. And want to know more. I used to watch contemporary dances. I don't have any surprise about the performance. But I don't know much about Khmer arts'

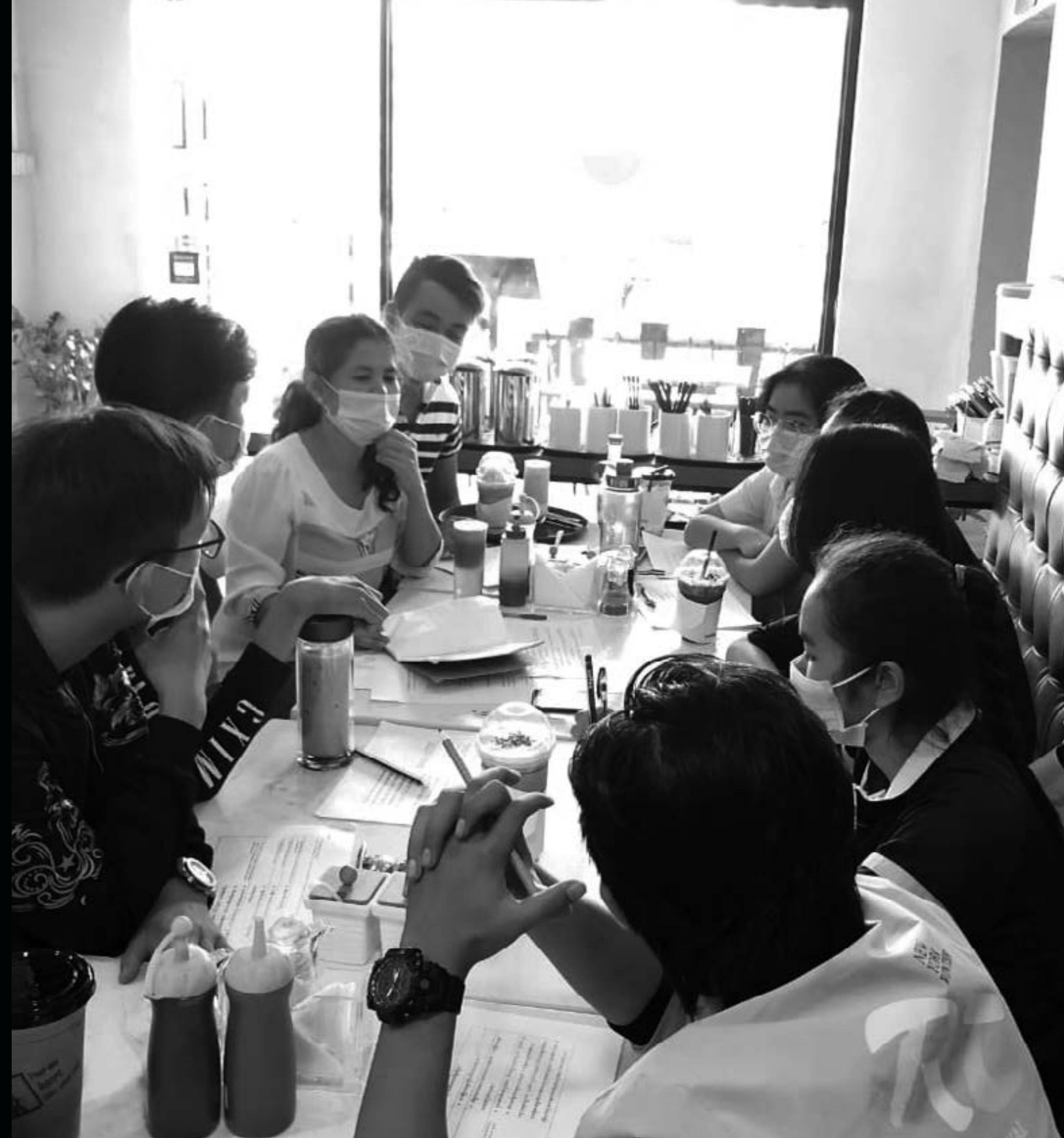


In focus groups, the performances of Dark and The Pillar were unanimously loved by young audiences for this reason. Although all the performances led young audiences to reflect in some way, these works in particular stimulated considerable connection with, and reflection among, young people in relation to their own experiences. For example:

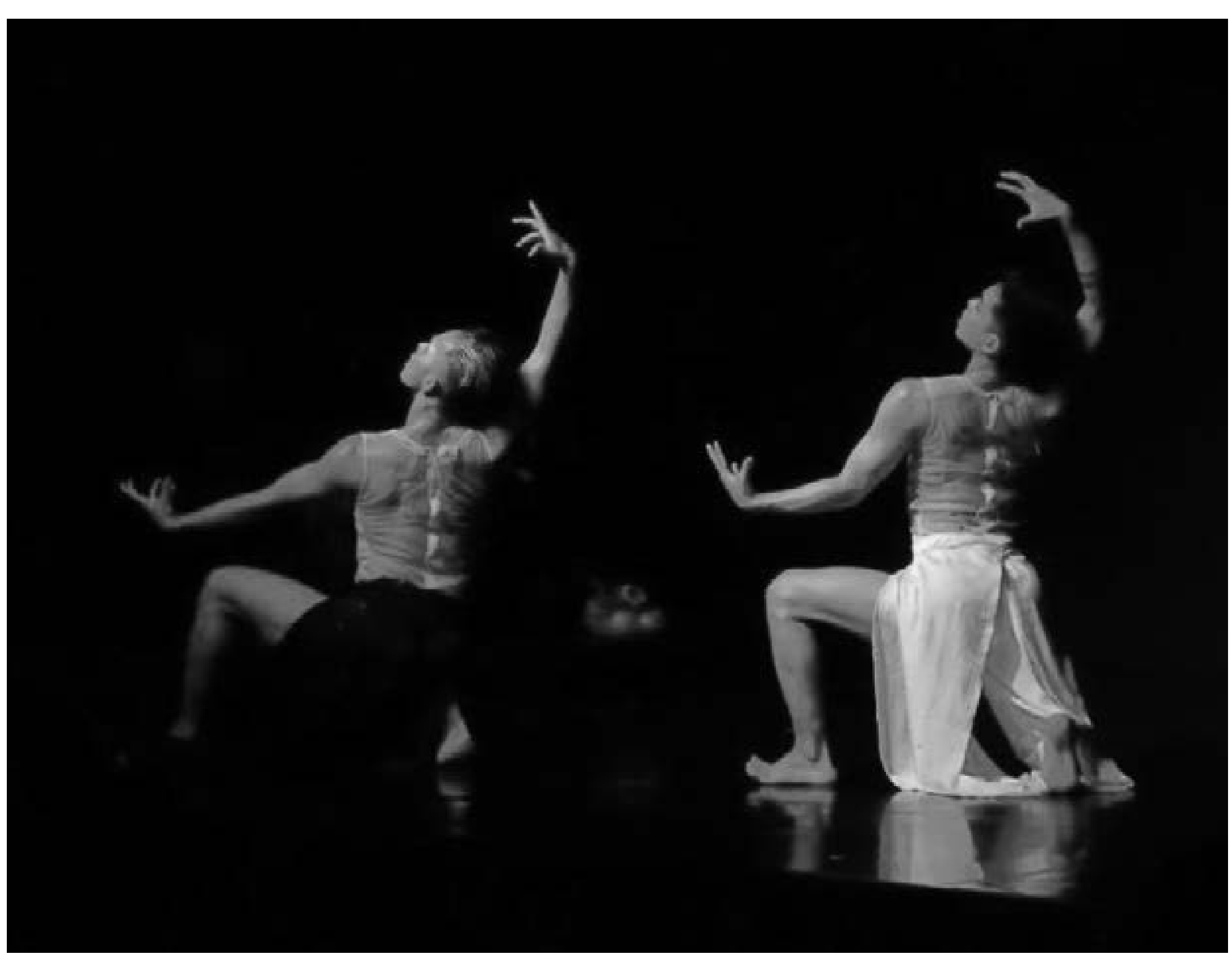

"T have a friend whe is $\mathcal{L} G \mathcal{B} T$. After T watched this performance [Dark], I thought about them so often. I saw them smile, but I did not know haw much pain he received daily through people calling him "ktuy" (a derogatory term for homesexual), this word of discrimination that he received. I thought akout him and how much pain he would receive daily. I thought about him and think what T could do to help him. I want to be a closer friend to him and find ways $T$ can support him.' 

only be 'for art's sake' but to speak to bigger concerns that was valued and seen as key to contemporary arts in particular. Audiences appreciated the length of time taken to consider what techniques to use in contemporary performance so that it could be understood, and the ability to create 'good content that reflected social issues' (short interview response).

\section{6}

'T used to have mental health instakility. INhen T watched The Pillar, it recalled me about my own life. I quit my job, I travelled alone, ate street food, stayed in a hostel, felt lonely. WWhen T watched (it), it made me recall my own feeling of being lost.'

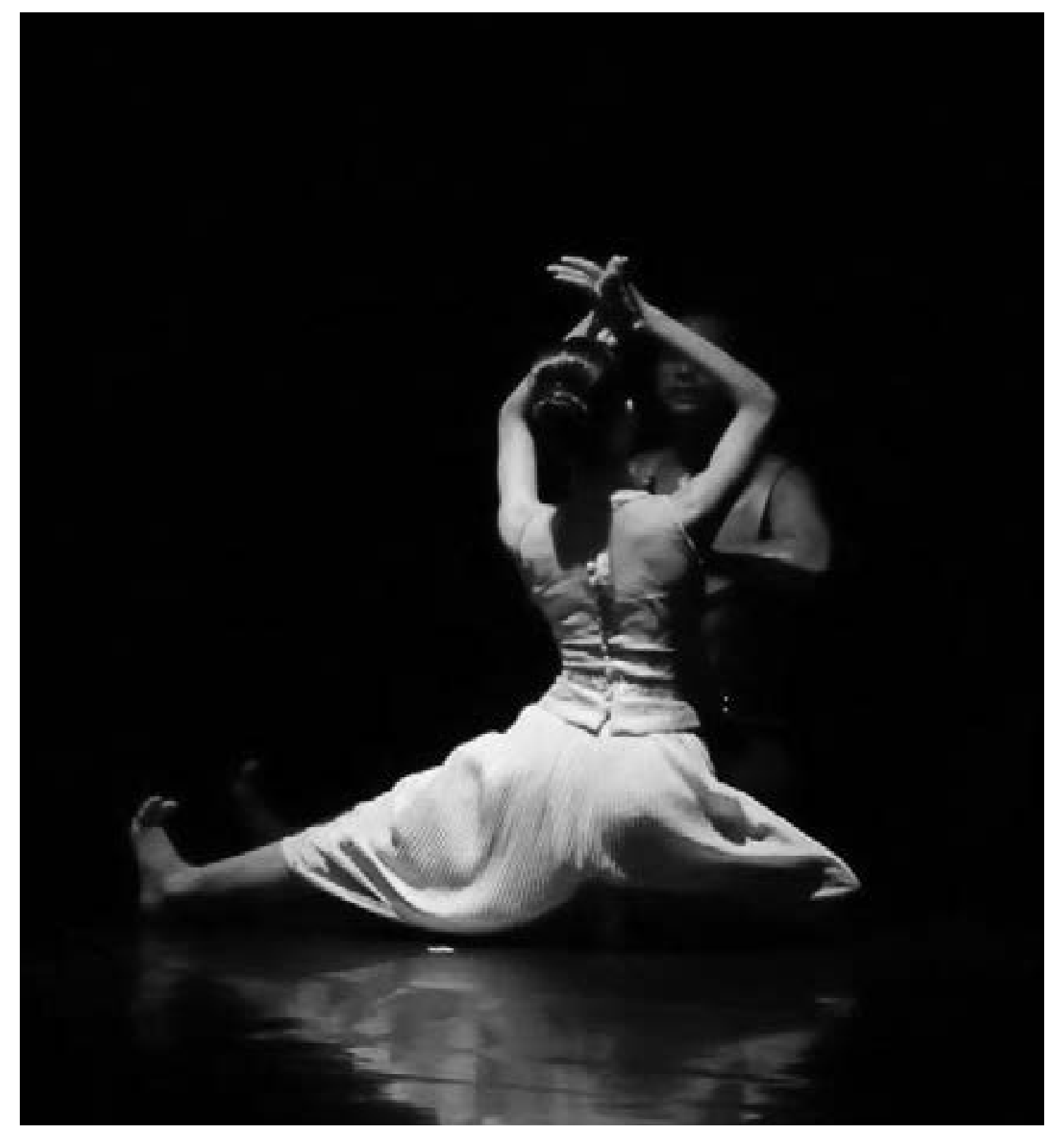




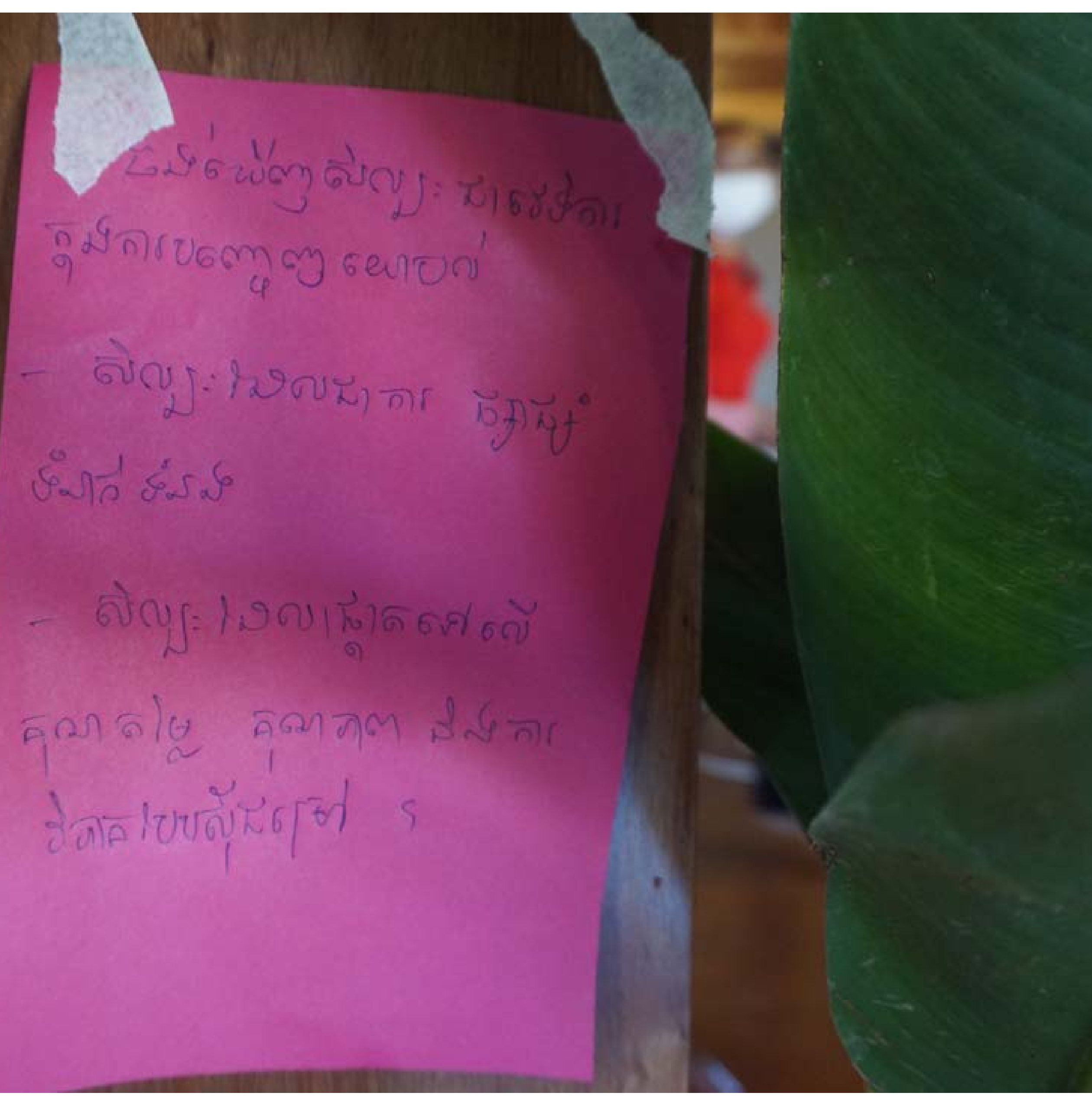

Another central feature of contemporary performances that audiences particularly liked was that they were seen as 'new', 'distinctive' and 'original':

It is unique and meaningful. The performers were absolutely good and active. When I watched I did not want to close my eyes. I wanted to follow every movement of the artists' (focus group respondent).

If feel it's distinctive. Often when we watch a performance, we see only one form of arts. i.e., if we watch a performance of Lakhon or Yike, we see only one form of it. Now they mixed those different forms of arts together, I found it distinctive. I feel amazed because this is my first time having seen this kind of performance' (short interview respondent).

'The performances were good because the performances projected about their own stories and they are new creations' (short interview respondent).

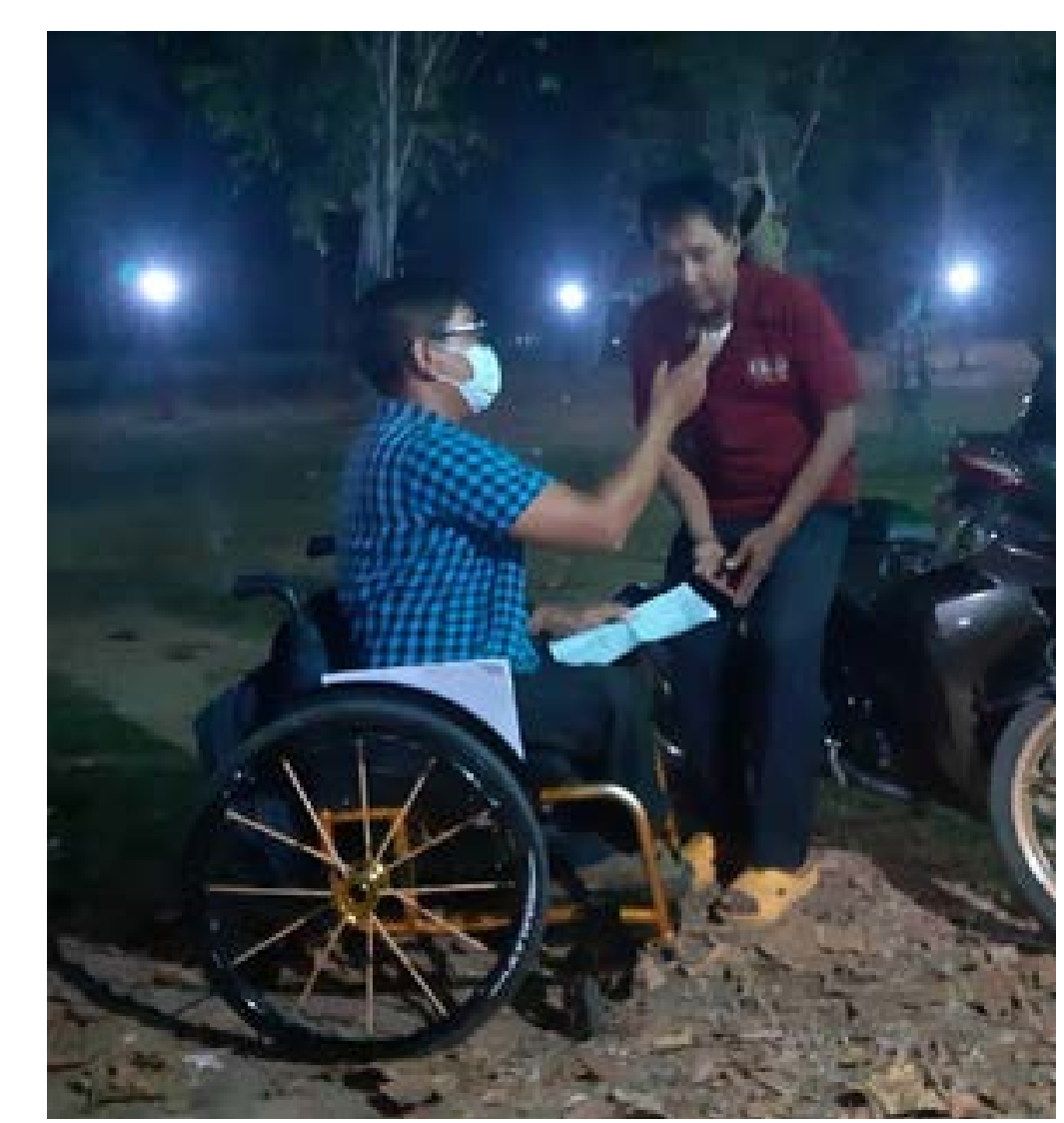


It was through these questions that young audiences who were not artists described how they wanted the arts 'to look and sound modern', and for them to be 'trendy' and 'cool', even if they were traditional (focus group respondents). The traditional alone, in and of itself, was seen as 'boring' and young people 'do not see the benefits of our traditional arts' both as a career and as a paying audience (focus group respondents). They did not feel cultural responsibility in the same way as artists themselves. As a result, the presentation and framing of traditional arts for young people needs consideration as they are looking for something 'full of creativity and looks interesting' (focus group respondent). This also included statements that may be uncomfortable for the arts community. Young audiences in the focus groups wanted to see higher production values and more slick performances - they wanted to see more investment not just in the artists but also the staging:

'It should reflect the environment. If it is in the city, it should be classy. If it is rural, it can be more traditional.

'I used to invite my friend to watch an art performance. But my friend told me "Why go to watch traditional performance? It looks poor. It is not high class."

'I don't think I would go to watch this kind of performance because it has no nice scene organized, the performers did not connect their feeling to the music and had no movement. I found it not attractive enough for me to attend next time.

Young urban audiences saw themselves as being in a developed country, as modernized, and they wanted the arts to reflect this. They wanted 'modern things [...] beautiful stars' (focus group respondent). Some artists also highlighted limited production budgets and were keen to imagine what could be performed with more money, clothes and materials.

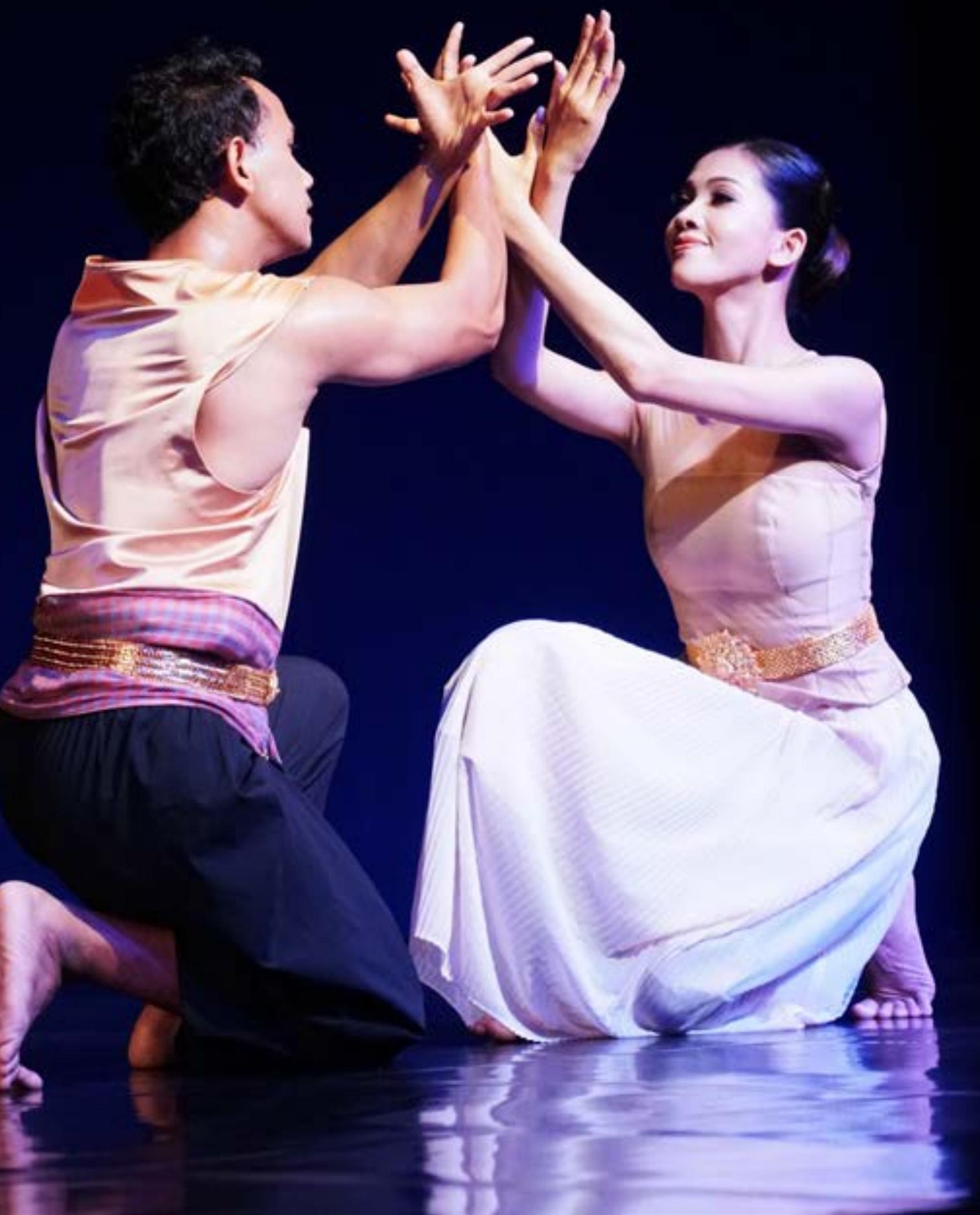




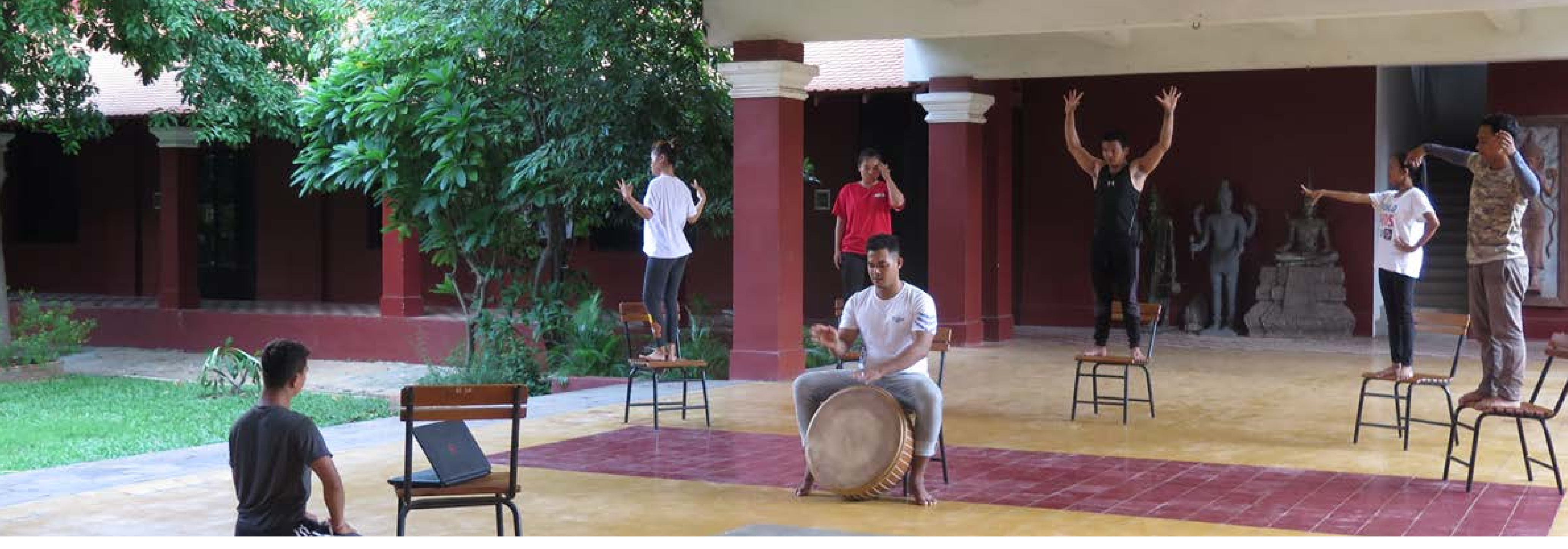

The arts were therefore not always seen as trendy and some participants in focus groups described how they attended the Cultural Season on their own out of interest, rather than following activities that their friends might otherwise pursue. Many audiences did bring friends along, or had been given a ticket by their friends, highlighting that these young people did try - at times successfully - to make their friends interested. Some respondents in the focus groups also described how in the last five years, there has been more support for the arts among young people but that it was still 'not to a favourable level' (focus group respondent). There were other hopeful signs as well:

'[I like] watching performances, exhibitions, shopping sometimes could be boring, so go to forest for a walk, exercise, homework (school work), drink beers and smoking, dining with friends, play digital games (phones/computer), ride motorbikes around' (focus group respondent).
For this respondent, the arts had clearly become part of their 'free time' activities, and this is what is needed for them to become sustainable. Many young people emphasised the role of social media promotion, and the Cultural Season marketing clearly tapped into that with Khmer language videos introducing what the Cultura Season was about, profiling some of the artists, showing clips of rehearsals and even doing a tv segment. These were shared via Facebook pages, but there may be a way to partner with other influencers to promote these more widely. Social media promotion was clearly working as evidenced by the survey results, but there may be additional ways to reach new audiences. This is also true of the reviews that the project commissioned. These are available on the CLA blog ${ }^{36}$ but the next step would be to try and place these in bigger media outlets (e.g. Wapatoa) and to promote arts journalism and criticism more widely. There is, of course, a risk that young people just come to the arts and consume them as entertainment, but without this there is a danger that they will not come at all. The Cultural Season also has elements in place through its interactive program to deepen that engagement, and these events are well attended. However, the research suggests young people also want to learn more 'in one sitting.' What is clear is that there is a desire to learn about the arts among many young audiences that can be mobilised - and, indeed, needs to be satisfied for their continued participation. 


\section{Organisational Considerations}

Although this report has already identified some dynamics that CLA can consider in future, some brief comments around 3 issues can additionally be mentioned.

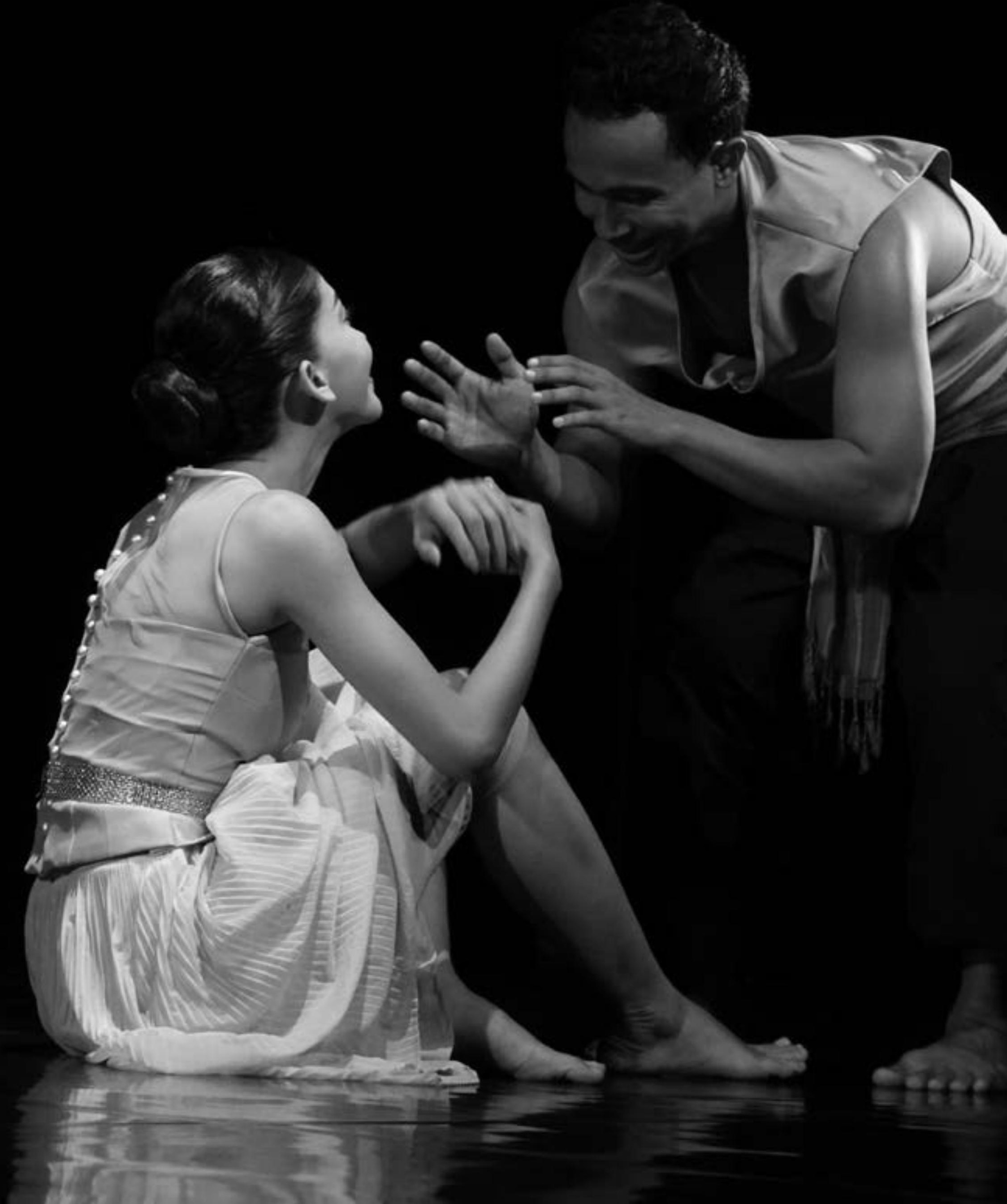


The first is that, in the main, artists feel very much part of CLA and many have been funded or connected to it in some way. The organisation has successfully fostered a feeling of 'family' that is supportive and allows for individual creative expression. Younger artists described meeting teachers and dancers during the Cultural Season and that this spurred them to keep moving on and find ways to support their work. This sense of community assists with artistic and creative development within the arts world more widely. However, it also raises issues around expectations, particularly regarding what one organisation can realistically achieve.

In a context where there is very little external funding for new work, weak funding infrastructures in general, but lots of artists with ideas for projects and opinions about the future of the arts, competing demands may be made on CLA in operational terms. In some ways, the organisation works like an informal arts council, and judgements around remit will have to be made. For example, if artists and audiences want to see more funding for more hi-tech and cutting-edge productions, can CLA provide this alongside seed funding, opportunities for international exchange, and arts engagement, for example? How does that connect with its organisational remit and planning? Is this a direction desired? When there are few performance venues and performance opportunities thrown into this mix, which works-in-progress will be developed further into fully fledged pieces?
How many will be - and how might this be traded against a desire to see diversity and multiple expressions of 'newness'? Is the market for these pieces simply going to remain domestic? These are a few simple questions that the research raises.

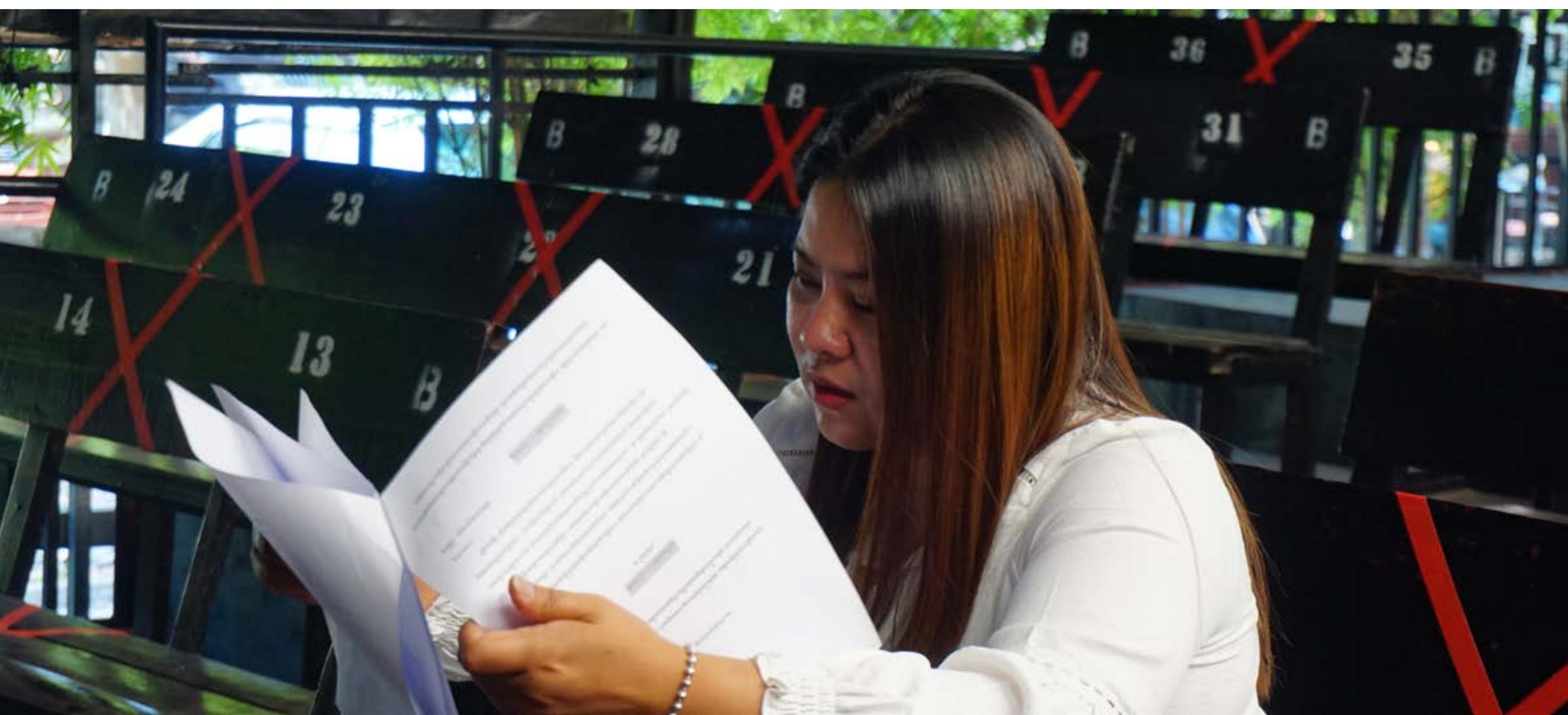



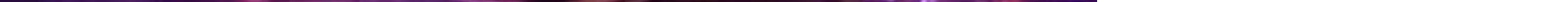

In considering what young artists and audiences wanted to see in future for the Cambodian arts scene, three issues emerged. The first is that everyone wanted to see greater promotion of the arts by the government and for the government to re-establish the cultural value of the arts to society. One central way that they felt this could be actioned was through funding, particularly the creation of new venues that could be used for different types of performance:

In Sorya shopping mall they have cinema, but if I want to watch arts performance, where can I go? There are very limited places for arts performance

(focus group participant).

I want to see more new creations of new art forms or dances in order to help Khmer people have a chance to see more than Apsara, blessing dance, and others (workshop participant).

If I want to see a chapei performance where do I see it? It's not often performed.... There should be more presentation of traditional arts and better pay for artists (workshop participant).

Artists wanted to see more competitions, more recognition, more arts advertising, and more funds for creating work. They wanted weekly events in a diverse ecosystem. They identified the lack of choice, and the boredom that came from seeing the same performances on offer, particularly given Cambodia's rich artistic heritage. Artists also repeatedly described feeling undervalued and inferior because they were paid little - particularly compared to other skilled fields that involve years of training. As a result, they struggled to make arts their livelihood. Čopič and Sešić ${ }^{37}$ describe a lack of data gathering in the arts sector, and the most recent study of artistic earnings is still CLA's employment sector report from 2014. This research found that artists only earn USD 92 per month on average, with the figure falling to USD 73 per month for theatre performers and musicians. ${ }^{38}$ This means many artists take other jobs which prohibits them from focusing solely on their creative practice. Artists were also sceptical that there was not enough money to promote the arts. In 2021, the Ministry of Culture and Fine Arts received the 17th largest budget out of 35 Royal Government of Cambodia Ministries. ${ }^{39}$ 
Money was strongly linked to the establishment of cultural and societal value in the arts as a profession. Many artists from families without an artistic background described being discouraged, and even physically abused, by their families for wanting to pursue an arts career - one seen as unstable, low paid, and bringing shame. Indeed, it was only when artists performed abroad and earned more money, that those families changed their minds. This importance of money societally and its relationship to valuing arts was well expressed by this focus group participant:

Money is not only one factor of our lives. We could literally learn a lot from arts and this could help us in developing our capacity in presenting our opinions and ideas. However, our society has taught the public to see the value of money. Money is everything, money to help us to have everything, solve the problem and gain success. [...] It can solve everything. This made people value money and spend time to earn money rather than spending time to enjoy watching arts for happiness. So people say arts is useless (because it does not generate money for themselves).

Academics and journalists have argued that Cambodia's economic neoliberalisation has traded political stability for widening inequalities. ${ }^{40}$ Within this, it seems that the arts have also been socially and economically devalued, and artists left behind. Practitioners repeatedly described how the arts were always seen societally as someone else's responsibility, as secondary to business, jobs, other forms of entertainment, and simply life in general. As one focus group respondent put it, 'At the end who will take care, participate in promoting the arts? No one!' The ability of the arts to show the beauty of life, to educate, to inculcate cultural values and pride in Cambodian identity was seen as having immense benefit but the social idea that it had an intrinsic value and could be a job and career seemed frustratingly out of reach.
Beyond the desires outlined above, the second future concern of artists and audiences was arts education, and this was seen as a key way of establishing cultural value. Cambodia's lack of arts education in the public sector is well-documented and viewed as central to the sector's sustainability and survival. ${ }^{41}$ As Brennert argues, 'in addition to few artistic activities, there is no universal arts education in public schools resulting in a generation that grows up culturally illiterate. ${ }^{42}$ Although the National Policy for Culture ${ }^{43}$ highlights this as an area to work on, there has been relatively little improvement. This is evidenced in the responses above, where it was evident that greater knowledge and awareness of the arts was desired and would help young people to understand what they were watching - whether 'traditional' or 'contemporary'. Educating young people to be involved in the arts without necessarily specialising in it, to try role plays, music and dance, were seen as key to fostering an appreciation of the arts. At the very least, artists were happy to promote greater arts education in the private sector. This was on the basis that those individuals were more likely to reach positions of power and influence in the future, and thus be of potential benefit to the sector.

In talking about arts education, however, this also needs to be broader than simply learning about the arts per se. Stereotypes of artists as prostitutes, or as being gay were seen as inhibiting people from pursuing the arts and from even watching the arts. Even if artists identified as gay, people were perceived as being concerned that those artists would 'persuade to be like them' (focus group respondent). Male artists in particular, repeatedly described experiences of bullying and harassment that stemmed from this wider societal prejudice. In this respect, arts education also needs to address these wider assumptions in order to establish their cultural value at a popular level. This is inevitably a difficult terrain as it entails shifting, or at least opening greater dialogue on, deeply held cultural assumptions and values. 
The final future dynamic that emerged was the importance of social media to the arts, something inevitably shaped by the pandemic, but which was not exclusively confined to the present moment. In asking artists to debate four key influences on the future of the Cambodian arts scene during our workshop, the role of technology became central. Artists were concerned that social media brought in foreign cultural influences (notably K-Pop and hip hop) that were more appealing to young people. Equally, however, both young and old artists recognised that they could promote their art forms and self-image through Facebook and Instagram - indeed, this was a way that they recruited students. The role of Facebook and YouTube in promoting Cambodian arts is of increasing interest ${ }^{44}$ but their potential in creating new arts experiences and forms specifically designed for the digital world (such as dance films) has yet to be fully explored. Artists described learning skills like film making and creative writing through YouTube, but this was self-directed. In this regard, digital skills and entrepreneurialism is a key area for arts education - and for artists more broadly. This wider capacity to develop 'soft skills' (time management, networking, entrepreneurialism, conflict resolution, contracts) is nascent in arts training ${ }^{45}$, and research has explored how employment in the Cambodian dance scene, for example, can be based more on the ability to network, rather than artistic ability. ${ }^{46}$ Of course, the digital arena is key to attracting young audiences - and in this regard, if a diverse and vibrant scene is established, a centralised app that lists and promotes all arts activities at city or province level, would potentially be a way to co-ordinate and develop interest.

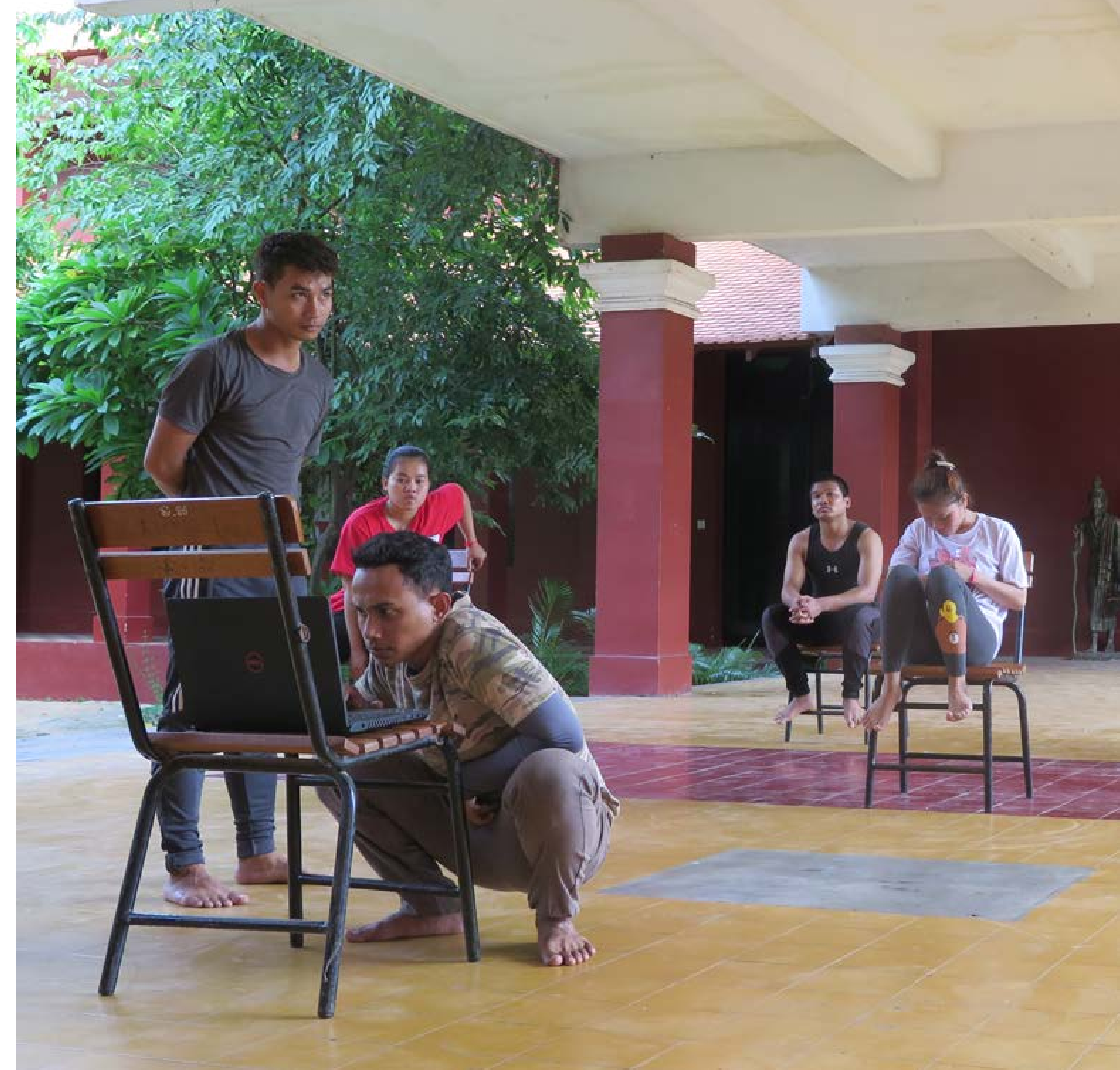




\section{Key Findings}

2

The Cultural Season re-framed existing debates around the performing arts in Cambodia. It established a theme that allowed for the exploration and expression of identity withou pre-determining it. There was an assumption that everyone/ everything being performed was Cambodian and that al expressions were equally valid. As such, it allowed artists to focus on the best expression of their story or idea and allowed audiences to connect with the performances in new ways. Critiques of the programme moved beyond existing debates of what is Cambodian in contemporary arts-making. Young artists are moving on from using the Khmer Rouge as a starting point for creativity, even as they recognise the importance of remembering the atrocities of this era.
A healthy arts scene needs to be diverse and lively. Both artists and audiences want to see more venues, more regular performances, and a greater range of artistic offerings. They want to see more performances of both traditional and contemporary arts forms - and to see that supported, funded and promoted by government (including better pay). This diversity is likely to be needed in order to maintain traditional arts for the next generation.

Artists show immense respect for their role as the guardians of Cambodia's cultural heritage and traditions. Contemporary performance is approached thoughtfully and critically Becoming involved in contemporary performance means artists often expend more effort in ensuring that they do not lose their traditional arts skills. Many young artists are concerned that contemporary arts will mean the loss of traditional arts. However, as stated above, one need not occur at the expense of the other. There is space for, and a desire to see, a range of art forms across the spectrum.
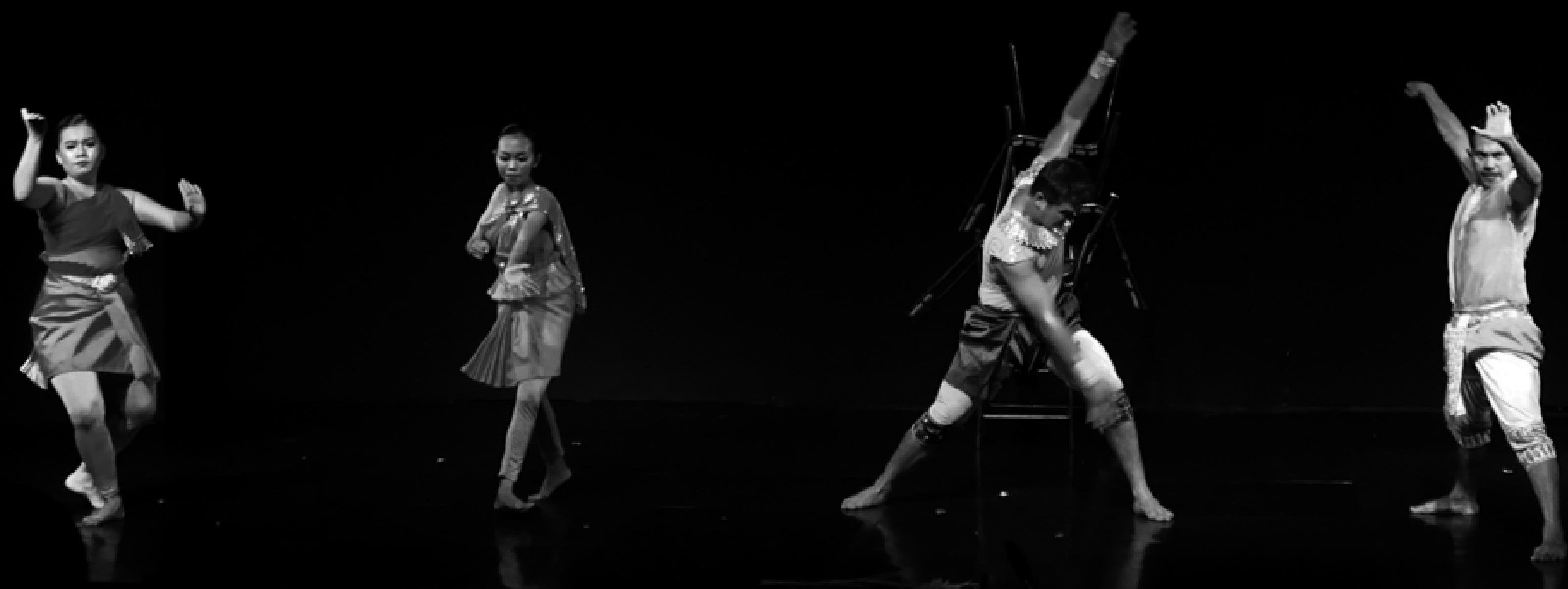
Young audiences, particularly urban young audiences who are not involved in the arts sector, primarily want to see new, contemporary works. This is what interests them, because they want to see reflected in the arts a modern Cambodian nation and relevant social issues. However, our research shows that the contemporary can also be a route to learning more about, and preserving, traditional art forms for both artists and audiences. The contemporary-traditional dynamic discussed within the artworld is not a zero-sum game. Without the contemporary there is a potential risk that young Cambodian adults beyond the arts community will not show interest in the arts at all.

Young audiences do not always understand exactly what they are watching. They want to engage with the arts, but sometimes struggle to know where to look for information. Audiences wanted to see more information about what they were watching, experience more interaction with artists, and gain insight into the creative process. However, there is a broader issue about establishing knowledge, value and awareness of the arts at a societal level. Both artists and audiences highlighted that there needs to be much more arts education in schools at all levels - with the majority of nonartist audiences not encountering the arts in a significant way until they were at university. Arts education is key to fostering a broader arts ecosystem, to engaging and maintaining interest, and to making the sector financially sustainable over the next generation. Arts education does not simply mean learning about traditional and contemporary arts as a whole, but also means dispelling cultural stereotypes about artists, providing greater documentation and resources about the arts that are publicly available, and presenting that information in imaginative formats.
These discussions point to a bigger question around who the arts are for. There are ideological choices attached to this, and to how policy is implemented in the future. At present, the arts can feel a 'small world', especially for audiences. If the arts as part of Cambodia's cultural heritage - is for everyone, then the sector needs to find new ways to access wider audiences and to engage with them. Evidence points to positive sign that this is happening. There is a growing young middle-clas with money who can be particularly harnessed in these efforts, which alongside arts education, and the promotion of creative diversity, can ensure support in future. 


\section{Acknowledgements}

Special thanks go to Cambodian Living Arts for all their assistance, discussion and collaboration during the course of this research, particularly Frances Rudgard, So Phina and Yon Sokhorn. Thank you to the Center for Khmer Studies for supporting Reaksmey Yean with a research affiliation. Thanks to Changing the Story for their advice and support at various stages, and for promoting the project with Oxfam. Thanks to Swansea University for additional funding to cover Covid-19 incurred expenses. The research was funded by the Arts and Humanities Research Council U.K. and the Global Challenges Research Fund through the Changing the Story programme, reference number AH/R005354/1.

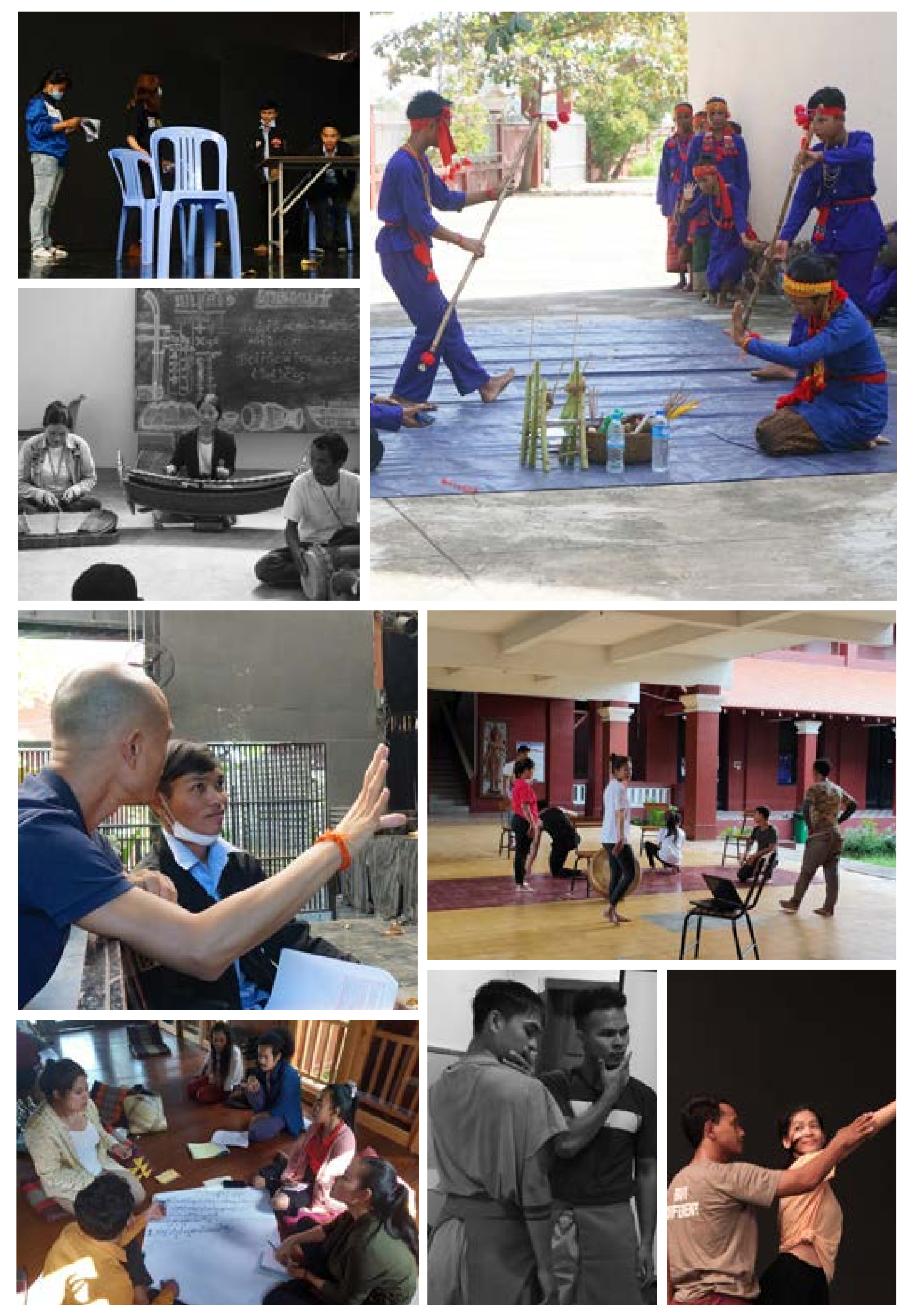


1 Phim, T. and Thompson, A. (1999) Dance in Cambodia. Oxford: Oxford University Press; Shapiro, T. (1994) Dance and the Spirit of Cambodia. Ithaca: Cornell University 'Sress; Shapiro-Phim, T., (2008a) Cambodia 'Seasons of Migration.' Dance Research (2008b) 'Mediating Cambodian History the Sacred and the Earth.' In N.Jackson and T.Shapiro-Phim (eds), Dance, Human and T.Shapiro-Phim (eds), Dance, Human Maryland. Scarecrow Press, pp. 304-22.

$2<$ https://changingthestory.leeds.ac.uk/ about/> (accessed 10th April 2021).

3 See Phim and Thompson (1999); Shapiro (1994); Shapiro-Phim (2008a, 2008b).

4 <https://changingthestory.leeds.ac.uk/ about/> (accessed 10th April 2021).

5 Many of Cambodia's art forms are protected through UNESCO frameworks. For instance, The Royal Ballet of Cambodia was inscribed in 2008 on the UNESCO Representative List of the Intangible Cultural Heritage of Humanity having been originally proclaimed in 2003. Other Cambodian dance, theatre and movement forms have also been inscribed on the List of Intangible Cultural Heritage in Need of Urgent Safeguarding (such as lakhon khaol in 2018) and as UNESCO Masterpieces of the Oral and Intangible Heritage of Humanity (such as sbek thom in 2005 - which was later inscribed on the list of the Intangible Cultural Heritage of Humanity in 2009). See also, for example, Lobban, W. (1994) 'The Revival of Masked Theater, Lkhaon Khaol, in Cambodia.' In M.M. Ebihara, C.A. Mortland and J.Ledgerwood (eds.), Cambodian Culture since 1975: Homeland and exile, Ithaca: Cornell University Press, pp. 48-56.

6 UNFPA (2015) Fact-Sheet: Cambodia Youth Data Sheet 2015. Available at: <https:// cambodia.unfpa.org/sites/default/files/pubpdf/Flyer Cambodia Youth Factsheet final draft \%28approved\%29.pdf > (accessed 10th April 2021).

7 Thompson, A. (2013) Forgetting to

remember, again: On curatorial practice and "Cambodian art" in the wake of genocide. Diacritics, 41, pp. 82-109 (p.87).
8 However, see Burridge, S. and Frumberg, F. (eds) (2010) Beyond the Apsara: Celebrating Dance in Cambodia. New Delhi: Routledge; Tuchman-Rosta, C (2014) From Ritual Form to Tourist Attraction: Negotiating the Transformation of Classical Cambodian Dance in a Changing World. Asian Theatre Journal, 31 , pp. $524-544$.

9 See, for example, Grant, C. (2016) 'Finding new ground: Maintaining and transforming traditional music.' In K. Brickell and S.

Springer (eds) The Handbook of Contemporary Cambodia, London: Routledge, pp.

is contemporary'. Performance and its is contemporary": Performance and its Udaya 12, pp 95-143. Rogers, A. (2018) Advancing the Geographies of the Performing Anrs: Intercultural gesthetics, migratory mobility and geopolitics. Progress in Hum Geography 42, pp. 549-568, Rog Huma (2020a) 'Contemporary Cambodian, and Sites of National Culture: Chumvan Sodhachivy's YouTube Page.' In L. Kong and A. De Dios (eds) The Geographies of Creativity Handbook, Cheltenham: Edward Elgar Publishing, pp. 217-233; Rogers, A. (2020b) Transforming the National Body: Choreopolitics and disability in contemporary Cambodian dance. cultural geographies, 27, pp 527-544; Tuchman-Rosta, C. (2018) 'Performance, Practice and Possibility: How Large-Sclae Processes Affect the Bodily Economy of Cambodia's Classical Dancers." PhD Thesis, UC Riverside, Riverside, CA.

10 Diamond, C. (2003) Emptying the Sea by the Bucketful: The dilemma in Cambodian theatre. S.H. (2019) 'Tradition, 20, pp. I47-178; Nut, the influence of NGOs': Myth or reality? In S. Labadi (ed), The Cultural Turn in International Aid: Impacts and challenges for heritage and the creative industries, Abingdon: Routledge, pp. 139-151.

1 Rogers, A. (2017) 'Post-conflict tensions in contemporary Cambodian dance.' In $\mathrm{H}$., Abingdon and New York: Routledge, pp. 290293; Tuchman-Rosta (2018).

12 <https://www.cambodianlivingarts.org/> (accessed 10th April 2021).
13 CLA (2019) Arts at the Heart of a Vital Society: 20th Anniversary Report. Available at: <https://www.cambodianlivingarts.org/wp-

4 These can be read here: htps://ww.

These can be read here: https://www.
cambodianlivingarts.org/blog/ (accessed 10th cambodianlivin
April 2021).

15 Pawson S., Richardson S., and D'Arcy P. (2018) 'Temples, Tuk-Tuks and Orphanages: A Contemporary Examination of Tourism Development, Management and

Community-Based Tourism in Cambodia In Y. Wang, A. Shakeela, A. Kwek and C. Khoo-Lattimore (eds) Managing Asian Destinations. Perspectives on Asian Tourism, Springer, Singapore, pp. 125-140; Winter, T. (2008) Post contlict Heritage and Touris in Cambodia: The Burden of Angkor. International Journal of Heritage Studies, 14, pp. 524-539.

16 Falser, M.S. (2014) From a colonial reinvention to postcolonial heritage and a global

commodity: performing and reenacting Angkor Wat and the Royal Khmer Ballet. International Journal of Heritage Studies, 20, pp. 702 723; Falser, M.S. (2016) 'Cultural Heritage as Performance: Reenacting Angkorian grandeu in postcolonial Cambodia 1953-1970. "In R. Craggs and C. Wintle (eds.), Cultures of Decolonisation: Iransnational productions and practices, 1945-1970 Manchester: Manchester University Press, pp. 126-155

17 Hirsch, M. (2012) The generation of postmemory: Writing and visual culture after the Holocaust. New York: Columbia University Press.

18 On the idea of a nationally repressed trauma, see Ly, B. (2020) Traces of Trauma: Cambodian visual culture and national identity in the aftermath of genocide. Honolulu: University of Hawai'i Press; see also Hamera, J. (2011) Dancing Communities: Performance, difference and connection in the global city. Houndmills: Palgrave Macmillan on her encounters with Cambodian dancers in Los Angeles.

19 For example, Brickell, K. (2020) Home SOS: Gender, violence and survival in crisis ordinary Cambodia. Chichester: Wiley-Blackwell; Springer, S. (2010) Cambodia's Neoliberal Order: Violence, Authoritarianism, and the Routledge. 
20 See, for example, Nut, H. (2015) 'Lokhon Luang', the Cambodian Court Theatre: Toward a Decline of Women's Supremacy? Asian Theatre Journal 32: 416-439. More widely see, for example, Burridge, S. (2015) 'Regional networks and cultural exchange.' In S. Burridge and C. Cariño (eds) Evolving Synergies: Celebrating Dance in Singapore, Abingdon: Routledge, pp. 124-139; Cohen M. I. (2016) Inventing the Performing Arts: Modenly and Tradition in Colonial Indonesia.

21 See also Grant (2016).

22 For example, Parsons, L., and Nielsen, J. O. (2020) The Subjective Climate Migrant: Climate Perceptions, Their Determinants, and Relationship to Migration in Cambodia. Annals of the Association of American Geographers early online view https://doi.org/10.1080/24 694452.2020.1 807899; Brickell, K; Parsons, L.; Natarajan, N., \& Chann, S. (2018) Blood Bricks: Untold Stories of Modern Slavery and Climate Change from Cambodia. Royal Holloway, University of London; Scheidel, A and Work, C. (2018) Forest plantations and climate change discourses: New powers of green' grabbing in Cambodia. Land Use Policy, 77, pp. 9-18.

23 For example, Young, S. (2021) Citizens of photography: visual activism, social media and rhetoric of collective action in Cambodia South East Asian Research, 29, pp. 53-71; Tsujino, R., Kajisa, T. and Yumoto, T. (2019) Causes and history of forest loss in Cambodia International Forestry Review, 21, pp. 372 384.

24 Rogers (2018).

25 For an overview of Kouy ethnic identities, see Switt, P. (2013) Changing ethnic identities among the Kuy in Cambodia. Assimilation, identity. Asia Pacific Viewpoint, 54, pp. 296 308.

26 Cambodia Indigenous Peoples Alliance, Cambodia Indigenous Youth Association, Asi Indigenous Peoples Pact (2019) Situation of at: < https://www.upr-info.org/sites/default/ files/document/cambodia/session 32 ianuary 2019/js 1 upr32 khm e main. pdf> (accessed 5th April 2021).

27 Phim and Thompson (1999).

28 Rogers (2020b).

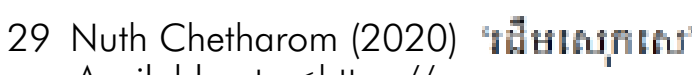
Available at: <https://www.

cambodianlivingarts.org/chetharom-writemyvillagetraditions/> (accessed 2nd April 2021)

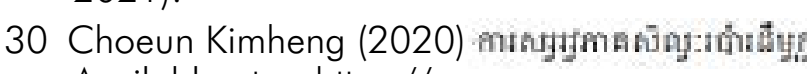
Available at: <https://www.

cambodianlivingarts.org/2-report-living-artsin-post-conflict-contexts-practices-partnershipspossibilities-2-2-3/> (accessed 2nd April 2021).

31 Rogers (2018)

32 Čopič, V. and Šešić, M. D. (2018) Challenges of public-civic partnership in Cambodia's cultural policy development. ENCATC Journal of Cultural Management and Policy 8, pp. 4-15; Nut (2019).

33 Sok Chan (2016) 'Report: Tourist Arrivals to Fall' Khmer Times (1 st September). Available (Kh: / www.khmertimeskh.com/64026/ report-tourist-arrivals-to-fall/> (accessed 27th March 2021).

34 Figures provided by CLA.

35 See <https://www.facebook. com/Cambodianlivingarts/

posts/10157666239470936> (accessed 2nd April 2021). See also Choeun Kimheng (2020)

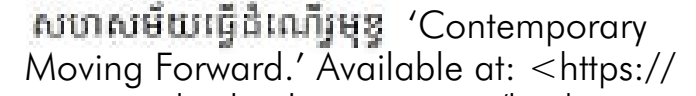
www.cambodianlivingarts. org/kimheng-write2021).

36 These can be read here: https://www. cambodianlivingarts.org/blog/ (accessed 10th April 2021)

37 Čopič and Šešić (2018).

38 Cambodian Living Arts (2014) Training \& Employment Needs Assessment on Cambodia or, Phnom Penh.

39 Ministry of Economy and Finance, Royal Government of Cambodia (2021) Budget in Brief: Fiscal year 2021. Phnom Penh. pp. 89-90 (The Ministry of Culture and Fine Arts budget is listed here as (riel) 173, 073 million)

40 Springer (2010); Ear, S. (2013) Aid Dependence in Cambodia: How Foreign Assistance Undermines Democracy. New York: Columbia University Press; Strangio, S. (2020) Cambodia: From Pol Pot to Hun Sen and Beyond. New Haven: Yale University Press.
41 Brennert, K. T. (2016) Towards an arts council formula: Exploring cultural governance solutions in Cambodia. Paper to the International Conference on Cultural Policy Research (ICCPR), Seoul; Copič and Šešic (2018).

42 Brennert (2016) p.9.

43 Royal Government of Cambodia (Prepared by Ministry of Culture and Fine Arts) (2014) National Policy for Culture. Phnom Penh.

44 Khoury, S. (2020) '(Re)Producing the Past Online: Oral History and Social Media-Based the Aftermath of Genocide.' In E. Zucker and D. Simon (eds) Mass Violence and Memory in the Digital Age. Houndsmill: Palgrave, pp. 95 122; Rogers (2020a).

45 Such skills started to be taught at the Secondary School of Fine Arts in 2018. See <htps:// School of Fine Arts in 2018. See <https: posts/793555790834299> (accessed 11 th April 2021).

46 Tuchman-Rosta (2018).

\section{N \\ $\operatorname{men}$}


